\title{
MACROFAUNA EDÁFICA EM ECOSSISTEMAS PRESERVADOS E DEGRADADOS DE ARAUCÁRIA NO PARQUE ESTADUAL DE CAMPOS DO JORDÃO, SP.
}

ANALy DE Oliveira MERLiM

Dissertação apresentada à Escola Superior de Agricultura "Luiz de Queiroz", Universidade de São Paulo, para obtenção do título de Mestre em Ecologia de Agroecossistemas.

P I R A C I C A B A

Estado de São Paulo - Brasil

Janeiro - 2005 


\title{
MACROFAUNA EDÁFICA EM ECOSSISTEMAS PRESERVADOS E DEGRADADOS DE ARAUCÁRIA NO PARQUE ESTADUAL DE CAMPOS DO JORDÃO, SP.
}

\section{ANALY DE OLIVEIRA MERLIM}

Bióloga

Orientadora: Profa. Dra. ELKE JURANDY BRAN NOGUEIRA CARDOSO

\begin{abstract}
Dissertação apresentada à Escola Superior de Agricultura "Luiz de Queiroz", Universidade de São Paulo, para obtenção do título de Mestre em Ecologia de Agroecossistemas.
\end{abstract}

P I R A C I C A B A

Estado de São Paulo - Brasil

Janeiro - 2005 
Dados Internacionais de Catalogação na Publicação (CIP) DIVISÃO DE BIBLIOTECA E DOCUMENTAÇÃO - ESALQ/USP

Merlim, Analy de Oliveira

Macrofauna edáfica em ecossistemas preservados e degrados de araucária no Parque Estadual de Campos de Jordão, SP / Analy de Oliveira Merlim. - - Piracicaba, 2005. 89 p. : il.

Dissertação (Mestrado) - - Escola Superior de Agricultura Luiz de Queiroz, 2005. Bibliografia.

1. Araucária 2. Campos de Jordão, SP 3. Degradação ambiental 4. Ecossistemas florestais 5. Fauna edáfica 6. Parques estaduais I. Título

CDD 634.9751

"Permitida a cópia total ou parcial deste documento, desde que citada a fonte - O autor" 


\section{AGRADECIMENTOS}

Ao Departamento de Solos e Nutrição de Plantas da ESALQ/USP, pela oportunidade de realização deste trabalho, como também aos funcionários Dorival, Udso e Valter pelo grande auxílio durante as coletas.

À Fundação de Estudos Agrários Luiz de Queiroz - FEALQ, pela bolsa de estudos concedida.

À Escola Superior de Agricultura "Luiz de Queiroz”, pela moradia na Vila Estudantil da Pós-Graduação.

À Professora Titular do Departamento de Solos e Nutrição de Plantas Elke Jurandy Bran Nogueira Cardoso, pela orientação e pela confiança.

Aos professores Dr. Igo Fernando Lepsch e Dr. Jairo Antonio Mazza, pela classificação dos solos do Parque Estadual de Campos do Jordão, discussões e sugestões que permitiram aperfeiçoar alguns aspectos da dissertação.

Ao Prof. Dr. Carlos Tadeu dos Santos Dias, pela ajuda com as análises estatísticas, pela paciência e por sempre estar disposto a ajudar.

Ao Prof. Dr. Sérgio Antônio Vanin, pelas identificações das larvas de Coleoptera e pelo tempo, pacientemente dedicado.

À Empresa Brasileira de Pesquisa Agropecuária, Embrapa Agrobiologia, pela oportunidade de desenvolver parte da dissertação no laboratório de Fauna do Solo.

À Pesquisadora $\operatorname{Dr}^{\mathrm{a}}$ Adriana Maria de Aquino, da Embrapa Agrobiologia, pelos primeiros passos no mundo científico e pela amizade.

À Pesquisadora Dra ${ }^{\mathrm{a}}$. Maria Elizabeth Fernandes Correia, da Embrapa Agrobiologia e ao Prof. Dr. José Leonardo de Moraes Gonçalves, pelas importantes contribuições oferecidas. 
Ao Sr. Anésio Dias Pereira, funcionário do Parque Estadual de Campos do Jordão, pelas identificações das espécies vegetais.

Ao amigo Hudson, pelas correções feitas no texto e ao Márcio, pela valiosa ajuda com os desenhos apresentados neste trabalho e, principalmente, pelo carinho e companherismo.

Aos companheiros da "salinha", pelo convívio agradável e paciência na fase final.

De forma especial, ao Maurício, por me acolher em sua casa e em seu coração e aos meus pais, por todo amor, orações e apoio durante mais esta etapa da minha vida. 


\section{SUMÁRIO}

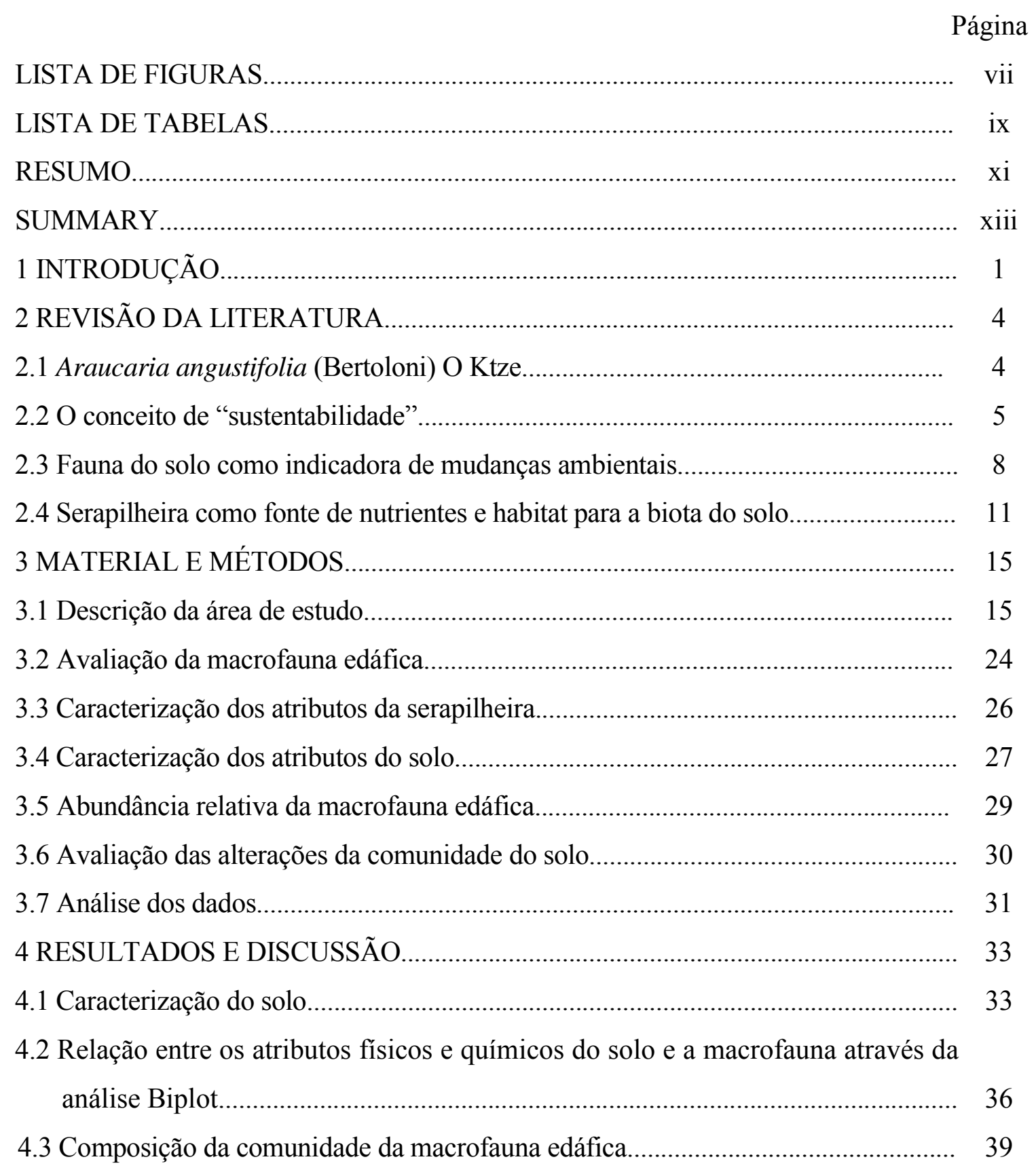




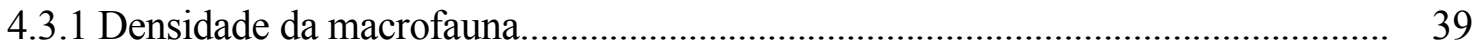

4.3.2 Análise Fatorial de Correspondência................................................................. 44

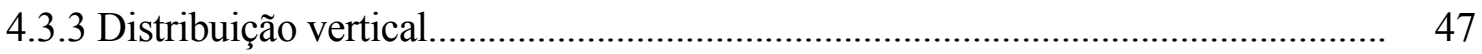

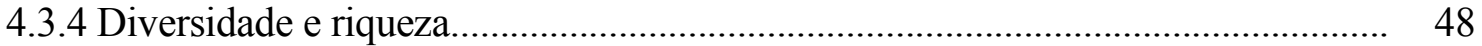

4.3.5 Larvas de Coleoptera................................................................................ 50

4.3.6 Abundância e freqüência dos grupos funcionais................................................ 55

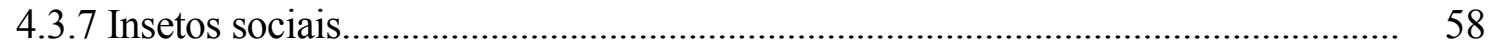

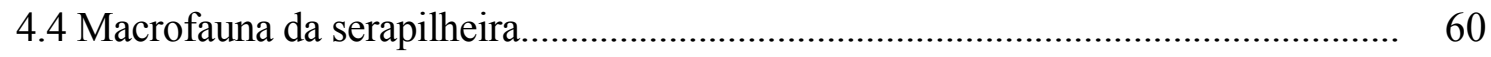

4.4.1 Relação entre os atributos químicos e a macrofauna da serapilheira através da

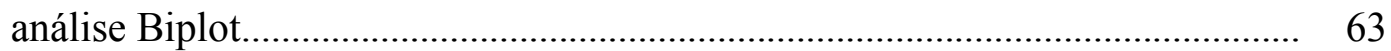

4.5 Alterações da comunidade da macrofauna edáfica pelo índice V de Wardle....... 66

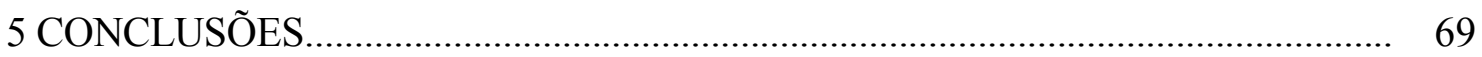

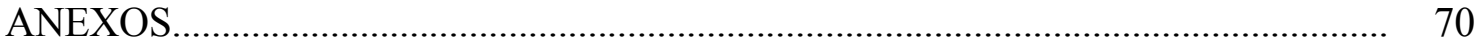

REFERÊNCIAS BIBLIOGRÁFICAS.............................................................. 73 


\section{LISTA DE FIGURAS}

Página

1 Localização do Parque Estadual de Campos do Jordão dentro do município de Campos do Jordão, SP

2 Vista da mata nativa de araucária (A) e da mata de araucária introduzida (B) no Parque Estadual de Campos do Jordão, SP.

3 Vista da mata de araucária introduzida e impactada pela ação do fogo no Parque Estadual de Campos do Jordão, SP.

4 Temperatura média mensal $\left({ }^{\circ} \mathrm{C}\right)$ e precipitação pluviométrica mensal $(\mathrm{mm})$ referentes aos anos de 2002 e 2003.

5 Desenho esquemático do método dos quadrantes para a amostragem da densidade das espécies vegetais nos diferentes ecossistemas e da coleta da macrofauna edáfica.

6 Desenho esquemático da coleta da macrofauna edáfica e das amostras indeformadas para determinação da porosidade do solo. Detalhe dos monólitos de solo; detalhe frontal da coleta das amostras indeformadas.

7 Biplot para a macrofauna pelos atributos físicos e químicos do solo sob os diferentes ecossistemas: mata nativa de araucária $(\mathrm{M})$, mata de araucária introduzida (RSF) e mata de araucária impactada pela ação do fogo (RF).

8 Diagrama de ordenamento obtido a partir da AFC para as densidades dos grupos da macrofauna edáfica em diferentes ecossistemas de araucária, na época seca (A) e na época chuvosa (B)

9 Dendrograma das Larvas de Coleoptera coletadas nos diferentes ecossistemas de araucária. A = época seca; $\mathrm{B}$ = época chuvosa. 
10 Densidades (ind $/ \mathrm{m}^{2}$ ) de Formicidae e Isoptera em diferentes ecossistemas de araucária. $0=$ serapillheira, $1=$ solo até $30 \mathrm{~cm}$ de profundidade. $\mathrm{A}=$ época seca; $\mathrm{B}=$ época chuvosa..

11 Biplot para a macrofauna pelos atributos químicos da serapilheira dos diferentes ecossistemas: mata nativa de araucária $(\mathrm{M})$, mata de araucária introduzida (RSF) e mata de araucária impactada pela ação do fogo (RF)

12 Resultado da aplicação do Índice V de Wardle (1995), aos grupos da macrofauna coletada na serapilheira e no solo sob diferentes ecossistemas de araucária, na época seca (A) e chuvosa (B). Os resultados estão expressos em porcentagem dos grupos classificados nas categorias de inibição/estimulação. IE = inibição extrema, IM = inibição moderada, $\mathrm{IL}=$ inibição leve, $\mathrm{SA}=$ sem alteração, $\mathrm{EL}=$ estimulação leve, $\mathrm{EM}=$ estimulação moderada $\mathrm{e} \mathrm{EE}=$ estimulação extrema. 


\section{LISTA DE TABELAS}

Página

1 Precipitação anual total $(\mathrm{mm})$ e médias da temperatura anual máximas e mínimas $\left({ }^{\circ} \mathrm{C}\right)$, no período de 1997 - 2003 no PECJ........................................... 21

2 Famílias, espécies e portes das vegetações que ocorrem associadas com a mata nativa de araucária e com as matas de araucária introduzida.

3 Densidade de espécies vegetais $\left(\right.$ ind.ha $^{-1}$ ) nos diferentes ecossistemas de araucária

4 Composição dos grupos funcionais selecionados para este estudo.

5 Caracterização física do solo nas profundidades 0-10, 10-20 e 20-30 cm, sob diferentes ecossistemas de araucária. Os valores são média \pm desvio-padrão $(\mathrm{n}=10)$

6 Classificação dos grupos funcionais em categorias de abundância (Modificado de Santos, 2000)

7 Categorias de inibição e estimulação dos grupos da macrofauna do solo em resposta ao manejo (modificado de Wardle, 1995 e Correia et al., 2003).

8 Caracterização química do solo sob diferentes ecossistemas: mata de araucária nativa (M), mata de araucária introduzida (RSF) e mata de araucária introduzida e impactada pela ação do fogo (RF), na época seca.

9 Caracterização química do solo sob diferentes ecossistemas: mata de araucária nativa (M), mata de araucária introduzida (RSF) e mata de araucária introduzida e impactada pela ação do fogo (RF), na época chuvosa.

10 Porosidade total, macroporos e densidade do solo sob diferentes ecossistemas de araucária 
11 Coeficientes de correlação de Spearman entre os atributos químicos e físicos do solo principais grupos da macrofauna dos diferentes ecossistemas de aracáuria... 37

12 Densidade média (indivíduos por metro quadrado) dos principais grupos da macrofauna edáfica coletados no solo $(0-30 \mathrm{~cm})$ sob diferentes ecossistemas de araucária.

13 Densidade total (indivíduos por metro quadrado) dos principais grupos da macrofauna edáfica nas camadas de serapilheira e solo em diferentes ecossistemas de araucária. Média das épocas de amostragens.

14 Índice de Diversidade de Shannon, Riqueza ( ${ }^{\circ}$ de grupos taxonômicos) e Uniformidade de Pielou da macrofauna coletada no solo até $30 \mathrm{~cm}$ (somatório das profundidades) sob diferentes ecossistemas de araucária.

15 Densidade (indivíduos por metro quadrado) das principais famílias de larvas de Coleoptera coletadas na serapilheira e no solo sob diferentes ecossistemas de araucária.

16 Classificação da abundância dos grupos funcionais coletados na serapilheira e solo até $30 \mathrm{~cm}$ de profundidade, na época seca, sob diferentes ecossistemas de araucária

17 Classificação da abundância dos grupos funcionais coletados na serapilheira e solo até $30 \mathrm{~cm}$ de profundidade, na época chuvosa, sob diferentes ecossistemas de araucária......

18 Densidade média (ind $/ \mathrm{m}^{2}$ ) da macrofauna coletada na serapilheira dos diferentes ecossistemas de araucária.

19 Caracterização química da serapilheira dos diferentes ecossistemas de araucária, nas duas épocas de coleta.

20 Coeficientes de correlação de Spearman entre os atributos químicos da serapilheira e principais grupos da macrofauna coletada nos diferentes ecossistemas de araucária. 


\title{
MACROFAUNA EDÁFICA EM ECOSSISTEMAS DE ARAUCÁRIA PRESERVADOS E DEGRADADOS NO PARQUE ESTADUAL DE CAMPOS DO JORDÃO, SP.
}

\author{
Autora: ANALY DE OLIVEIRA MERLIM \\ Orientadora: Prof $^{\mathrm{a}}$. Dr ${ }^{\mathrm{a}}$. ELKE JURANDY BRAN NOGUEIRA CARDOSO
}

\section{RESUMO}

A Araucaria angustifolia (Bertoloni) O. Ktze. é uma espécie de elevado valor sócio-econômico e ambiental, característica da floresta subtropical brasileira. Por sua excelente qualidade e ampla utilização de sua madeira ela tem sido uma das espécies nativas mais exploradas no Brasil. Atualmente, encontra-se presente na lista oficial de espécies da flora brasileira ameaçadas de extinção, exigindo emprego imediato de tecnologias visando sua manutenção e recuperação. O objetivo desse trabalho foi estabelecer as alterações da comunidade da macrofauna edáfica decorrentes do manejo e da ação do fogo em ecossistemas com araucária nativa e ecossistemas com araucária introduzida, no município de Campos do Jordão (SP). A macrofauna foi coletada em superfície amostral de 25 x $25 \mathrm{~cm}$, nas profundidades do solo de 0-10, 10-20 e 20-30 cm e na serapilheira. Os pontos de amostragens ficaram distanciados 10 metros entre si, ao longo de um transecto determinado ao acaso. Foram coletadas dez amostras por ecossistema, nos meses de outubro de 2002 e março de 2003, caracterizados como sendo de período seco e período chuvoso, respectivamente. Alterações na densidade e diversidade da macrofauna do solo foram observadas nos ecossistemas que sofreram intervenção na sua cobertura vegetal. A ocorrência do fogo acarretou em baixa qualidade 
da serapilheira, tendo sido esta agravada na época seca. Os resultados demonstraram que a fauna está correlacionada com os parâmetros químicos da serapilheira e do solo nestes ecossistemas. As características químicas do solo e da serapilheira, aliadas às condições climáticas, contribuiram para as alterações nesta comunidade. 


\title{
SOIL MACROFAUNA IN PRESERVED AND DEGRADED ARAUCARIA ECOSYSTEMS IN THE STATE PARK OF CAMPOS DO JORDÃO, SP, BRAZIL
}

\author{
Author: ANALY DE OLIVEIRA MERLIM \\ Adviser: ELKE JURANDY BRAN NOGUEIRA CARDOSO, Ph. D.
}

SUMMARY

Araucaria angustifolia (Bertoloni) O. Ktze. is a species with a high socialeconomical and envirommental value, and it is characteristic of the subtropical Brazilian forest. Due to the excellent quality of the wood, it has been one of the most exploited native species in Brazil. Today this tree is considered an endangered species, requiring maintenance and recuperation through an immediate use of technologies. This study had the objective to evaluate the changes in the soil macrofauna community in an ecosystem with native araucaria and in replanted areas in Campos do Jordão, São Paulo, Brazil. The macrofauna was collected in $25 \times 25 \mathrm{~cm}$ areas, at 0-10, 10-20 and 20-30 cm soil depth and in the litter. Along the transect determined at random, the sampling points were distributed with 10 meter distance from one another. Was collected ten sampling points por ecossistema. in october 2002 and in march 2003, which represent the dry and rainy seasons, respectively. Changes in density and diversity of the soil macrofauna due to an intervention in the litter layer were observed. The litter was partially eliminated by the fire and its quality was even worse in the dry season. The results suggest that there is a great influence of soil chemical parameters as well as of the climatic conditions upon the soil macrofauna. 


\section{INTRODUÇÃO}

A Araucaria angustifolia é uma espécie característica da floresta subtropical brasileira, também conhecida como pinheiro-brasileiro, pinheiro-do-Paraná ou araucária. É uma conífera típica da América do Sul, a qual, no Brasil, abrange uma superfície que se estende por uma vasta área da região sul do Brasil, alcançando também, manchas esparsas no sudeste e nordeste de São Paulo, no sul de Minas Gerais, no sudoeste do Rio de Janeiro e no leste da Província de Missiones, Argentina (Reitz et al., 1988). Contudo, é no Estado do Paraná que essa espécie possui maior representatividade. Daí, ser designada por Pinheiro do Paraná. Conjuntamente com a Araucaria araucana, endêmica nas vertentes andinas da Argentina e do Chile, seriam duas coníferas das anteriores formações Antártico-Andinas que, numa passada Era geológica, teriam avançado para o norte (Azevedo, 1994).

A excelente qualidade e ampla utilização de sua madeira fez com que a Araucaria angustifolia fosse considerada uma das espécies nativas mais exploradas no Brasil. Ela está presente na lista oficial de espécies da flora brasileira ameaçadas de extinção, sendo classificada pelo IBAMA como vulnerável (Brasil, 1992).

Britez et al. (1992) comentam que as áreas cobertas por araucária ocupavam primitivamente uma extensão de 7,5 milhões de hectares. Atualmente, no Brasil, estas florestas são restritas quase totalmente a áreas protegidas, que totalizam cerca de 20.000 hectares. Entretanto, a maioria das pesquisas envolvendo Araucaria angustifolia direciona-se à produção e manejo dessas populações e poucas estão relacionadas com os organismos edáficos e seus processos.

Não há relatos disponíveis relacionados à diversidade da fauna edáfica sob floresta de araucária. As características de um solo, bem como a sua qualidade, podem 
ser determinados pelos organismos nele presentes. Essa interferência pode ser clara em processos tais como a decomposição ou fixação de nitrogênio, ou menos óbvias, como no caso da textura e da estrutura do solo ou da capacidade de retenção de água (Pankhurst \& Lynch, 1994). Tanto os microrganismos como os invertebrados edáficos são capazes de modificar propriedades físicas, químicas e biológicas do solo. A comunidade de organismos do solo é influenciada pela quantidade e, principalmente, pela qualidade do material vegetal que aporta ao solo, fato este que justifica o seu uso como indicadora da qualidade do solo (Stork \& Eggleton, 1992, Linden et al., 1994).

$\mathrm{O}$ uso de indicadores biológicos associado a outros fatores ambientais que refletem adequadamente as condições do hábitat em estudo (Fowler, 1998) torna-se extremamente útil, pois atuam antecipando eventos, o que permite a intervenção no momento adequado. Fatores desse tipo podem ser encontrados na fauna, pois o retorno de diversos animais a áreas em recuperação acontece de forma gradativa. Fowler (1998) afirma que, embora a contribuição da fauna à reabilitação de ambientes degradados ainda precise ser melhor pesquisada no Brasil, alguns organismos podem ter grande utilidade como bioindicadores.

O conhecimento da comunidade da fauna edáfica pode contribuir para a avaliação do grau de sustentabilidade de uma prática, seja de recuperação de uma área degradada ou até mesmo no caso de um sistema natural interferido (Linden et al., 1994). Nesse sentido, o conhecimento da composição da comunidade no ambiente edáfico e as alterações que esta comunidade sofre em função da intervenção poderão dar subsídios aos programas que visam o restabelecimento da Araucaria angustifolia em seu ambiente de origem, o qual se encontra, normalmente, degradado física, química e biologicamente.

Esse trabalho está viculado ao projeto BIOTA/FAPESP sobre "Biodiversidade Vegetal e de Organismos Edáficos em Ecossistemas de Araucaria angustifolia Naturais e Impactados no Estado de São Paulo”, tendo como objetivo estabelecer as alterações da comunidade da macrofauna edáfica decorrentes do manejo da araucária em ecossistemas naturais, ecossistemas introduzidos e impactados pela ação do fogo, no município de Campos do Jordão (SP). 
Quase todas as classes ou ordens de invertebrados estão representadas no solo (Ehrnsberger, 1993). Dentre estes, a macrofauna representa uma comunidade diversificada de invertebrados, que apresenta o comprimento do corpo entre 4,0 e 80,0 mm, como por exemplo: Diplopoda, Oligochaeta e Coleoptera (Ehrnsberger, 1993), influencia os processos do solo através da escavação e/ou ingestão e transporte de material mineral e orgânico do solo. Além disso, ao utilizarem significativa quantidade da matéria orgânica para se alimentarem e produzirem as suas estruturas biogênicas, estes organismos que integram a macrofauna afetam a dinâmica da matéria orgânica do solo (Lavelle et al., 1997) e desenvolvem ações no solo que, por sua especificidade, lhe conferem papel de destaque. Essas especificidades estão relacionadas principalmente com o volume de material que pode ser modificado, em suas características genéticas, por cada um dos grupos de animais envolvidos. Essa modificação depende do tamanho do organismo e da posição ecológica que ele ocupa no ambiente edáfico.

A macrofauna edáfica também é fortemente influenciada pela ação antrópica que pode modificar consideravelmente a abundância e a diversidade da comunidade, principalmente pela perturbação do ambiente físico e pela modificação da quantidade e qualidade da matéria orgânica (Lavelle et al., 1993). Apesar da relação entre diversidade e estabilidade ser objeto de muita discussão, entende-se que a interação entre as espécies é muito importante, na medida em que a falta de variabilidade genética leva a uma diminuição da habilidade de sobrevivência das populações frente às condições adversas do ambiente.

Portanto, analisar a diversidade e a importância de determinados grupos funcionais poderá ser a abordagem que mais contribua para a compreensão da capacidade reguladora da fauna edáfica nos ecossistemas de araucária e as conseqüências esperadas a partir da exclusão de um ou mais grupos. 


\section{REVISÃO DE LITERATURA}

\subsection{Araucaria angustifolia (Bertoloni) O. Ktze.}

A família Araucariaceae é representada por plantas arbóreas de grande porte, em geral, densamente dispostas e, em certos casos, imbricadas. São plantas dióicas, ou seja, as flores femininas são reunidas em grandes e densos estróbilos com mais de duas centenas de flores. O óvulo nasce na axila de um megasporófilo pouco desenvolvido e é protegido por uma folha estéril, a escama de cobertura, que acaba envolvendo e encerrando o óvulo fecundado, de tal forma que o cone maduro formado é composto por unidades isoladas, o chamado pinhão (Joly, 1977). Uma araucária pode viver em torno de 200 a 300 anos e esta idade é calculada através dos anéis de crescimento que vão sendo formados pelos troncos (Azevedo, 1994).

A Araucaria angustifolia tem sua ocorrência natural entre altitudes que variam de 500 a 1500 metros, sendo encontrada entre os paralelos $21^{\circ}$ e $30^{\circ}$ de latitude sul (Mattos, 1972). Desenvolve-se em regiões de clima temperado caracterizado por verões frescos e invernos relativamente frios, com temperaturas mínimas de até $-8^{\circ} \mathrm{C}$ (Golfari, 1970). Atualmente, emprega-se a terminologia Floresta Ombrófila Mista, proposta pelo IBGE, que é adequada a um sistema de classificação da vegetação intertropical.

O pinheiro brasileiro distribui-se da Mantiqueira ao Rio Grande do Sul, chegando ao leste da Província de Missiones, Argentina. Inclui-se em variados tipos florísticos, sejam matas ou campos. Há zonas em que, de acordo com as condições do meio, os pinheiros são preponderantes em relação às diferentes espécies. Em outras áreas, entretanto, onde a vegetação é herbácea ou graminácea, o pinheiro junto com 
outras espécies arbóreas da região, surge em capões ou geralmente acompanhando um curso de água qualquer (Oliveira, 1948).

A. angustifolia ocorre sobre os mais variados tipos de solo, desde os mais pobres, como os dos campos gerais do Paraná (derivados de arenitos), até os solos escuros e férteis (derivados de basalto) que ocorrem no sudoeste do Paraná e oeste de Santa Catarina (Romariz, 1973). Oliveira (1948) ressaltou que a ocorrência da araucária está condicionada, entre outros fatores, à geologia e à pedologia do ambiente. Solos arenosos e rasos não retêm a umidade do solo exigida, podendo provocar períodos de estresse (Golfari, 1970).

Por ser uma espécie ameaçada de extinção, conforme classificação do IBAMA (Brasil, IBAMA, 1992), torna-se obrigatória sua conservação (Portaria IBAMA 06-N), além do que a floresta de araucária abriga uma rica fauna e flora silvestres, também ameaçadas de extinção. No interior do sub-bosque encontram-se espécies economicamente viáveis, como a erva-mate, imbuia, canela, etc. Estas poucas matas que ainda existem podem ser manejadas de forma auto-sustentável, desde que sejam estabelecidos critérios adequados que assegurem essa sustentabilidade.

\subsection{O conceito de "sustentabilidade”}

Avaliar o grau de sustentabilidade de um sistema é algo extremamente complexo, já que envolve uma grande variedade de processos igualmente de considerável complexidade. Duas abordagens com relação a essa avaliação têm sido propostas: a primeira consiste em estabelecer um índice geral de qualidade do solo,

incluindo-se fatores relativos à produtividade, características físicas, químicas e biológicas do solo em questão (Doran \& Parkin, 1994). A segunda abordagem consiste em isolar um processo que seja relevante no sistema e considerá-lo como indicador do comportamento do conjunto em relação a impactos específicos. É nesse sentido que a fauna de invertebrados do solo pode contribuir para a avaliação do "status" da sustentabilidade em um sistema qualquer, seja ele de produção, de recuperação de uma 
área degradada, ou até mesmo no caso de um sistema natural interferido (Linden et al., 1994).

Diferentes interpretações do que se entende sobre sustentabilidade foram propostas por Paoletti (1999), sendo baseadas no trabalho de Noss \& Westra (1998). Por "sustentabilidade social", podemos entender que a coesão da comunidade, a identidade cultural, a diversidade, a solidariedade, a compaixão, a fraternidade, o amor, as leis e a disciplina, constituem alguns dos aspectos do capital social, menos sujeitos às medidas rigorosas, mas essenciais para a sustentabilidade social. Capital humano e social, investimento em educação, saúde e nutrição dos indivíduos são agora aceitos como parte do desenvolvimento econômico, mas a criação e manuntenção do capital social ainda não é adequadamente reconhecida. A definição mais amplamente aceita de "sustentabilidade econômica" é a de manutenção do capital ou manutenção do capital intacto. Os economistas raramente têm se preocupado com o capital natural (ex. florestas intactas, ar saudável, fertilidade do solo). Estando os valores econômicos restritos a dinheiro, a valorização da geração interna de capital natural, como solo, água, ar, biodiversidade torna-se problemática. A "sustentabilidade ambiental" originou-se devido às preocupações sociais e busca melhorar o bem-estar humano ao proteger as fontes de recursos naturais usados para necessidades humanas e assegurar que os drenos para resíduos não sejam excessivos, a fim de prevenir danos aos humanos. Neste sentido, para alcançar esta sustentabilidade é preciso que haja um consumo sustentável por uma população estável.

Em qualquer definição de qualidade do solo $^{1}$ está implícita a noção de sustentabilidade, sendo esta também um conceito novo e bastante amplo. A sustentabilidade de um sistema de produção agrícola não inclui apenas aspectos ambientais, mas econômicos e sociais, já que o homem é, neste, mais do que em sistemas naturais, parte integrante.

\footnotetext{
${ }^{1}$ A boa capacidade da função específica do solo em ecossistemas naturais ou manejados, para sustentar a produtividade das plantas e animais, mantendo ou melhorando a qualidade do ar, da água, e sustentando ademais a ocupação e a saúde humana (Karlen et al., 1997).
} 
Os indicadores que definem a qualidade do solo (Karlen et al., 1997) representam uma ferramenta importante para avaliar processos de recuperação do solo em áreas degradadas e a evolução do funcionamento do solo em sistemas agroflorestais, visando à construção de uma fertilidade mais duradoura. No entanto, indicadores ecológicos são utilizados para avaliar condições do ambiente, fornecendo sinais rápidos de mudanças na estrutura e no funcionamento do solo, diagnosticando as causas destas alterações. A principal característica de um bom indicador é ser sensível tanto às mudanças pelo uso da terra, quanto às práticas do manejo, devendo mostrar mudanças significativas entre 1 e 3 anos, tendo 5 anos como o limite máximo (Stott et al., 1999). Outros autores (Power et al., 1998) recomendam que um bom indicador deve compreender 3 categorias: (a) física (estrutura do solo); (b) nutricional (que integre a quantidade e a qualidade da matéria orgânica e a atividade microbiana); e (c) biológica (que integre a atividade dos organismos do solo em relação às propriedades físicas e químicas).

O declínio na produtividade dos solos tropicais, após vários anos de cultivo e manejo numa área determinada, mesmo com a adição de fertilizantes, tem sido bem documentado (Lal, 1979). Esse declínio é relacionado a mudanças na estrutura física do solo (compactação), que afetam a dinâmica da água (Libardi et al., 1982) e dos solutos no solo (Landina \& Klevensk, 1984), provocando má aeração e limitando o desenvolvimento radicular. Os fluxos sub-superficiais da água no solo podem ocorrer por duas vias: lenta, através dos microporos, e rápida, através dos macroporos (Bouma, 1981).

No entanto, a distribuição dos poros no solo pode ser afetada pela atividade das raízes e da macrofauna, que, por sua vez, modificam os fluxos da água e nutrientes dentro do solo.

O declínio na produtividade, além de estar relacionado com mudanças na estrutura física do solo, pode também estar ligado a reduções nos conteúdos de M.O. (Power et al., 1998).

Por outro lado, é importante ressaltar que a fauna do solo, além de agente, é também reflexo das condições do solo. São as características do habitat, tanto a nível 
macro, ou seja, tipo de solo e fitofisionomia (Al Assiuty et al., 1993; Oliveira, 1996) quanto a nível micro, quantidade de serapilheira acumulada (Álvarez-Sánchez et al., 2003), qualidade da matéria orgânica (Tian et al., 1993), tipos de manejo (Curry \& Good, 1992); que determinam quais os grupos da fauna de solo estarão presentes e em que quantidades. Desta forma, mudanças na abundância relativa e na diversidade das espécies de invertebrados do solo constituem um bom indicador de mudanças no sistema (Curry \& Good, 1992; Stork \& Eggleton, 1992).

Spain et al. (1992) observaram que, em alguns casos, um incremento na biomassa de certas plantas pode estar positivamente correlacionado à biomassa de minhocas adicionadas.

Diversos parâmetros físicos e químicos têm sido propostos como indicadores de qualidade do material que aporta ao solo: relações $\mathrm{C} / \mathrm{N}$ e Lignina/ $\mathrm{N}$, o conteúdo de polifenóis, sílica e fibras, a dureza e espessura da cutícula e outros. O aporte de um material foliar rico em nitrogênio parece favorecer o estabelecimento de comunidades de fauna do solo mais abundantes e diversas (Tian et al., 1993). Além disso, um material com maiores concentrações de outros nutrientes e matéria orgânica também influencia positivamente o estabelecimento de comunidades com maior diversidade (Correia et al., 1997). Por sua vez, maiores concentrações de lignina ou de compostos fenólicos presentes no material foliar podem atuar como inibidores do estabelecimento de alguns grupos da fauna do solo (Bandeira \& Souza, 1982; Tian et al., 1993).

Estudos com enfoque ecológico abordam respostas do ecossistema aos tipos de manejo, poluição e outras formas de perturbação. Existe, ainda, o conceito de "resiliência", que pode ser definido como sendo o tempo que o sistema leva para que alguma fração específica do solo retorne a um estado estável de equilíbrio após algum tipo de perturbação (DeAngelis et al., 1989).

\subsection{Fauna do solo como indicadora de mudanças ambientais}

A comunidade de organismos que vive no solo, composta de microrganismos (principalmente fungos e bactérias) e invertebrados, atua através de interações sinérgicas 
e antagônicas (Anderson et al., 1983), visando garantir a decomposição dos detritos que chegam ao solo (Swift et al.,1979). Como resultado de sua atividade esses organismos influenciam outros processos básicos do solo como: humificação, agregação e estruturação do solo, que operam em diferentes escalas de tempo e espaço (Lavelle, 1996).

Os organismos do solo alimentam-se de detritos e utilizam a energia e os nutrientes para o seu próprio crescimento. Com o catabolismo dos recursos orgânicos, diversos elementos são convertidos de sua forma orgânica para inorgânica, em um processo denominado mineralização. Uma vez mineralizados, estes recursos podem ser reaproveitados pelos organismos do solo, juntamente com a energia liberada, para a manutenção de suas atividades metabólicas, tornando-se imobilizados na biomassa do solo. Sendo assim, a imobilização inevitavelmente acompanha a mineralização (Swift et al., 1979) e, à medida que o sistema perde carbono como $\mathrm{CO}_{2}$, o balanço entre estes processos termina por disponibilizar nutrientes para o crescimento vegetal.

Com relação aos invertebrados do solo, estes podem ser classificados de acordo com seu comprimento em três grupos: microfauna $(<0,2 \mathrm{~mm})$ que inclui nematódeos e rotíferos; mesofauna $(0,2-2 \mathrm{~mm})$ que inclui ácaros, alguns insetos e enquitreídeos; e a macrofauna ( $>2 \mathrm{~mm}$ ) composta por miriápodes, insetos e oligoquetos (Swift et al., 1979).

Analisar a diversidade e a importância de determinados grupos funcionais talvez seja a abordagem que mais contribua para a compreensão da capacidade reguladora da fauna edáfica nos ecossistemas e das consequências esperadas a partir da exclusão de um ou mais grupos.

Devido à impossibilidade de se avaliar uma comunidade na íntegra, o que tem sido feito é retratar parcelas desta comunidade, escolhendo determinados grupos taxonômicos, grupos associados a frações do habitat ou grupos que tenham uma função semelhante no ecossistema. São comuns trabalhos sobre as comunidades de colêmbolos (Badejo \& Van Straalen, 1993), ácaros (Blair et al., 1994), minhocas (González et al., 1996), diplópodes (Dangerfield \& Telford, 1992), entre outros grupos. 
Outro tipo de retrato da comunidade é o que envolve a determinação da composição de organismos a nível de grandes grupos taxonômicos em uma determinada fração do habitat. Estudos relativos à composição das comunidades de invertebrados de solo, a nível de classe ou ordem, encontram-se nesta categoria (Dangerfield, 1992). Qualquer que seja a abordagem de estudo da comunidade, é necessário que se utilizem duas ferramentas básicas: a abundância e a variedade de espécies ou grupos presentes. Por abundância, entende-se qualquer medida de tamanho de uma determinada espécie ou grupo presente, como biomassa ou quantidade. Tais medidas devem obrigatoriamente estar associadas a alguma unidade de espaço que pode ser área $\left(\mathrm{m}^{2}, \mathrm{ha}\right)$, ou volume $\left(\mathrm{cm}^{3}\right.$ de solo).

Medir a abundância das espécies é o ponto de partida para estudos ecológicos de comunidades (Begon et al., 1996). Ao se optar por uma medida de abundância em particular, ou seja, biomassa ou densidade, deve-se ter em mente que qualquer das duas medidas fornece uma visão parcial da presença dos organismos na comunidade.

$\mathrm{O}$ fato de que animais maiores são menos numerosos do que animais menores (Colinvaux, 1986) limita o uso da biomassa ou da densidade, isoladamente, como determinantes da função que desempenham os diferentes grupos da fauna de solo. Animais como as minhocas geralmente possuem uma grande biomassa, enquanto animais pequenos como os ácaros apresentam uma excepcional densidade, porém com uma biomassa menor qaundo comparados com animais maiores. Ambos os grupos são relevantes no ambiente do solo. Essa discrepância é resolvida de forma mais eficiente ao se compararem as modificações na biomassa ou na densidade em comunidades submetidas a diferentes condições abióticas ou diferentes sistemas de manejo.

A diversidade de espécies envolve o número de espécies (riqueza de espécies) e a distribuição do número de indivíduos entre as espécies (eqüitabilidade). Esta definição está explicitada nos índices de diversidade, que conjugam estes dois parâmetros (Odum, 1988; Colinvaux, 1986). No entanto, em um sentido mais amplo a própria riqueza de espécies pode ser utilizada como uma medida geral da diversidade (Connell, 1978). Uma vantagem do uso da riqueza de espécies é que ela fornece uma ampla medida da complexidade das comunidades e talvez da sua resiliência. As 
desvantagens estão associadas à identificação das espécies e de que pouco é revelado sobre as interações entre espécies (Stork \& Eggleton, 1992). No entanto, não parece haver também nenhuma razão para que as medidas de diversidade não sejam aplicadas a outros níveis taxonômicos além da espécie.

De acordo com Doran \& Parkin (1994), um bom indicador da qualidade do solo deve obedecer aos seguintes critérios: estar associado aos grandes processos do ecossistema; integrar propriedades físicas, químicas e biológicas; ser acessível a muitos usuários e aplicável a condições de campo; ser sensível a variações no manejo e no clima e, quando possível, fazer parte de bancos de dados.

Quando o estudo da organização da comunidade se restringe a grandes grupos taxonômicos, não implicando em um conhecimento taxonômico profundo, o acesso a muitos usuários é facilitado, o que amplia as possibilidades de sua utilização como indicador.

No entanto, apesar de haver um número considerável de trabalhos a respeito das funções da fauna de solo, bem como das respostas a interferências antrópicas, tais estudos estão concentrados em determinadas regiões, particularmente nas de clima temperado. O número de trabalhos sobre fauna de solo em regiões tropicais, apesar de crescente, está ainda muito aquém do necessário. No Brasil, o número de trabalhos é irrelevante frente à diversidade de ecossistemas do país e ao desconhecimento da própria biodiversidade do solo. É possível que muitas espécies sejam extintas sem antes serem conhecidas.

Como o uso da organização de comunidades como indicador se baseia em comparações, é de fundamental importância a criação de bancos de dados e o estabelecimento de padrões e categorizações que qualifiquem a interferência antrópica em um sistema.

\subsection{Serapilheira como fonte de nutrientes e habitat para a biota do solo}

O compartimento formado pela serapilheira e solo é o sítio por excelência de todas as etapas da decomposição da matéria orgânica e ciclagem de nutrientes. Neste 
compartimento, concentram-se os organismos responsáveis pela tarefa de desmontar as cadeias carbônicas elaboradas de maneira complexa por outros organismos, neste caso, os produtores. O conjunto serapilheira - solo não representa somente alimento para os organismos do solo, mas também o habitat, ou seja, o espaço físico onde todas as ações do organismo ocorrem, garantindo assim, a sua sobrevivência e reprodução (Correia \& Andrade, 1999).

Em florestas tropicais, a queda de serapilheira é um dos aspectos da ciclagem de nutrientes mais importante, pois a nutrição dos vegetais destes ecossistemas, geralmente com baixo conteúdo de nutrientes no solo, depende da reciclagem dos nutrientes contidos nos detritos vegetais (Britez et al., 1992).

A importância da queda contínua de serapilheira é destacada por Krapfenbauer \& Gasch (1989) como sendo, após a mineralização, a base da nutrição da floresta. Isto porque a superfície do solo florestal, composto por estes detritos orgânicos, é o traço mais distintivo do solo florestal, além de contribuir quanto às suas características particulares. Nestes sistemas a acumulação líquida de nutrientes pela biomassa é a diferença entre o total de nutrientes absorvidos e o total retornado ao solo via serapilheira, lixiviação da copa e morte das raízes (Pritchett, 1979).

A produção seguida pela decomposição da camada de serapilheira é o principal meio de transferência dos nutrientes para o solo, possibilitando a sua reabsorção pelos vegetais vivos. Dessa forma, a serapilheira torna-se um dos mais intensos sítios de interação entre a ciclagem de elementos inorgânicos e a transferência de energia, sendo que a relação destes no complexo solo/folhedo condicionada à capacidade de produção do ecossistema (Delitti, 1984).

De acordo com Schumacher et al. (2004) a sazonalidade de deposição, nas regiões tropicais e sub-tropicais, varia de espécie para espécie. Nas florestas de regiões temperadas e frias, a chegada do outono desencadeia o processo de derrubada total das folhas.

Fernandes \& Backes (1998), em estudo com florestas nativas de araucária na Floresta Nacional de São Francisco de Paula, RS, constataram que a contribuição da araucária na serapilheira é maior que a do restante da vegetação, tanto para estruturas 
vegetativas como reprodutivas. Entretanto, os períodos de maior queda de material são diferenciados: enquanto no verão e no outono a contribuição da araucária varia de 85-67 $\%$, no inverno e na primavera varia de 70-46 \%. De forma inversa, as latifoliadas contribuem com 33-15\% durante o verão e o outono e com 54-30 \% durante o inverno e primavera.

Poggiani \& Schumacher (2000) consideram que decomposição da serapilheira em povoamentos com espécies nativas, como a Araucaria angustifolia, é um dos aspectos primordiais a serem estudados na avaliação da nutrição mineral e ciclagem de nutrientes nestas florestas, visando o planejamento do uso destas espécies para recuperação de áreas degradadas ou para produção de madeiras nobres.

Na serapilheira, as fontes de carbono incluem desde os açúcares simples, que são utilizados por uma grande quantidade de organismos, até componentes estruturais da planta como a celulose e a lignina, os quais são mineralizados por um número restrito de espécies de fungos, bactérias e animais (Guzmán \& Àlvarez-Sánchez, 2003). Dos nutrientes, o nitrogênio e o fósforo são usualmente os mais críticos (Anderson et al., 1989). A concentração de lignina e as proporções de lignina/nitrogênio e carbono/nitrogênio dos materiais vegetais, em geral, estão correlacionadas com a velocidade de decomposição da maioria dos recursos, cuja maior quantidade de lignina e carbono nos tecidos vegetais provoca a diminuição da taxa de decomposição (Shaw et al., 1991).

Pode-se entender a decomposição da camada de serapilheira como um mecanismo regulado, principalmente por três grupos de variáveis: a natureza da comunidade decompositora (os macro e microrganismos), as características do material orgânico que determinam sua degradabilidade (a qualidade do material) e as condições físico-químicas do meio ambiente, as quais são controladas pelo clima e pelas características edáficas do sítio (Swift et al., 1979; Lekha \& Gupta, 1989). A atividade de fragmentação do material vegetal da serapilheira é uma das funções mais importantes desempenhadas pela fauna do solo, particularmente a macrofauna (Correia \& Andrade, 1999). 
A passagem do material vegetal em decomposição pelo trato digestivo de alguns invertebrados do solo provoca o aumento na concentração de nutrientes nos coprólitos em relação ao recurso inicial. Teuben \& Verhoef (1992) encontraram concentrações totais de $\mathrm{K}^{+}, \mathrm{Ca}^{2+}$ e concentrações de $\mathrm{K}^{+}, \mathrm{Ca}^{2+}, \mathrm{NO}_{3}{ }^{-}, \mathrm{NH}_{4}^{+}$trocáveis, significativamente maiores nas fezes de isópodes do que em seu alimento, sendo que $\mathrm{NO}_{3}{ }^{-}$encontrava-se cerca de 40 vezes mais disponível nas fezes do que no recurso. Um número de bactérias significativamente maior nas fezes do que no material inicial, juntamente com uma tendência à redução das populações fúngicas também têm sido relatados (Byzov et al., 1998). Assim, pode-se considerar que as altas taxas de consumo e produção de fezes podem alterar de forma significativa a disponibilidade de nutrientes no solo (Costa, 2002). 


\section{MATERIAL E MÉTODOS}

\subsection{Descrição da área de estudo}

O estudo foi realizado em ecossistemas com Araucaria angustifolia (Bertoloni) O. Ktze, localizados no Parque Estadual de Campos do Jordão (PECJ), distante $210 \mathrm{~km}$ da cidade de São Paulo, cujas coordenadas são $22^{\circ} 44^{\prime} \mathrm{S}$ e $45^{\circ} 30^{\prime} \mathrm{W}$, em Campos do Jordão, São Paulo (Figura 1).

A região de Campos do Jordão, do ponto de vista florístico é marcada pelo encontro de três regiões florísticas principais: a Mata de Araucaria-Podocarpus; Campos do Brasil Central e Mata Latifoliada da Encosta Atlântica. A Mata de Araucaria-Podocarpus recobre as maiores extensões dentro do Parque, sendo caracterizada pela grande densidade de Podocarpus lambertii Klotz. e de Araucaria angustifolia (Bertoloni) O. Ktze, concentradas em vales e grotões com maior grau de umidade e solos mais protegidos (Berzaghi, 1994). 


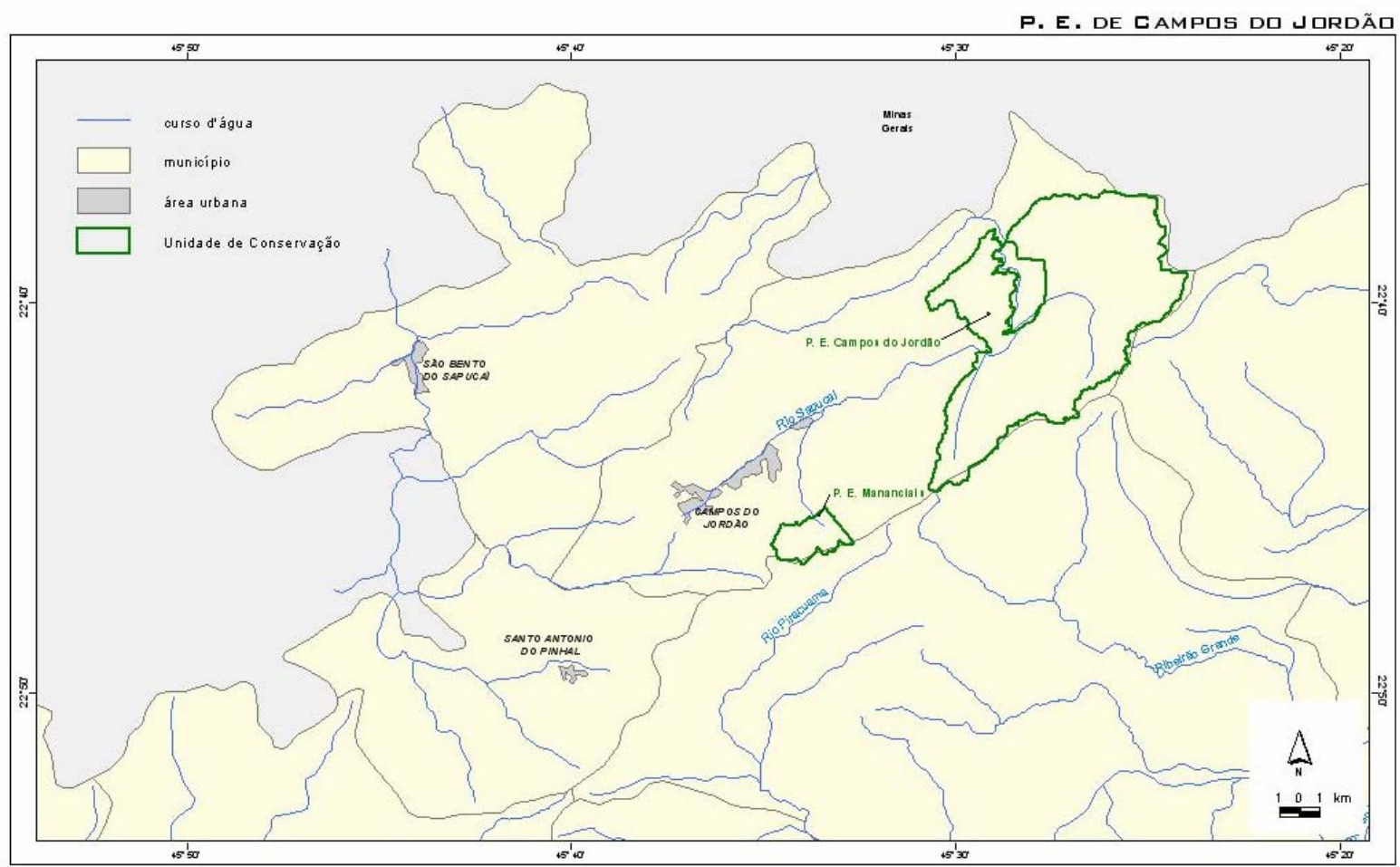

Figura 1 - Localização do Parque Estadual de Campos do Jordão dentro do município de Campos do Jordão, SP

Com uma extensão de 8341,86 ha, o PECJ encontra-se em sua totalidade no planalto de Campos do Jordão, que corresponde ao segundo degrau dos "maciços antigos do Brasil Atlântico". O relevo do parque é muito acentuado, com declives superiores a $45 \%$, ficando seu ponto mais alto a $2007 \mathrm{~m}$ na borda SW do planalto e a parte mais baixa, a 1030 m, no vale do rio Sapucaí - Guaçú (Seibert, 1975).

O PECJ apresenta várias propriedades agrícolas confrontantes com o elevado valor cênico da paisagem. Desta forma, de modo geral, a vegetação se apresenta profundamente modificada pela presença antrópica (Seibert, 1975). Muitas áreas de matas, atuamente protegidas, foram utilizadas no passado para o cultivo e pastoreio.

O estudo foi estabelecido em diferentes ecossistemas sob mata de araucária (Figuras 2 e 3 ): 
(a) Área 1: mata nativa de araucária (M)

Localizada próxima à cachoeira da Galharada, apresenta uma vegetação estruturalmente pluriestratificada, rica em epífitas, musgos, pteridófitas, bromeliáceas, orquidáceas e, ainda, complexando a estrutura desta mata, possui alta densidade de outras espécies vegetais não-araucária (Tabela 3) e araucárias de grande porte. Encontram-se várias espécies arbóreas, algumas delas apresentadas na Tabela 2. É ocupada por Latossolo Vermelho-Amarelo distrófico câmbico textura argilosa A húmico com A proeminente $(44 \mathrm{~cm})$ sobreposto.

(b) Área 2: mata de araucária introduzida (RSF)

Localiza-se próxima à estrada do Retiro que liga o Parque ao estado de Minas Gerais. Àrea plantada em 1959, apresenta uma regeneração de araucárias, as espécies presentes em conjunto com a araucária são as mesmas pertencentes à mata nativa, porém, em maior densidade (Tabela 3). É ocupada por Latossolo Amarelo distrófico câmbico textura argilosa A húmico com A proeminente $(28 \mathrm{~cm})$ sobreposto.

(c) Área 3: mata de araucária introduzida e impactada pela ação do fogo (RF)

Localiza-se próxima à estrada do Retiro. Àrea plantada em 1958, apresenta a menor densidade de outras espécies vegetais (Tabela 3). Consta em seu histórico a ocorrência de um incêndio acidental no período de julho de 2001. É comum visualizar a presença de cavalos nesta área. É ocupada por Cambissolo Háplico Tb Distrófico latossólico textura argilosa A moderado. 

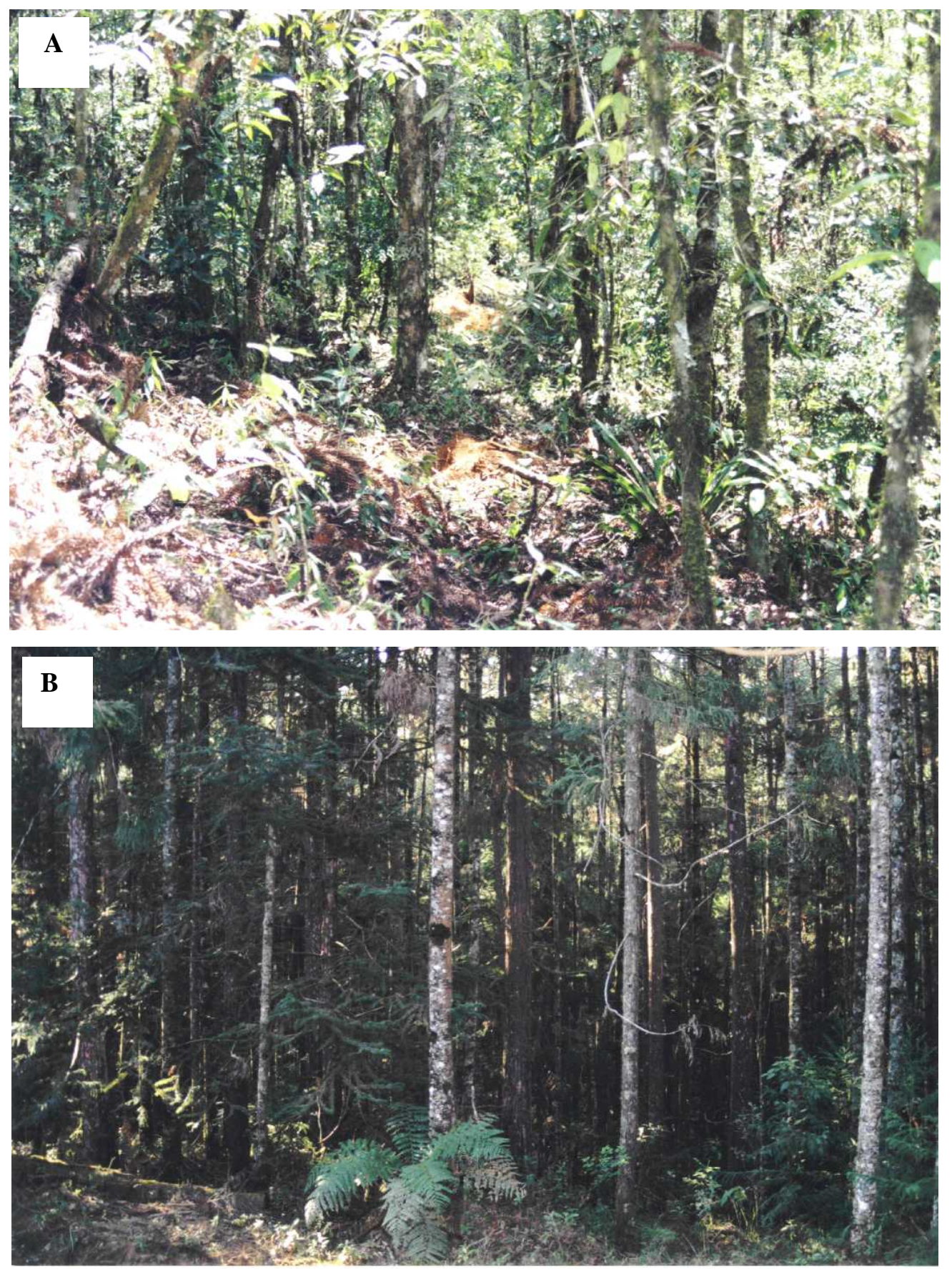

Figura 2 - Vista da mata nativa de araucária (A) e da mata de araucária introduzida (B) no Parque Estadual de Campos do Jordão, SP 


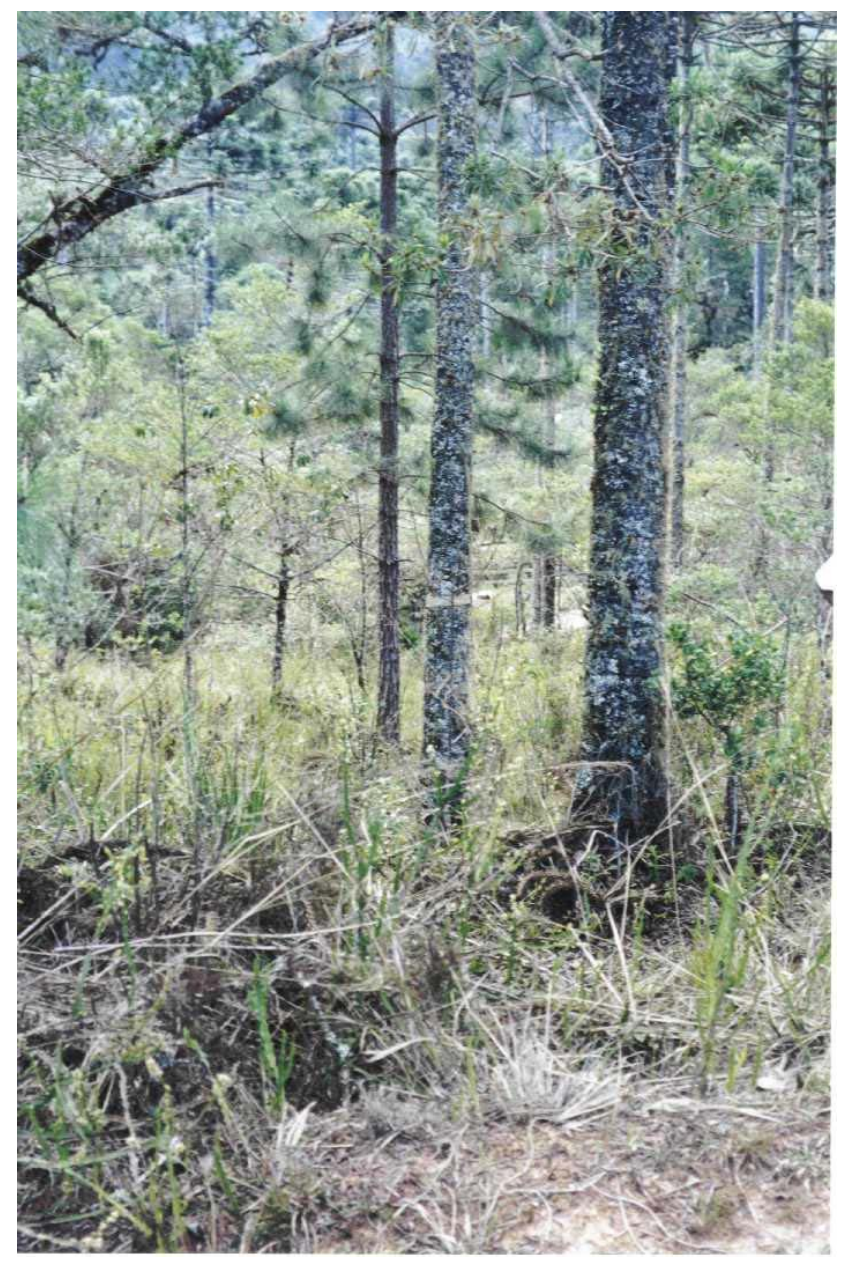

Figura 3 - Vista da mata de araucária introduzida e impactada pela ação do fogo no Parque Estadual de Campos do Jordão, SP

Dada sua localização geográfica o PECJ tem sua classificação climática na sub-região da Mantiqueira. O clima local é determinado pela classificação de Köppen como $\mathrm{Cfb}$, que significa: clima subtropical de altitude, mesodérmico e úmido, ocasionalmente ficando a temperatura abaixo de zero. Dados fornecidos pela Estação Hidrometeorológica de Campos do Jordão permitiram a construção de um climadiagrama para os anos de 2002 e 2003, época do estudo (Figura 4). Observa-se que o mês mais frio é julho, com temperatura média próxima a $10^{\circ} \mathrm{C}$ e o mais quente é fevereiro, com temperatura média superior a $18^{\circ} \mathrm{C}$. 


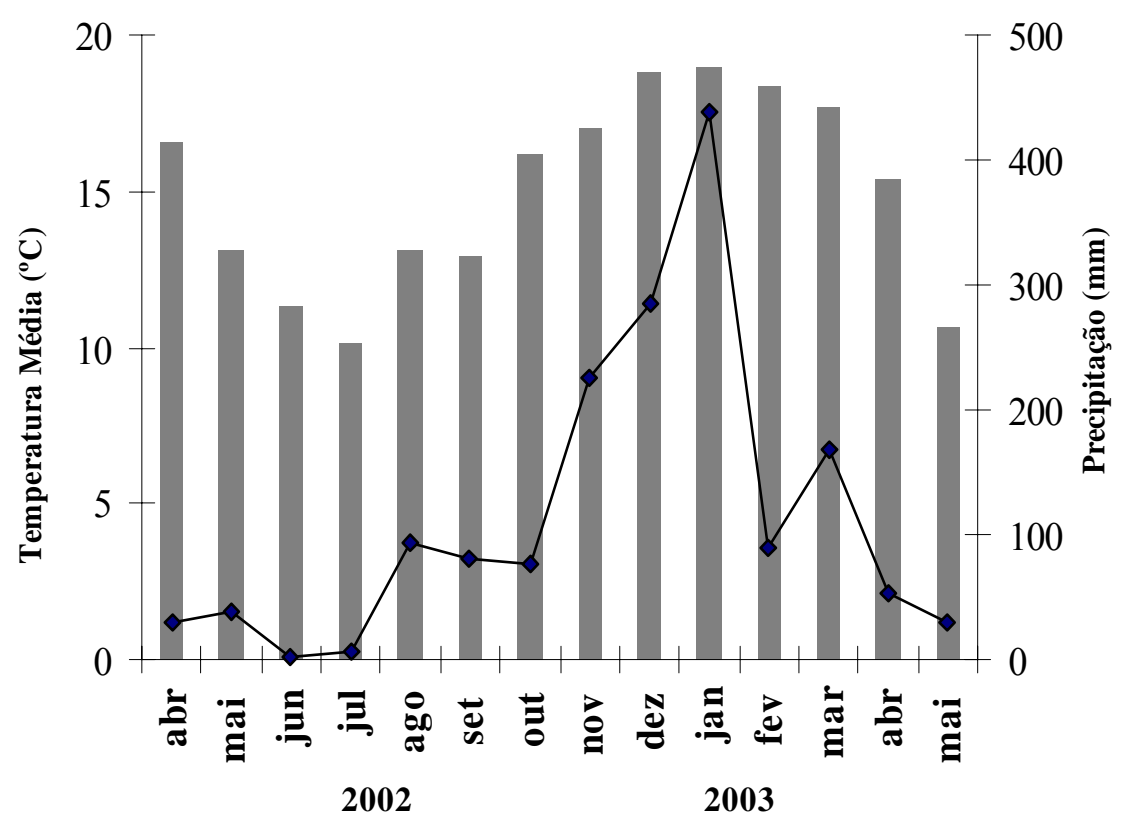

Temperatura Média Mensal $\left({ }^{\circ} \mathrm{C}\right) \multimap$ Precipitação (mm)

Figura 4 - Temperatura média mensal $\left({ }^{\circ} \mathrm{C}\right)$ e precipitação pluviométrica mensal $(\mathrm{mm})$ referentes aos anos de 2002 e 2003

O regime pluviométrico da região, apresentado na Figura 4, mostra uma concentração de chuvas no verão, sendo janeiro o mês de maior precipitação total (acima de $300 \mathrm{~mm}$ ) e o inverno menos chuvoso, tendo julho a menor precipitação (cerca de 10 $\mathrm{mm})$. A escassez de chuvas foi acentuada no período deste estudo (2002/2003).

Os dados de clima, registrados nos últimos sete anos (Tabela 1), mostram uma precipitação anual total que varia de $1287,6 \mathrm{~mm} \cdot \mathrm{ano}^{-1}$ (2003) a 2128,0 mm.ano ${ }^{-1}$ (2000). A temperatura variou de $21,0{ }^{\circ} \mathrm{C}$ como máxima no ano 2002 e $8,6^{\circ} \mathrm{C}$ como mínima no ano 1999. 
Tabela 1. Precipitação anual total $(\mathrm{mm})$ e médias da temperatura anual máximas e mínimas $\left({ }^{\circ} \mathrm{C}\right)$, no período de 1997 - 2003 no PECJ

\begin{tabular}{cccc}
\hline Anos & Temperatura Máxima $\left({ }^{\circ} \mathbf{C}\right)$ & Temperatura Mínima $\left({ }^{\circ} \mathbf{C}\right)$ & Precipitação (mm) \\
\hline 1997 & 20,3 & 9,5 & 1593,6 \\
1998 & 20,9 & 9,8 & 1393,8 \\
1999 & 19,9 & 8,6 & 1552,8 \\
2000 & 20,1 & 8,8 & 2128,0 \\
2001 & 20,4 & 9,4 & 1670,0 \\
2002 & 21,0 & 9,4 & 1605,0 \\
2003 & 19,9 & 8,8 & 1287,6 \\
\hline
\end{tabular}

Fonte: Estação Meteorológica de Campos do Jordão, SP.

As coletas foram realizadas em outubro de 2002 e em março de 2003. Caracterizaram-se as amostragens como "período seco" e "período úmido" a partir da média de precipitação dos cinco meses anteriores às coletas. A primeira amostragem foi caracterizada como um período seco, com temperatura média (maio a setembro de 2002) de $12,1^{\circ} \mathrm{C}$ e precipitação de $44 \mathrm{~mm}$; a segunda amostragem, apesar da coleta não coincidir com os picos de chuva, foi caracterizada como período úmido, apresentou temperatura média (outubro a fevereiro de 2003) de $17,9^{\circ} \mathrm{C}$ e precipitação de $223 \mathrm{~mm}$.

As áreas de coleta foram georeferenciadas usando um GPS MAGELAN 300. A mata nativa de araucária localiza-se entre as latitudes $22^{\circ} 41^{\prime} 57^{\prime \prime}$ e $22^{\circ} 41^{\prime} 45^{\prime \prime}$ e entre as longitudes $45^{\circ} 27^{\prime} 58^{\prime \prime}$ e e $45^{\circ} 27^{\prime} 47^{\prime}$ '; a mata de araucária introduzida entre as latitudes

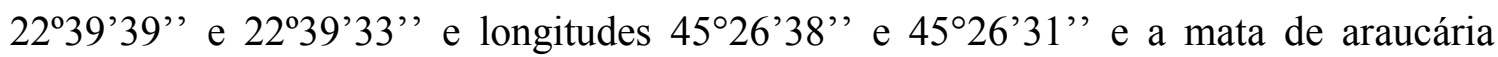
introduzida e impactada pela ação do fogo entre as latitudes $22^{\circ} 40^{\prime} 08^{\prime \prime}$ e $22^{\circ} 40^{\prime} 05^{\prime \prime}$ e entre as longitudes $45^{\circ} 27^{\prime} 54^{\prime \prime}$ e $45^{\circ} 27^{\prime} 39^{\prime}$ '.

Para conhecer a composição vegetal, foi realizado um levantamento, com auxílo de mateiros da região, das espécies arbóreas, arbustivas e herbáceas que ocorriam nos diferentes ecossistemas estudados (Tabela 2). A mata de araucária introduzida e impactada pela ação do fogo, devido ao incêndio, apresentava um predomínio das gramíneas: Aristida longiseta (conhecida na região como barba de bode) e capim do 
campo (nome científico não identificado); e da composta Baccharis trimera (carqueja). Em todas as áreas ocorriam a presença de diferentes espécies de bromélias que não foram identificadas neste trabalho.

Tabela 2. Famílias, espécies e portes das vegetações que ocorrem associadas com a mata nativa de araucária e com as matas de araucária introduzida

\begin{tabular}{lll}
\hline Família & Espécie & porte \\
\hline Clethraceae & Clethra scabra & arbórea \\
Cunnoniaceae & Weinmannia pinnata & arbórea \\
Lauraceae & Ocotea diospyrifolia & arbórea \\
& Ocotea catharinensis & arbórea \\
Melastomataceae & Miconia biglomerata & arbórea \\
& Tibouchina sellowiana & arbórea \\
Podocarpaceae & Podocarpus lambertii & arbórea \\
Rosaceae & Prunus sellowii & arbórea \\
Symplocaceae & Symplocos aegrota & arbórea \\
Myrsinaceae & Myrsine ferruginea & arbórea \\
Euphorbiaceae & Alchornea triplinervia & arbórea \\
Tiliaceae & Luehea grandiflora & arbórea \\
Rutaceae & Esenbeckia leiocarpa & arbórea \\
Meliaceae & Guarea macrophylla & arbusto \\
Combretaceae & Terminalia brasiliensis & arbórea \\
Winteraceae & Drimys winterii & arbórea \\
$*$ Mirtaceae & Pitanga preta & arbórea \\
$*$ Rubiaceae & Uvália & arbórea \\
$*$ & Cinzeiro & arbórea \\
$*$ & Guamirim & arbórea \\
$*$ & Melaleuca & arbórea \\
$*$ & Imbira amarela & arbórea \\
$*$ & Guamirim miúdo & arbórea \\
$*$ & Criptomeria & arbórea \\
\hline$*$ Devia & a & espóa
\end{tabular}

* Devido a sinonímia, não foi possível obter o nome científico destas espécies.

Foi realizado um levantamento da densidade das espécies vegetais (número de indivíduos por hectare) que ocorriam próximas aos pontos de amostragem da macrofauna edáfica para que fosse possível inferir sobre quais os ecossistemas foram mais densos e, consequentemente, que possuíam um maior aporte de biomassa. $\mathrm{O}$ critério de inclusão adotado para as araucárias foi de $\geq 30 \mathrm{~cm}$ e para as demais espécies 
$\geq 20 \mathrm{~cm}$, escolhidas pelo diâmetro à altura do peito. Utilizou-se o método dos quadrantes (Cottan \& Curtis, 1956), que consiste no estabelecimento, dentro de um povoamento a ser amostrado, de pontos distribuídos de modo sistemático. Tais pontos são divididos em quatro quadrantes. Em cada quadrante é amostrado o indivíduo mais próximo ao ponto. Desse modo, em cada unidade amostral, distanciadas entre si em $10 \mathrm{~m}$, foram observadas quatro árvores de araucária e quatro de outras espécies (Figura 5).

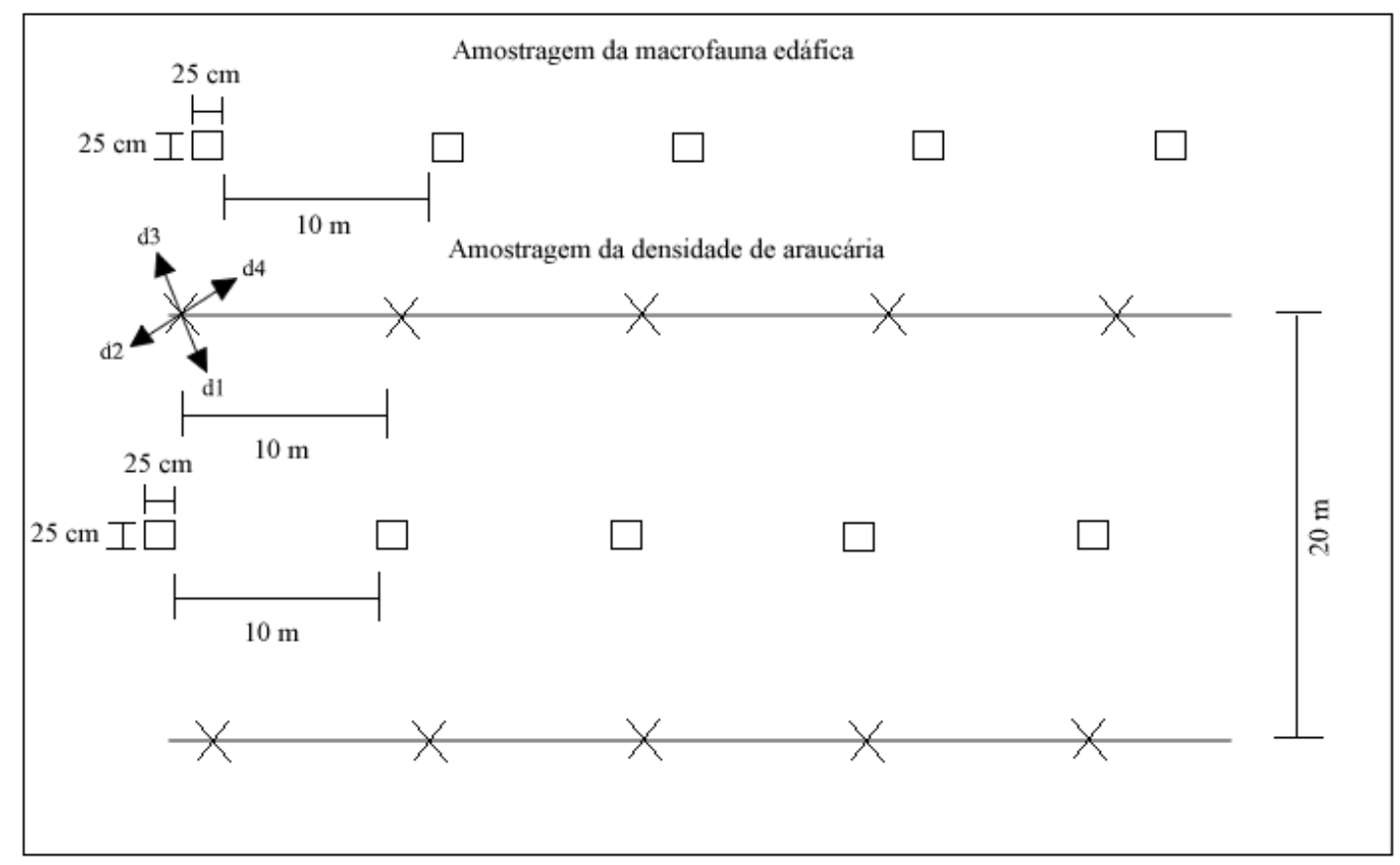

Figura 5 - Desenho esquemático do método dos quadrantes para a amostragem da densidade das espécies vegetais nos diferentes ecossistemas e da coleta da macrofauna edáfica 
Tabela 3. Densidade de espécies vegetais (ind.ha ${ }^{-1}$ ) nos diferentes ecossistemas de araucária

\begin{tabular}{ccc}
\hline & Araucaria angustifolia & Outras espécies \\
\hline Mata de araucária nativa & 357,0 & 285,0 \\
Mata de araucária introduzida & 1437,0 & 232,0 \\
Mata de araucária impactada & & 182,0 \\
pela ação do fogo & 652,0 & \\
\hline
\end{tabular}

\subsection{Avaliação da macrofauna edáfica}

Foram realizadas amostragens utilizando o método recomendado pelo Programa Tropical Soil Biology and Fertility (TSBF) descrito por Anderson \& Ingram (1993). Em cada área foram amostrados 10 blocos de solo de 25 x $25 \mathrm{~cm}$ de lado e 30 $\mathrm{cm}$ de profundidade, sendo posteriormente subdivididos em horizontes de 0-10, 10-20, 20-30 cm de profundidade (Figura 6), para avaliar a distribuição vertical dos animais, dando indicações do volume de solo potencialmente explorado e mobilizado. Antes da retirada do solo a serapilheira foi amostrada na mesma área do monólito. Os pontos de amostragens ficaram distanciados 10 metros entre si ao longo de um transecto determinado ao acaso.

Os componentes da macrofauna acima de $10 \mathrm{~mm}$ de comprimento e/ou $2 \mathrm{~mm}$ de diâmetro (Swift et al., 1979), foram extraídos manualmente, com auxílio de pinças. Os animais foram identificados com auxílio de lupa binocular, contados e separados em grandes grupos taxonômicos, ordem ou família em alguns casos. A identificação dos componentes da macrofauna foi realizada na Embrapa Agrobiologia, RJ.

Após a identificação, foram reunidos em grupos funcionais. Foi realizada a pesagem de todos os invertebrados, após 15 minutos de secagem ao ar livre em papel absorvente, obtendo-se a biomassa $\left(\mathrm{g}\right.$ de peso fresco. $\mathrm{m}^{-2}$ ) por grupo taxonômico.

Para a identificação taxonômica do material coletado foram utilizados os trabalhos de Borror \& Delong (1969), Barnes (1984) e chaves de identificação. Os 
invertebrados foram separados taxonomicamente em: Diplopoda, Chilopoda, Symphyla (Myriapoda); Araneae, Pseudoescorpionida (Arachnida); Diplura, Thysanura (Apterygota); Psocoptera, Isoptera, Dermaptera, Lepidoptera, Thysanoptera, Coleoptera, Diptera, Hemiptera (Heteroptera e Homoptera), Hymenoptera (Pterygota); Isopoda (Crustacea); Oligochaeta e a Família Enchytraeidae.

A ordem Hymenoptera foi separada em Formicidae e outros Hymenoptera; a Ordem Orthoptera foi separada em Blattodea e outros Orthoptera; as Ordens Diptera, Coleoptera, Hemiptera e Thysanoptera foram separadas em estádio adulto e imaturo por existir grande diferenciação no hábito alimentar e no habitat entre estes dois estádios de vida.

Após a classificação em grupos taxonômicos, os taxa foram reunidos nos seguintes grupos funcionais (Tabela 4): Decompositores, Predadores e Herbívoros, de acordo com o hábito alimentar predominante em cada grupo (Hanagarth et al., 1999; Moore et al., 1988). A designação de outros grupos foi dada para aqueles cujo hábito alimentar não pôde ser determinado ao nível de ordem. O grupo Sociais reuniu os grupos taxonômicos Formicidae e Isoptera.

As larvas de Coleoptera foram identificadas até ao nível de Família, em alguns casos chegando a Gênero, sob orientação do Dr Antônio Sérgio Vanin, IB/USP. Estes espécimes serão incorporados à Coleção Entomológica do Museu de Zoologia da USP, SP. 
Tabela 4. Composição dos grupos funcionais selecionados para este estudo

\begin{tabular}{|c|c|c|c|c|}
\hline Decompositores & Predadores & Herbívoros & Outros Grupos & Sociais \\
\hline Diplopoda & Araneae & $\begin{array}{l}\text { Homoptera } \\
\text { adultos }\end{array}$ & Blattodea & Formicidae \\
\hline Diptera imaturos & Dermaptera & $\begin{array}{l}\text { Homoptera } \\
\text { imaturos }\end{array}$ & $\begin{array}{l}\text { Coleoptera } \\
\text { adultos }\end{array}$ & $\begin{array}{c}\text { Isoptera } \\
\text { (Subfamília } \\
\text { Apicotermitinae) }\end{array}$ \\
\hline Enchytraeidae & $\begin{array}{c}\text { Diplura } \\
\text { (Famílias Campodeidae e } \\
\text { Japygidae ) }\end{array}$ & $\begin{array}{c}\text { Thysanoptera } \\
\text { adultos }\end{array}$ & $\begin{array}{l}\text { Coleoptera } \\
\text { imaturos }\end{array}$ & \\
\hline Isopoda & Pseudoscorpinida & $\begin{array}{c}\text { Thysanoptera } \\
\text { imaturos }\end{array}$ & Diptera adultos & \\
\hline Oligochaeta & Chilopoda & $\begin{array}{l}\text { Heteroptera } \\
\text { adultos }\end{array}$ & $\begin{array}{c}\text { Outros } \\
\text { Hymenoptera }\end{array}$ & \\
\hline Psocoptera & & $\begin{array}{l}\text { Heteroptera } \\
\text { imaturos }\end{array}$ & Thysanura & \\
\hline Symphyla & & $\begin{array}{l}\text { Outros } \\
\text { Orthoptera }\end{array}$ & & \\
\hline
\end{tabular}

\subsection{Caracterização dos atributos da serapilheira}

A serapilheira foi coletada em cada ponto de amostragem, dentro da área de 25 x $25 \mathrm{~cm}$. Após a triagem da macrofauna na serapilheira, o $\mathrm{pH}$ do material foi determinado em $50 \mathrm{ml}$ de solução $0,01 \mathrm{M}$ de cloreto de cálcio. O material restante foi acondicionado em sacos de papel e levado à estufa com circulação de ar a $65^{\circ} \mathrm{C}$, por 50 horas. Após a secagem foi pesado em balança analítica com a finalidade de obter a massa seca total (folhas, galhos e partes reprodutivas) em cada área de estudo.

Posteriormente, esse material foi encaminhado ao Laboratório de Fertilidade do Solo da ESALQ/USP para caracterização química, seguindo a método descrito por Kiehl (1985). A porcentagem de água contida nas amostras da serapilheira foi determinada pela umidade perdida a $60-65^{\circ} \mathrm{C}$ e a $100-110{ }^{\circ} \mathrm{C}$. A análise de matéria orgânica total e do resíduo mineral total foi realizada de acordo com o método de perda por combustão, com remoção dos inertes e moagem da amostra. Para determinação do carbono orgânico, da matéria orgânica compostável e da matéria orgânica resistente à compostagem, foi utilizada mistura sulfocrômica com umidade perdida a $65^{\circ} \mathrm{C}$. Para 
nitrogênio total a determinação foi realizada pelo método Kjeldahl, descrita em Kiehl (1985). As concentrações de fósforo foram analisadas por colorimetria pelo método do vanadato-molibdico de amônio, potássio e sódio foram analisados por fotômetro de chama. As leituras de cálcio e magnésio foram feitas em espectrofotômetro de absorção atômica. $\mathrm{O}$ enxofre foi determinado pelo método gravimétrico da precipitação do enxofre pelo cloreto de bário, na forma de sulfato de bário.

As análises de lignina foram realizadas seguindo o método descrito por Silva \& Queiroz (2002), por permanganato de potássio. As análises foram realizadas no Laboratório de Bromatologia da Faculdade de Zootecnia e Engenharia de Alimentos FZEA/USP. Essa análise fornece informações quanto ao aspecto qualitativo da serapilheira e sua degradação no ambiente.

\subsection{Caracterização dos atributos do solo}

Foi realizada uma descrição morfológica dos solos das áreas de coleta e análises químicas e físicas para classificação e caracterização dos perfis.

As amostras de solo foram coletadas em sub-amostras por profundidade (0-10, 10-20 e 20-30 cm), num total de três amostras compostas por área de estudo (Figura 6). Os atributos físicos do solo foram analisados seguindo o método proposto por Camargo et al. (1986). A análise granulométrica realizada pelo método do densímetro foi apresentada na Tabela 5 para caracterização das áreas. Para determinação da densidade aparente e do volume dos macroporos do solo, foram coletadas amostras de solo com estrutura indeformada, utilizando-se cilindros de aço, com altura média e diâmetro medido com auxílio de um paquímetro para cada amostra, em um total de 90 subamostras. A coleta foi facilitada com a construção de uma mini-trincheira do lado oposto ao ponto de coleta da macrofauna (Figura 6). As amostras indeformadas foram saturadas e submetidas à mesa de tensão sob uma pressão referente a $40 \mathrm{~cm}$ de coluna d'água para que se atingisse a umidade na capacidade de campo. 

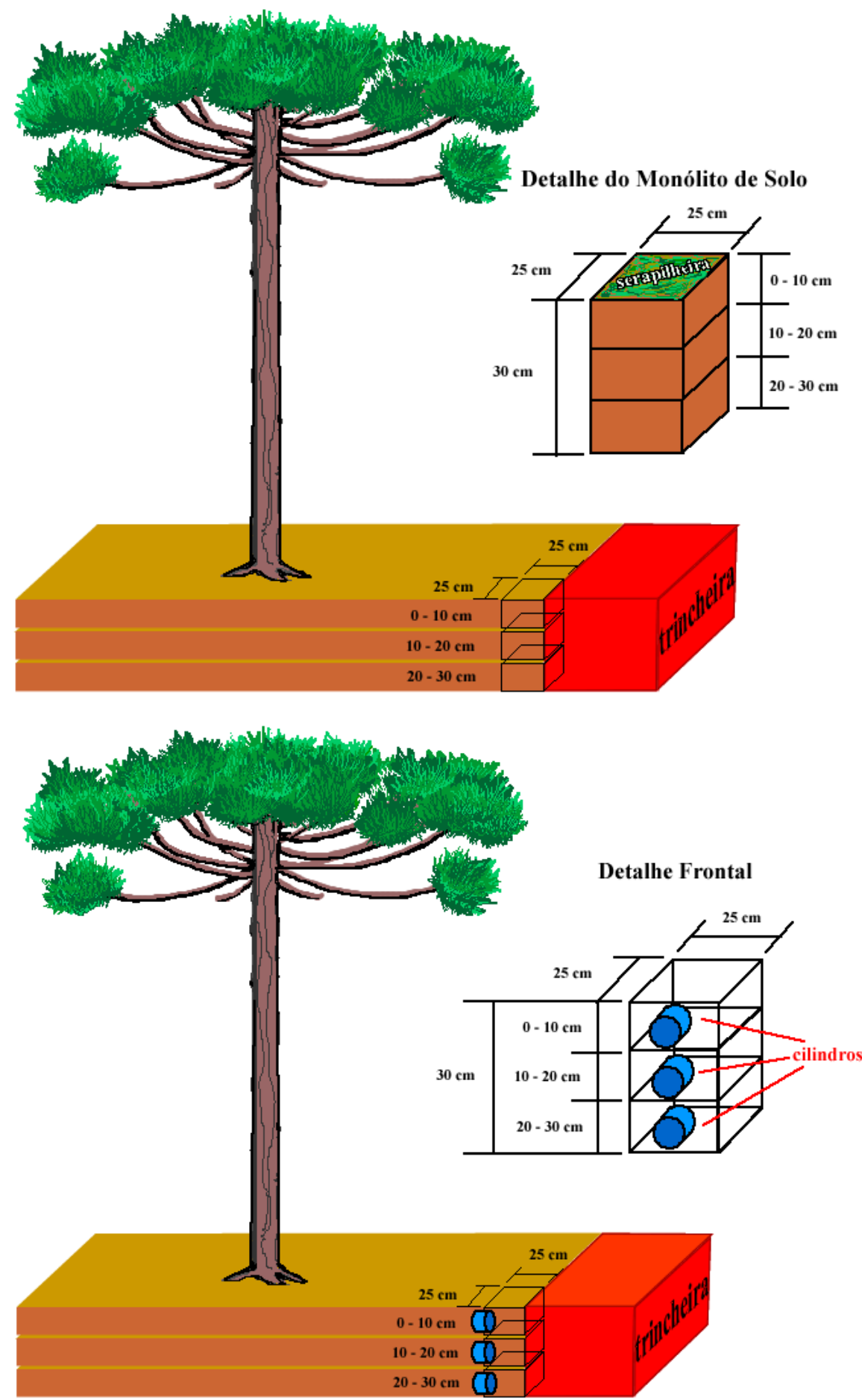

Figura 6 - Desenho esquemático da coleta da macrofauna edáfica e das amostras indeformadas para determinação da porosidade do solo. Detalhe dos monólitos de solo; detalhe frontal da coleta das amostras indeformadas 
A caracterização química do solo seguiu a metodologia descrita por Raij et al. (2001). $\mathrm{O}$ pH foi determinado em $5 \mathrm{ml}$ de solução $0,01 \mathrm{M} \mathrm{CaCl}_{2}$, para $\mathrm{H}+\mathrm{Al}$ foi utilizado o método de tampão SMP para determinação da acidez total. A matéria orgânica foi mensurada fotometricamente após digestão ácida de dicromato/sulfúrico. Cálcio, fósforo, magnésio e potássio foram extraídos com resina íon-trocável. O fósforo foi quantificado colorimetricamente usando amônio-molibdênio. Cálcio e magnésio foram determinados por espectrofotometria de absorção atômica e potássio por fotometria de chamas. As análises foram realizadas nos Laboratórios de Fertilidade e de Física do Solo da ESALQ/USP.

Tabela 5. Caracterização física do solo nas profundidades 0-10, 10-20 e 20-30 cm, sob diferentes ecossistemas de araucária. Os valores são média \pm desvio-padrão $(\mathrm{n}=10)$

\begin{tabular}{|c|c|c|c|c|}
\hline $\begin{array}{c}\text { Profundidade do } \\
\text { solo }(\mathrm{cm})\end{array}$ & $\begin{array}{l}\text { Argila total (\%) } \\
<0,002 \mathrm{~mm} \\
\end{array}$ & $\begin{array}{c}\text { Areia total (\%) } \\
0,02-2 \mathrm{~mm} \\
\end{array}$ & $\begin{array}{l}\text { Silte total (\%) } \\
0,002-0,02 \mathrm{~mm}\end{array}$ & Textura \\
\hline \multicolumn{5}{|c|}{ Mata nativa de araucária (M) } \\
\hline $0-10$ & $44 \pm 2,96$ & $46 \pm 2,46$ & $10 \pm 1,06$ & argilosa \\
\hline $10-20$ & $46 \pm 1,20$ & $43 \pm 0,72$ & $12 \pm 1,61$ & argilosa \\
\hline $20-30$ & $46 \pm 1,30$ & $43 \pm 0,46$ & $10 \pm 1,29$ & argilosa \\
\hline \multicolumn{5}{|c|}{ Mata de araucária introduzida (RSF) } \\
\hline $0-10$ & $39 \pm 1,21$ & $41 \pm 1,94$ & $19 \pm 1,88$ & argilosa \\
\hline $10-20$ & $40 \pm 2,70$ & $41 \pm 2,89$ & $18 \pm 3,03$ & argilosa \\
\hline $20-30$ & $43 \pm 2,63$ & $39 \pm 2,50$ & $18 \pm 1,06$ & argilosa \\
\hline \multicolumn{5}{|c|}{ Mata de araucária impactada pela ação do fogo (RF) } \\
\hline $0-10$ & $35 \pm 1,32$ & $43 \pm 0,39$ & $23 \pm 1,37$ & média-argilosa \\
\hline $10-20$ & $35 \pm 5,45$ & $41 \pm 1,51$ & $23 \pm 3,98$ & média-argilosa \\
\hline $20-30$ & $36 \pm 6,33$ & $38 \pm 3,51$ & $26 \pm 3,42$ & média-argilosa \\
\hline
\end{tabular}

\subsection{Abundância relativa da macrofauna edáfica}

A abundância relativa foi expressa como a porcentagem do número médio de indivíduos por $\mathrm{m}^{2}$ do táxon em relação ao número total de indivíduos para cada grupo funcional. Foi utilizada a soma do número de indivíduos por $\mathrm{m}^{2}$ coletados em cada época de coleta e, separadamente, para cada ecossistema avaliado. Procedeu-se à classificação dos grupos funcionais em categorias de abundância (Tabela 6). A fórmula utilizada para este estudo foi: 
Abundância (número médio de indivíduos por $\mathrm{m}^{2}$ ) $=\underline{\text { Total } \mathbf{t} * \mathbf{1 0 0}}$

Tinv.

Onde: Total $\mathrm{t}=$ Total de indivíduos por $\mathrm{m}^{2}$ daquele táxon para a coleta $\mathrm{n}$

Tinv. $=$ Total de invertebrados por $\mathrm{m}^{2}$ da coleta $\mathrm{n}$

$\mathrm{n}=$ época de coleta.

Tabela 6. Classificação dos grupos funcionais em categorias de abundância (Modificado de Santos, 2000)

\begin{tabular}{ccc}
\hline $\begin{array}{c}\text { Faixa de abundância } \\
\text { relativa }\end{array}$ & Classes & Códigos \\
\hline$<2 \%$ & Raros & 1 \\
2 a $10 \%$ & Ocasionais & 2 \\
10 a $50 \%$ & Abundantes & 3 \\
$>50 \%$ & Dominantes & 4 \\
\hline
\end{tabular}

\subsection{Avaliação das alterações da comunidade do solo}

Para a avaliação da macrofauna do solo nos diferentes ecossistemas estudados foi utilizado o índice V de Wardle (1995). Este índice é uma relação entre as abundâncias na área sem manejo (M) com as áreas manejadas (replantadas) e impactadas ou não pela ação do fogo (RF e RSF). Foi realizada a seguinte adaptação da fórmula original:

$$
V=\frac{2 d M}{d M+d R F \text { ou (dRSF) }}
$$

Onde: $\mathrm{V}$ = índice de mudança;

$\mathrm{d}=$ densidade da macrofauna;

$\mathrm{M}=$ mata de araucária nativa;

$\mathrm{RF}=$ mata de araucária impactada pela ação do fogo;

RSF = mata de araucária não impactada pela ação do fogo 
$\mathrm{O}$ índice varia de -1 a 1 , com o valor 0 indicando abundâncias iguais nos diferentes ecossistemas. Pela aplicação do índice foram estabelecidas categorias para expressar a inibição ou estimulação dos grupos da macrofauna do solo em resposta ao manejo (Tabela 7).

Tabela 7. Categorias de inibição e estimulação dos grupos da macrofauna do solo em resposta ao manejo (modificado de Wardle, 1995 e Correia et al., 2003)

\begin{tabular}{lcc}
\hline Categoria & Símbolo & Índice V \\
\hline Inibição extrema & IE & $\mathrm{V}<-0,67$ \\
Inibição moderada & IM & $-0,33>\mathrm{V}>-0,67$ \\
Inibição leve & IL & $-0,05>\mathrm{V}>-0,33$ \\
Sem alteração & $\mathrm{S} \mathrm{A}$ & $-0,05<\mathrm{V}<0,05$ \\
Estimulação leve & EL & $0,05<\mathrm{V}<0,33$ \\
Estimulação moderada & EM & $0,33<\mathrm{V}<0,67$ \\
Estimulação extrema & EE & $\mathrm{V}>0,67$ \\
\hline
\end{tabular}

\subsection{Análise dos dados}

Para a padronização dos dados, o número de indivíduos encontrados em cada amostra foi transformado em indivíduos por metro quadrado (densidade), sendo calculadas as médias e os respectivos erros-padrão para cada tratamento.

As comparações das comunidades dos diferentes ecossistemas estudados foram feitas mediante a utilização do índice de diversidade: Shannon $(\mathrm{H}=-\Sigma$ pi.log pi; onde $\mathrm{pi}=\mathrm{ni} / \mathrm{N} ; \mathrm{ni}=$ densidade de cada grupo, $\mathrm{N}=\Sigma$ da densidade de todos os grupos); Índice de Uniformidade de Pielou (H/log $10 \mathrm{n}^{\circ}$ de grupos) e Riqueza de Grupos (Martins $\&$ Santos, 2000).

Foram realizadas Análises de Variância (ANOVA) para verificar as diferenças entre as médias dos índices, da distribuição vertical da macrofauna e das análises físicas e químicas do solo e da serapilheira de cada ecossistema avaliado. Quando estas ocorreram, foi aplicado o teste de Tukey ao nível de 5\%. Para avaliar a distribuição vertical foi realizada uma análise independente para cada profundidade. Para as análises estatísticas foi utilizado o aplicativo estatístico SAS. 
Aplicou-se a Análise Fatorial de Correspondência (AFC) como método de ordenamento. Esta análise tem um caráter exploratório e descritivo, sendo utilizada para a análise de dados categóricos que visa avaliar tabelas de contingências com um grande número de variáveis. O programa utilizado para esta análise foi o SPAD (Lebart \& Fénelon, 2004).

A frequência das famílias de larvas de Coleoptera, nas diferentes áreas e épocas de estudo, foi analisada pela Análise Multivariada de Agrupamento, por ligação completa (vizinho mais distante), tomando o coeficiente de correlação r-de Pearson como medida de distância. O complemento r-de Pearson ajusta as variáveis para o seu valor médio, ignorando seus valores totais (Digby \& Kempton, 1987). O método de ligação completa, vizinho mais distante, caracteriza-se pela formação de grupos a partir da fusão dos dois elementos mais distantes, sendo o método mais recomendado para estudos ecológicos que tenham como objetivo identificar fortes descontinuidades (Valentin, 1995). Foi utilizado o aplicativo estatístico "Statistica" para esta análise.

Foi aplicada a Análise Biplot para estabelecer as relações entre a densidade da macrofauna e os atributos físicos e químicos do solo e da serapilheira. A representação gráfica em Biplot é utilizada para apresentar, simultaneamente, as observações (linhas) e variáveis (colunas) referentes a uma matriz de dados (Gabriel, 1971). Pode indicar a existência de agrupamentos entre as observações, assim como, mostrar as variâncias e correlações entre as variáveis. Foi utilizada a matriz de correlação de Spearman, uma correlação não paramétrica, para estabelecer as relações entre as variáveis. Foi utilizado o aplicativo estatístico SAS para estas análises. 


\section{RESULTADOS E DISCUSSÃO}

\subsection{Caracterização do solo}

Na época seca e chuvosa, observou-se que a mata de araucária impactada pela ação do fogo (RF) apresentou menores teores de matéria orgânica (MO) e, consequentemente, menor capacidade de troca catiônica (Tabelas 8 e 9) que os demais ecossistemas avaliados. O solo desta área apresentou as piores condições para a atividade biológica, que é diretamente dependente da MO como fonte de matéria e energia, sendo agravado pela ocorrência do fogo que eliminou o sub-bosque, com conseqüente redução dos resíduos deixados sobre o solo.

$\mathrm{Na}$ época chuvosa, a mata nativa de araucária (M) apresentou maior teor de cálcio e magnésio, quando comparada às demais áreas. Entretanto, os teores de $\mathrm{Ca}$ e $\mathrm{Mg}$ foram baixos em todas as áreas (Tabelas 8 e 9), o que pode ser explicado pela maior imobilização destes nutrientes na biomassa vegetal, especialmente de troncos e galhos que possuem ciclagem demorada, sendo, desta forma, a biomassa vegetal seu principal compartimento de reserva e não o solo.

Pela análise do perfil do solo da mata de araucária introduzida (RSF) observou-se uma coloração amarela-acinzentada que serve como indicação de um regime hídrico do solo bastante favorável, ou seja, a permanência de umidade neste perfil tende a ser maior quando comparado às demais áreas.

Esta área possui o maior estoque de matéria orgânica e maior teor de argila, apresentando, em média, 5\% de MO até três metros de profundidade, enquanto a área M apresenta, em média, 3\% até esta profundidade. 
Tabela 8. Caracterização química do solo sob diferentes ecossistemas: mata de araucária nativa (M), mata de araucária introduzida (RSF) e mata de araucária introduzida e impactada pela ação do fogo (RF), na época seca

\begin{tabular}{|c|c|c|c|c|c|}
\hline \multicolumn{2}{|c|}{ Atributos químicos } & \multirow{2}{*}{$\begin{array}{c}\text { Profundidade } \\
0-10\end{array}$} & \multirow{2}{*}{ M } & \multirow{2}{*}{$\frac{\mathbf{R F}}{3.6 \mathrm{~A} \mathrm{~b}}$} & RSF \\
\hline $\mathrm{pH}\left(\mathrm{CaCl}_{2}\right)$ & 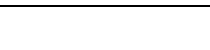 & & & & $3,4 \mathrm{~B} \mathrm{~b}$ \\
\hline & & $10-20$ & $3,8 \mathrm{~A} \mathrm{a}$ & $3,7 \mathrm{~A} a b$ & $3,7 \mathrm{~A} \mathrm{a}$ \\
\hline \multirow{4}{*}{$\begin{array}{l}\text { Matéria Orgânica } \\
\text { (MO) }\end{array}$} & & $20-30$ & $3,9 \mathrm{~A} \mathrm{a}$ & $3,8 \mathrm{~A} \mathrm{a}$ & $3,8 \mathrm{~A} \mathrm{a}$ \\
\hline & $\left(\mathrm{g} . \mathrm{dm}^{-3}\right)$ & $0-10$ & $67 \mathrm{~A} \mathrm{a}$ & $45 \mathrm{~B} \mathrm{a}$ & $73 \mathrm{~A} \mathrm{a}$ \\
\hline & & $10-20$ & $56 \mathrm{~A} \mathrm{a}$ & $29 \mathrm{~B} \mathrm{~b}$ & $46 \mathrm{~A} \mathrm{~b}$ \\
\hline & & $20-30$ & $39 \mathrm{AB} \mathrm{b}$ & $25 \mathrm{~B} \mathrm{~b}$ & $44 \mathrm{~A} \mathrm{~b}$ \\
\hline \multirow{3}{*}{$\begin{array}{l}\text { Fósforo } \\
\text { (P) }\end{array}$} & $\left(\mathrm{mg} . \mathrm{dm}^{-3}\right)$ & $0-10$ & $7,0 \mathrm{~A} \mathrm{a}$ & $7,0 \mathrm{~A} \mathrm{a}$ & $7,0 \mathrm{~A} \mathrm{a}$ \\
\hline & & $10-20$ & $4,0 \mathrm{~A} \mathrm{ab}$ & $3,0 \mathrm{~A} \mathrm{~b}$ & $4,0 \mathrm{~A} \mathrm{a}$ \\
\hline & & $20-30$ & $3,0 \mathrm{~A} \mathrm{~b}$ & $2,0 \mathrm{~A} \mathrm{~b}$ & $2,0 \mathrm{~A} \mathrm{~b}$ \\
\hline \multirow{3}{*}{$\begin{array}{l}\text { Potássio } \\
(\mathrm{K})\end{array}$} & $\left(\mathrm{mmol} . \mathrm{dm}^{-3}\right)$ & $0-10$ & $1,7 \mathrm{~A} \mathrm{a}$ & $1,9 \mathrm{~A} \mathrm{a}$ & $1,8 \mathrm{~A} \mathrm{a}$ \\
\hline & & $10-20$ & $1,1 \mathrm{~A} \mathrm{ab}$ & $1,0 \mathrm{~A} \mathrm{~b}$ & $1,4 \mathrm{~A} \mathrm{a}$ \\
\hline & & $20-30$ & $0,8 \mathrm{~A} \mathrm{~b}$ & $0,8 \mathrm{~A} \mathrm{~b}$ & $1,1 \mathrm{~A} \mathrm{a}$ \\
\hline \multirow{3}{*}{$\begin{array}{l}\text { Cálcio } \\
(\mathrm{Ca})^{*}\end{array}$} & $\left(\mathrm{mmol} . \mathrm{dm}^{-3}\right)$ & $0-10$ & 2,0 & 1,0 & 1,0 \\
\hline & & $10-20$ & 1,0 & 1,0 & 1,0 \\
\hline & & $20-30$ & 1,0 & 1,0 & 2,0 \\
\hline \multirow{3}{*}{$\begin{array}{l}\text { Magnésio } \\
(\mathrm{Mg})^{*}\end{array}$} & $\left(\right.$ mmol.dm $\left.{ }^{-3}\right)$ & $0-10$ & 3,0 & 2,0 & 1,0 \\
\hline & & $10-20$ & 3,0 & 2,0 & 1,0 \\
\hline & & $20-30$ & 2,0 & 1,0 & 2,0 \\
\hline \multirow{3}{*}{$\begin{array}{l}\text { Acidez potencial } \\
\qquad(\mathrm{H}+\mathrm{Al})\end{array}$} & $\left(\mathrm{mmol} . \mathrm{dm}^{-3}\right)$ & $0-10$ & $228 \mathrm{~B}$ a & $166 \mathrm{C} \mathrm{a}$ & $281 \mathrm{~A} \mathrm{a}$ \\
\hline & & $10-20$ & $150 \mathrm{~B} \mathrm{~b}$ & $135 \mathrm{~B}$ ab & $205 \mathrm{~A} \mathrm{~b}$ \\
\hline & & $20-30$ & $135 \mathrm{~A} \mathrm{~b}$ & $121 \mathrm{~A} \mathrm{~b}$ & $185 \mathrm{~B} \mathrm{~b}$ \\
\hline Cap. de Troca & $\left(\mathrm{mmol} . \mathrm{dm}^{-3}\right)$ & $0-10$ & $234,7 \mathrm{AB}$ a & $170,9 \mathrm{~B} \mathrm{a}$ & $284,8 \mathrm{~A} \mathrm{a}$ \\
\hline \multirow[t]{2}{*}{ Catiônica (CTC) } & & $10-20$ & $155,1 \mathrm{~B} \mathrm{~b}$ & $139,0 \mathrm{~B} \mathrm{ab}$ & $208,4 \mathrm{~A} \mathrm{~b}$ \\
\hline & & $20-30$ & $138,8 \mathrm{~B} \mathrm{~b}$ & $123,8 \mathrm{~B} \mathrm{~b}$ & $190,1 \mathrm{~A} \mathrm{~b}$ \\
\hline Saturação de & $(\%)$ & $0-10$ & 3 & 3 & 1 \\
\hline \multirow{2}{*}{ Bases $(V)^{*}$} & & $10-20$ & 3 & 3 & 2 \\
\hline & & $20-30$ & 3 & 2 & 3 \\
\hline \multirow[t]{3}{*}{ Umidade } & $(\%)$ & $0-10$ & $19,7 \mathrm{Aa}$ & $16,9 \mathrm{Ba}$ & $23,4 \mathrm{Aa}$ \\
\hline & & $10-20$ & $19,6 \mathrm{Aa}$ & $17,4 \mathrm{Ba}$ & $22,3 \mathrm{Aa}$ \\
\hline & & $20-30$ & $18,7 \mathrm{Aa}$ & $18,0 \mathrm{Aa}$ & $21,9 \mathrm{Aa}$ \\
\hline
\end{tabular}

Letras iguais maiúsculas na mesma linha ou minúsculas na mesma coluna não diferem entre si significativamente ao nível de $5 \%$ de probabilidade de acordo com o teste de Tukey. 
Tabela 9. Caracterização química do solo sob diferentes ecossistemas: mata de araucária nativa (M), mata de araucária introduzida (RSF) e mata de araucária introduzida e impactada pela ação do fogo (RF), na época chuvosa

\begin{tabular}{|c|c|c|c|c|c|}
\hline \multicolumn{2}{|c|}{ Atributos químicos } & \multirow{2}{*}{$\begin{array}{c}\text { Profundidade } \\
0-10\end{array}$} & \multirow{2}{*}{$\frac{\mathbf{M}}{3.6 \mathrm{~B} \mathrm{~b}}$} & \multirow{2}{*}{ RF } & RSF \\
\hline $\mathrm{pH}\left(\mathrm{CaCl}_{2}\right)$ & & & & & $3,8 \mathrm{AB} \mathrm{b}$ \\
\hline & & $10-20$ & $3,9 \mathrm{~A} \mathrm{a}$ & $3,9 \mathrm{~A} \mathrm{a}$ & $4,0 \mathrm{~A} \mathrm{~b}$ \\
\hline \multirow{4}{*}{$\begin{array}{l}\text { Matéria orgânica } \\
\text { (MO) }\end{array}$} & \multirow{4}{*}{$\left(\right.$ g.dm $\left.{ }^{-3}\right)$} & $20-30$ & $4,1 \mathrm{~A} \mathrm{a}$ & $4,0 \mathrm{~A} \mathrm{a}$ & $4,0 \mathrm{~A} \mathrm{a}$ \\
\hline & & $0-10$ & $98 \mathrm{~A} \mathrm{a}$ & $46 \mathrm{C} \mathrm{a}$ & $80 \mathrm{~B} \mathrm{a}$ \\
\hline & & $10-20$ & $62 \mathrm{~A} \mathrm{~b}$ & $40 \mathrm{~B} \mathrm{a}$ & $67 \mathrm{~A} \mathrm{ab}$ \\
\hline & & $20-30$ & $54 \mathrm{~A} \mathrm{~b}$ & $33 \mathrm{~B} \mathrm{a}$ & $62 \mathrm{~A} \mathrm{~b}$ \\
\hline \multirow{3}{*}{$\begin{array}{l}\text { Fósforo } \\
\text { (P) }\end{array}$} & \multirow{3}{*}{$\left(\mathrm{mg} . \mathrm{dm}^{-3}\right)$} & $0-10$ & $12,0 \mathrm{~A} \mathrm{a}$ & $8,0 \mathrm{~B} \mathrm{a}$ & $12,0 \mathrm{~A} \mathrm{a}$ \\
\hline & & $10-20$ & $8,7 \mathrm{~A} \mathrm{ab}$ & $7,0 \mathrm{~A} \mathrm{a}$ & $9,0 \mathrm{~A} \mathrm{ab}$ \\
\hline & & $20-30$ & $5,3 \mathrm{~A} \mathrm{~b}$ & $5,7 \mathrm{~A} \mathrm{a}$ & $7,7 \mathrm{~A} \mathrm{~b}$ \\
\hline \multirow{3}{*}{$\begin{array}{l}\text { Potássio } \\
(\mathrm{K})^{*}\end{array}$} & \multirow{3}{*}{$\left(\mathrm{mmol} . \mathrm{dm}^{-3}\right)$} & $0-10$ & 1,1 & 0,8 & 0,4 \\
\hline & & $10-20$ & 1,1 & 0,8 & 0,5 \\
\hline & & $20-30$ & 0,9 & 0,5 & 0,4 \\
\hline \multirow{3}{*}{$\begin{array}{l}\text { Cálcio } \\
(\mathrm{Ca})\end{array}$} & \multirow{3}{*}{$\left(\mathrm{mmol} . \mathrm{dm}^{-3}\right)$} & $0-10$ & $2,0 \mathrm{~A} \mathrm{a}$ & $1,0 \mathrm{~B} \mathrm{a}$ & $1,0 \mathrm{~B} \mathrm{a}$ \\
\hline & & $10-20$ & 1,0 Aab & $1,0 \mathrm{~A} \mathrm{a}$ & $1,0 \mathrm{~A} \mathrm{a}$ \\
\hline & & $20-30$ & $0,3 \mathrm{~A} \mathrm{~b}$ & $1,0 \mathrm{~A} \mathrm{a}$ & $1,0 \mathrm{~A} \mathrm{a}$ \\
\hline \multirow{3}{*}{$\begin{array}{l}\text { Magnésio } \\
(\mathrm{Mg})^{*}\end{array}$} & \multirow{3}{*}{$\left(\mathrm{mmol} . \mathrm{dm}^{-3}\right)$} & $0-10$ & 3,0 & 1,0 & 1,0 \\
\hline & & $10-20$ & 2,0 & 1,0 & 1,0 \\
\hline & & $20-30$ & 1,0 & 1,0 & 1,0 \\
\hline \multirow{3}{*}{$\begin{array}{l}\text { Acidez potencial } \\
\qquad(\mathrm{H}+\mathrm{Al})\end{array}$} & \multirow[t]{3}{*}{$\left(\mathrm{mmol} . \mathrm{dm}^{-3}\right)$} & $0-10$ & $193 \mathrm{~A} \mathrm{a}$ & $114 \mathrm{~B} \mathrm{a}$ & $185 \mathrm{~A} \mathrm{a}$ \\
\hline & & $10-20$ & 117 AB b & $106 \mathrm{~B}$ a & $145 \mathrm{~A} \mathrm{~b}$ \\
\hline & & $20-30$ & $98 \mathrm{~B} \mathrm{~b}$ & $99 \mathrm{~B} \mathrm{a}$ & $140 \mathrm{~A} \mathrm{~b}$ \\
\hline Cap. de Troca & \multirow{3}{*}{$\left(\mathrm{mmol} . \mathrm{dm}^{-3}\right)$} & $0-10$ & $206,1 \mathrm{~A} \mathrm{a}$ & $114,8 \mathrm{~B} \mathrm{a}$ & $185,4 \mathrm{~A} \mathrm{a}$ \\
\hline \multirow{2}{*}{ Catiônica (CTC) } & & $10-20$ & $119,8 \mathrm{ABb}$ & $107,1 \mathrm{~B} \mathrm{a}$ & $145,5 \mathrm{~A} a b$ \\
\hline & & $20-30$ & $99,6 \mathrm{~B} \mathrm{~b}$ & $99,5 \mathrm{~B} \mathrm{a}$ & $140,7 \mathrm{~A} \mathrm{~b}$ \\
\hline Saturação de & $(\%)$ & $0-10$ & $7 \mathrm{~A} \mathrm{a}$ & $1 \mathrm{~B} \mathrm{a}$ & $0,2 \mathrm{~B} \mathrm{a}$ \\
\hline \multirow{2}{*}{$\operatorname{Bases}(\mathrm{V})$} & & $10-20$ & $2 \mathrm{~A} \mathrm{a}$ & $1 \mathrm{~A} \mathrm{a}$ & $0,3 \mathrm{~A} \mathrm{a}$ \\
\hline & & $20-30$ & $2 \mathrm{~A} \mathrm{a}$ & $1 \mathrm{~A} \mathrm{a}$ & $0,3 \mathrm{~A} \mathrm{a}$ \\
\hline \multirow[t]{3}{*}{ Umidade } & $(\%)$ & $0-10$ & $44,7 \mathrm{Aa}$ & $30,1 \mathrm{Ba}$ & 42,9 Aa \\
\hline & & $10-20$ & $32,06 \mathrm{Aa}$ & $26,2 \mathrm{Ba}$ & 38,9 Аa \\
\hline & & $20-30$ & $30,9 \mathrm{Aa}$ & $26,2 \mathrm{Ba}$ & $40,0 \mathrm{Aa}$ \\
\hline
\end{tabular}

* não significativo $(\mathrm{P}<0,05)$ para a interação área $\times$ profundidade.

Letras iguais maiúsculas na mesma linha ou minúsculas na mesma coluna não diferem entre si significativamente ao nível de 5\% de probabilidade de acordo com o teste de Tukey.

$\mathrm{Na}$ Tabela 10 têm-se os valores de porosidade total, macroporosidade e densidade do solo dos ecossistemas estudados. Através desses dados observa-se que, em média, a porosidade total foi menor $(\mathrm{P}<0,05 ; \mathrm{F}=6,44)$ e a densidade do solo maior $(\mathrm{P}<0,05 ; \mathrm{F}=6,25)$ na $\mathrm{RF}$. A redução da porosidade nesta área provavelmente é resultado da perda de matéria orgânica do solo.

A maior atividade biológica e o maior aporte de matéria orgânica ocorrem na 
camada superficial de 0-10 $\mathrm{cm}$ de profundidade no solo. Nesta profundidade observa-se que a $\mathrm{M}$ apresenta $67 \%$ de porosidade total, destes, $18 \%$ são de macroporos e densidade de $0,87 \mathrm{~g} . \mathrm{m}^{-3}$ na profundidade de $0-10 \mathrm{~cm}$. Na RSF, nesta profundidade, tem-se $64 \%$ de porosidade total, sendo apenas $9 \%$ de macroporos e densidade de 0,94 g.m ${ }^{-3}$. Na RF, a maior porosidade $(52 \%)$ e a menor densidade $\left(1,26 \mathrm{~g} . \mathrm{m}^{-3}\right)$ foi encontrada nesta área (Tabela 10), indicando o efeito da atividade da fauna edáfica sobre as propriedades físicas do solo.

Tabela 10. Porosidade total, macroporos e densidade do solo sob diferentes ecossistemas de araucária

\begin{tabular}{llll}
\hline & \multicolumn{1}{c}{ M } & \multicolumn{1}{c}{ RF } & RSF \\
\hline & & Porosidade Total (\%) & $64 \mathrm{AB}$ \\
$0-10$ & $67 \mathrm{~A}$ & $52 \mathrm{~B}$ & $67 \mathrm{~A}$ \\
$10-20$ & $62 \mathrm{AB}$ & $50 \mathrm{~B}$ & $64 \mathrm{~A}$ \\
$20-30$ & $61 \mathrm{AB}$ & $48 \mathrm{~B}$ & $9 \mathrm{~A}$ \\
& & Macroporosidade (\%) & \\
$0-10$ & $18 \mathrm{~A}$ & $10 \mathrm{~A}$ & $2 \mathrm{~B}$ \\
$10-20$ & $12 \mathrm{~A}$ & $14 \mathrm{~A}$ & $7 \mathrm{~A}$ \\
$20-30$ & $11 \mathrm{~A}$ & $14 \mathrm{~A}$ & $0.94 \mathrm{AB}$ \\
& & Densidade $\mathbf{( g / \mathbf { c m } ^ { 3 } )}$ & \\
$0-10$ & $0.87 \mathrm{~B}$ & $1.26 \mathrm{~A}$ & $0.87 \mathrm{~A}$ \\
$10-20$ & $1.01 \mathrm{AB}$ & $1.31 \mathrm{~B}$ & $0.93 \mathrm{~A}$ \\
$20-30$ & $1.01 \mathrm{AB}$ & $1.38 \mathrm{~B}$ & \\
\hline
\end{tabular}

Letras iguais maiúsculas na mesma linha não diferem entre si significativamente ao nível de $5 \%$ de probabilidade de acordo com o teste de Tukey.

\subsection{Relação entre os atributos físicos e químicos do solo e a macrofauna através da análise Biplot}

A partir das correlações de Spearman observa-se que os grupos Coleoptera e Chilopoda estão positivamente correlacionados com o conteúdo de matéria orgânica (MO), sendo $\mathrm{P}, \mathrm{Ca}$ e $\mathrm{Mg}$ negativamente correlacionadas à densidade do solo (Tabela 11). 
Os atributos físicos e químicos do solo e a densidade da macrofauna estão associados, principalmente, ao solo sob os ecossistemas M e RSF como pode ser observado na Figura 7.

Tabela 11. Coeficientes de correlação de Spearman entre os atributos químicos e físicos do solo e principais grupos da macrofauna dos diferentes ecossistemas de araucária

\begin{tabular}{|c|c|c|c|c|c|}
\hline \multirow{2}{*}{ Solução do solo } & \multicolumn{5}{|c|}{ Grupos da macrofauna } \\
\hline & Coleoptera & Chilopoda & L. Coleoptera & Formicidae & Isoptera \\
\hline $\begin{array}{l}\text { Matéria orgânica } \\
(\text { g.dm } \\
\text {-3) }\end{array}$ & 0,40 & 0,45 & 0,40 & s.c. & s.c. \\
\hline$P\left(\mathbf{m g} \cdot \mathbf{d m}^{-3}\right)$ & 0,37 & 0,37 & 0,45 & s.c. & s.c. \\
\hline Ca $\left(\mathrm{mmol} . \mathrm{dm}^{-3}\right)$ & 0,30 & 0,31 & s.c. & 0,22 & s.c. \\
\hline $\operatorname{Mg}\left(\mathrm{mmol} \mathrm{dm}^{-3}\right)$ & 0,18 & 0,27 & 0,23 & 0,29 & s.c. \\
\hline Densidade $\left(\mathrm{g} / \mathrm{cm}^{3}\right)$ & $-0,19$ & $-0,26$ & s.c. & s.c. & s.c. \\
\hline Macroporos (\%) & s.c. & s.c. & s.c. & 0,16 & s.c. \\
\hline Argila total (\%) & s.c. & s.c. & 0,17 & 0,20 & $-0,16$ \\
\hline
\end{tabular}

s.c. sem correlação para o nível de significância de 5\%

O maior aporte de MO encontrado na $\mathrm{M}$ e na RSF pode atuar como uma fonte de nutrientes para o solo, mantendo sua fertilidade e favorecendo, desta forma, a ocorrência da comunidade da fauna edáfica. De acordo com Primavesi (1990), o número e as espécies de organismos que populam um solo estão associados, em grande parte, à alimentação disponível e ao teor de MO no solo. Deste modo, quanto maior o teor de MO e melhor a sua qualidade, tanto maior a ocorrência dos organismos edáficos.

Foram encontradas correlações positivas entre a $\mathrm{MO}$ do solo e os grupos Chilopoda, adultos e larvas de Coleoptera (Tabela 11). A hipótese é de que a MO selecionou os grupos saprófagos pela oferta direta de alimentos, consequentemente favorecendo os predadores pela presença de presas para este grupo.

Na Figura 7 os diferentes ecossistemas são apresentados como vetores correspondentes ao ponto médio das observações (repetições). Os solos estão distintamente separados no gráfico, isto é, para as variáveis analisadas os solos sob os ecossistemas de araucária apresentam distinção entre si. 


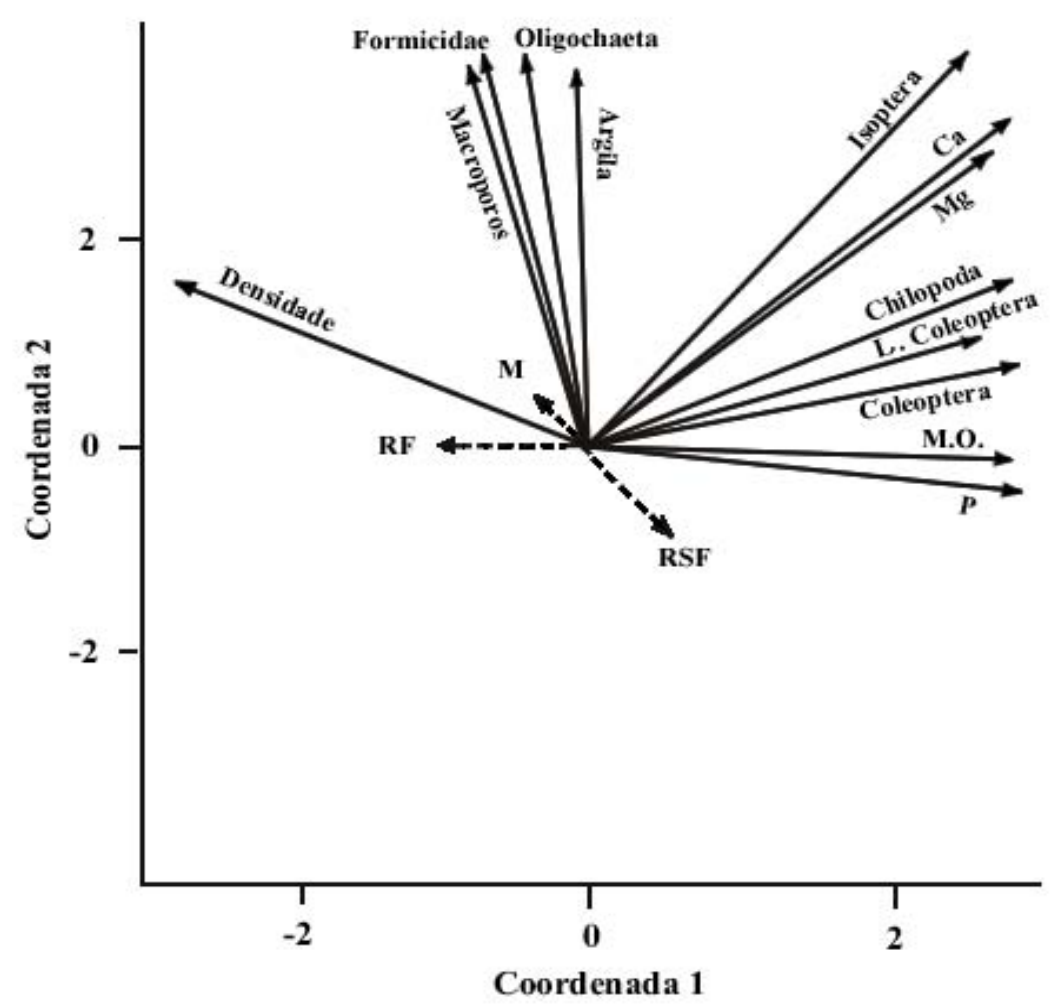

Figura 7 - Biplot para a macrofauna pelos atributos físicos e químicos do solo sob os diferentes ecossistemas: mata nativa de araucária (M), mata de araucária introduzida (RSF) e mata de araucária impactada pela ação do fogo (RF)

O distanciamento observado entre as variáveis consideradas e a área RF está relacionado aos menores teores encontrados de $\mathrm{MO}$ e demais nutrientes e, consequentemente à menor densidade e diversidade da macrofauna neste solo. Este resultado reforça o conceito da fauna edáfica como reveladora dos processos do solo.

As larvas de Coleoptera estão positivamente correlacionadas com a $\mathrm{MO}, \mathrm{Ca}$, $\mathrm{Mg}$ e argila. Formicidae apresenta correlação positiva com a argila do solo.

A densidade do solo ficou negativamente correlacionada aos grupos Coleoptera e Chilopoda. De forma geral, a alta densidade apresentada por um solo indica sua compactação e, como conseqüência, limita a atividade da comunidade da 
macrofauna como um todo, fato que pode ser observado na área RF que apresenta a maior densidade do solo e a menor densidade e diversidade da macrofauna.

A porcentagem de macroporos está positivamente correlacionada com Formicidae, esta correlação se deve à atividade das formigas na formação de túneis e galerias no solo, favorecendo, deste modo, a porosidade dos solos aos quais estão associadas.

$\mathrm{Ca}$ e $\mathrm{Mg}$ estão positivamente correlacionados aos adultos e larvas de Coleoptera, Chilopodas, Formicidae e às áreas M e RSF (Figura 7). A hipótese é de que onde ocorre uma reserva maior destes nutrientes há um favorecimento de alguns grupos da macrofauna.

O grupo Gastropoda, que inclui animais exigentes em Ca para a construção de suas conchas, não foi encontrado neste trabalho devido aos baixos teores deste nutriente no solo. Este fato destaca a influência das características de um solo sobre a composição da comunidade da fauna edáfica.

\subsection{Composição da comunidade da macrofauna edáfica}

Foram coletados 6768 indivíduos por metro quadrado neste estudo. Deste total, $55 \%$ foram coletados na época seca $\left(3742 \mathrm{ind} / \mathrm{m}^{2}\right.$ ) e $45 \%$ na época chuvosa (3026 ind $\left./ \mathrm{m}^{2}\right)$.

A densidade (ind $/ \mathrm{m}^{2}$ ) e a biomassa ( $\mathrm{g}$ de peso fresco $/ \mathrm{m}^{2}$ ) da macrofauna foram estudadas separadamente para solo e serapilheira.

\subsubsection{Densidade da macrofauna}

A densidade $\left(\mathrm{ind} / \mathrm{m}^{2}\right)$ da macrofauna do solo não apresentou diferenças significativas para a interação área×profundidade, desta forma, foi utilizado o somatório das profundidades $(0-30 \mathrm{~cm})$ para as análises estatísticas. 
As maiores densidades ocorreram na $\mathrm{M}$ e na época chuvosa. Este resultado está de acordo com outros trabalhos, principalmente, o de Bandeira \& Harada (1998), demonstrando que a macrofauna edáfica é prejudicada pela estação seca.

A diferença significativa entre o ecossistema $M$ e os demais foi mais expressiva na época seca (Tabela 12). Esta diferença indica uma maior capacidade de transformação deste ecossistema. Resultados semelhantes foram encontrados por Fragoso \& Rojas (1994) em sistemas de policultivos ou diversificados, demonstrando que estes sistemas têm efeitos positivos sobre a conservação da biodiversidade, isto é, a provisão de habitats e alimentos em sistemas diversificados podem favorecer algumas comunidades de invertebrados do solo, sobretudo de epígeos e anécicos. Assim, a diversidade das espécies de plantas pode ser um componente importante para determinar a qualidade do recurso e conseqüente colonização da comunidade de invertebrados do solo.

Dentre todos os grupos coletados no solo (ver em Anexos) apenas Homoptera, Coleoptera adultos e larvas, Chilopoda, Formicidae e Diplura apresentaram diferença significativa $(\mathrm{P}<0,05)$ para a interação área e época de estudo (Tabela 12).

Adultos de Coleoptera, Homoptera, Chilopoda e Diplura apresentaram diferença entre as áreas na época seca, sendo encontradas as maiores densidades (ind $/ \mathrm{m}^{2}$ ) na M (Tabela 12).

A subordem Homoptera (Ordem Hemiptera), insetos fitófagos e terrestres que sugam tanto a parte aérea quanto as raízes das plantas (Lara, 1992), não foi encontrada na área RF.

A classe Chilopoda não apresentou diferenças significativas entre as áreas na época chuvosa, este grupo é constituído por animais conhecidos por lacraias ou centopéias. São descritos como carnívoros, quase exclusivamente predadores, embora ocasionalmente possam alimentar-se de material vegetal em decomposição (Coleman \& Crossley, 1996).

Diplopoda não apresentou diferenças significativas entre as áreas, foram coletados 30 indivíduos na época seca e 21 na época chuvosa. A densidade de quilópodes e diplópodes é normalmente maior em solos argilosos, onde a cobertura 
vegetal e a alta umidade asseguram um maior suprimento de alimento (Ekschimitt et al., 1997). Por estas razões, foram encontrados em maior abundância nas áreas M e RSF.

Os dipluros são encontrados em locais úmidos, sob casca de árvores, pedras, em detritos e em madeira podre (Lara, 1992), no solo e na serapilheira (Palacios-Vargas, 1991). A Classe Diplura possui quatro famílias: Campodeidae, Japygidae, Protojapygidae e Anajapygidae. A Família Japygidae preda Collembola, Isopoda, Symphyla, espécies da Família Campodeidae, larvas de Diptera, Coleoptera, micélios de fungo e, embora sejam onívoros, preferem presas animais. A Família Campodeidae é descrita como predadora de ácaros, Enchytraeidae, esporos e micélio de fungos, pequenos artrópodes e detritos (Dindal, 1990). Os dipluros foram coletados em alta abundância na M na época seca e na RSF na época chuvosa (Tabela 12).

Coleoptera foi o terceiro grupo mais importante numericamente, após Isoptera e Formicidae, apresentando maior densidade na M (102 ind $\left./ \mathrm{m}^{2}\right)$. Resultado semelhante foi encontrado por Tapia-Coral (2004) em diferentes vegetações de terra firme na Amazônia peruana. De acordo com Coleman \& Crossley (1996), Coleoptera é a maior ordem de insetos, possuindo extensas variações na forma, tamanho, função e distribuição, sendo encontrada em todos os habitats, exceto nos oceanos. Os besouros do solo podem ser separados em predadores, fitófagos e saprófagos, embora um grande número de famílias desta ordem esteja associado aos processos de decomposição, via predação, da fauna detritívora propriamente dita, existe uma grande variação de funções dentro desta ordem. Assim como os diplópodes e os quilópodes, muitas espécies de coleópteros preferem solos argilosos. Os adultos preferem solos não excessivamente úmidos, embora seu desenvolvimento possa ocorrer sob estas circunstâncias (Ekschimitt et al., 1997), o que justifica serem encontrados em maior abundância na época seca.

Para as larvas de Coleoptera apenas na época chuvosa foram detectadas diferenças significativas entre as áreas. Nesta época, a M e a RSF apresentaram uma maior densidade (Tabela 12).

A Família Formicidae apresentou diferença significativa $(\mathrm{P}<0,05)$ entre as áreas apenas na época seca. As altas densidades encontradas para este grupo, em todas as áreas de estudo, podem ser explicadas pelo método de amostragem utilizado que 
privilegia a captura dos insetos sociais, mas como descrito por Della Lucia \& Fowler (1993b), uma outra explicação seria pelo fato da eliminação do sub-bosque ou o manejo antrópico de ecossistemas naturais causar uma desestruturação temporal da comunidade de Formicidae, reduzindo, consequentemente, o número de competidores e inimigos naturais, fornecendo às formigas, assim como a muitos outros organismos do solo, o meio ideal para a propagação e ocupação de áreas antes não ocupadas ou ocupadas em baixas densidades.

As formigas preferem explorar ambientes que possuem alimentos de mais alta qualidade (Della Lucia \& Araújo, 1993a), apesar de sua ampla ocorrência em ambientais diversificados. A M que apresentou as maiores densidades deste grupo $\left(756 \mathrm{ind} / \mathrm{m}^{2}\right)$.

Dos hábitos descritos para formigas, Lopes Assad (1997) cita que algumas constroem ninhos em vários tipos de cavidades de plantas, outras escavam galerias em troncos de árvores (formigas arborícolas), mas que a maioria constroi seus ninhos no solo, sendo responsáveis pelo transporte de grande quantidade de subsolo para a superfície, com grande influência no equilíbrio pedológico.

Apesar da Ordem Isoptera não ter apresentado diferença significativa entre áreas e épocas estudadas, este grupo merece destaque devido à dominância, junto com Formicidae, em todas as áreas.

Os cupins estão entre os mais importantes decompositores da matéria orgânica. Vários estudos têm demonstrado uma tendência dos cupins em aumentar a concentração de matéria orgânica e nutrientes em suas estruturas (Peres Filho et al., 1990; Wood, 1988).

As minhocas não apresentaram diferenças significativas para a interação área e épocas de estudo. Observou-se uma maior ocorrência das minhocas na época chuvosa. A baixa densidade apresentada por este grupo em todas as áreas pode estar relacionada a acidez do solo sob araucária $(\mathrm{pH}$ em torno de 3,5$)$ e pela baixa disponibilidade de nutrientes do solo e da serapilheira produzida nas matas de araucária. Este resultado está de acordo com Curry \& Good (1992) que destacam que solos ácidos possuem baixa biomassa de fauna, refletindo a escassez de minhocas. 
Segundo Lee (1985), as minhocas são geralmente ausentes ou raras em solos com textura grossa ou com alto conteúdo de argila, o que é agravado em regiões de altas taxas de chuva devido ao déficit de oxigênio. Fatores como um $\mathrm{pH}<4$ e baixas concentrações de cálcio no solo podem impedir a sobrevivência e a abundância destes animais.

Embora as minhocas tenham ocorrido em baixa densidade em todas as áreas estudadas, o grupo merece destaque por ser considerado um dos mais importantes grupos de animais do solo (Lopes Assad, 1997). Alguns autores (Stork \& Eggleton, 1992; Lavelle, 1994) têm nomeado o grupo de invertebrados composto pelas minhocas e os insetos sociais (cupins e formigas) como "engenheiros do ecossistema". Foram classificados assim pela capacidade de cavar eficientemente o solo e produzir uma grande variedade de poros (galerias, câmaras e vazios), bem como a produção de outras estruturas organo-minerais (macro-agregados, montículos e ninhos). As estruturas construídas pelos "engenheiros do ecossistema" podem facilitar significativamente o funcionamento do solo ao privilegiar estes locais com a funcionalidade de seus processos básicos (infiltração da água e do ar, mineralização do $\mathrm{C}$ e $\mathrm{N}$, desnitrificação ou fixação do $\mathrm{N}$, entre outros.

A nutrição deste grupo é baseada principalmente em restos vegetais em decomposição provenientes da serapilheira, de troncos mortos e de fezes de animais, misturados com quantidades variáveis de terra, mas nunca ingerem material vegetal vivo, a menos que o solo não tenha matéria orgânica suficiente (Lopes Assad, 1997). 
Tabela 12. Densidade média (indivíduos por metro quadrado) dos principais grupos da macrofauna edáfica coletados no solo $(0-30 \mathrm{~cm})$ sob diferentes ecossistemas de araucária

\begin{tabular}{ccccc}
\hline Grupos & Época de coleta & M & RF & RSF \\
\hline Homoptera & seca & $21 \mathrm{~A} \mathrm{a}$ & $0 \mathrm{~B} \mathrm{a}$ & $2 \mathrm{~B} \mathrm{a}$ \\
& chuvosa & $2 \mathrm{~A} \mathrm{~b}$ & $0 \mathrm{~A} \mathrm{a}$ & $0 \mathrm{~A} \mathrm{a}$ \\
Coleoptera & seca & $102 \mathrm{~A} \mathrm{a}$ & $14 \mathrm{~B} \mathrm{a}$ & $14 \mathrm{~B} \mathrm{~b}$ \\
& chuvosa & $20 \mathrm{~B} \mathrm{~b}$ & $34 \mathrm{AB} \mathrm{a}$ & $64 \mathrm{~A} \mathrm{a}$ \\
Chilopoda & seca & $85 \mathrm{~A} \mathrm{a}$ & $15 \mathrm{~B} \mathrm{a}$ & $15 \mathrm{~B} \mathrm{a}$ \\
& chuvosa & $39 \mathrm{~A} \mathrm{a}$ & $6 \mathrm{~A} \mathrm{a}$ & $38 \mathrm{~A} \mathrm{a}$ \\
L. de Coleoptera & seca & $80 \mathrm{~A} \mathrm{~b}$ & $56 \mathrm{~A} \mathrm{a}$ & $17 \mathrm{~A} \mathrm{~b}$ \\
& chuvosa & $185 \mathrm{~A} \mathrm{a}$ & $56 \mathrm{~B} \mathrm{a}$ & $151 \mathrm{~B} \mathrm{a}$ \\
Formicidae & seca & $756 \mathrm{~A} \mathrm{a}$ & $333 \mathrm{AB} \mathrm{a}$ & $28 \mathrm{~B} \mathrm{a}$ \\
& chuvosa & $75 \mathrm{~A} \mathrm{~b}$ & $278 \mathrm{~A} \mathrm{a}$ & $32 \mathrm{~A} \mathrm{a}$ \\
Diplura & seca & $59 \mathrm{~A} \mathrm{a}$ & $0 \mathrm{~B} \mathrm{a}$ & $2 \mathrm{~B} \mathrm{a}$ \\
& chuvosa & $3 \mathrm{~A} \mathrm{~b}$ & $6 \mathrm{~A} \mathrm{a}$ & $43 \mathrm{~A} \mathrm{a}$ \\
Outros & seca & $214 \mathrm{~A} \mathrm{a}$ & $715 \mathrm{~B} \mathrm{a}$ & $376 \mathrm{~B} \mathrm{a}$ \\
& chuvosa & $532 \mathrm{~A} \mathrm{a}$ & $953 \mathrm{~B} \mathrm{a}$ & $461 \mathrm{~B} \mathrm{a}$ \\
Total & seca & $1317 \mathrm{~A} \mathrm{a}$ & $1133 \mathrm{AB} \mathrm{a}$ & $454 \mathrm{~A} \mathrm{a}$ \\
& chuvosa & $856 \mathrm{~A} \mathrm{a}$ & $1333 \mathrm{~A} \mathrm{a}$ & $789 \mathrm{~A} \mathrm{a}$ \\
\hline
\end{tabular}

Para a análise estatística os valores foram transformados por $\sqrt{x}+1$.

Letras iguais maiúsculas na mesma linha (entre áreas) ou minúsculas na mesma coluna (entre épocas), não diferem entre si significativamente ao nível de $5 \%$ de probabilidade de acordo com o teste de Tukey.

\subsubsection{Análise Fatorial de Correspondência}

Para a Análise Fatorial de Correspondência (AFC) observa-se a porcentagem de contribuição da explicação dos dados fornecida por cada fator (eixo), assumindo-se que o somatório dos fatores explica $100 \%$ da variância global. Observam-se as contribuições absolutas de cada variável no lado positivo e/ou negativo do eixo e, de acordo com a categoria das variáveis que mais contribuem na caracterização dos fatores, no caso deste estudo, a estabilidade dos ecossistemas. Pela interpretação do gráfico produzido por estes fatores observa-se que, quanto mais próximas duas variáveis no gráfico, mais freqüente a sua ocorrência conjunta. 
Pela AFC os três ecossistemas estudados apresentaram-se em quadrantes separados nas duas épocas, indicando que a macrofauna ocorre de forma diferenciada nesses sistemas.

$\mathrm{Na}$ época seca, o eixo 1 explicou $83 \%$ da variabilidade dos dados. No quadrante superior esquerdo do gráfico (Figura 8A), encontra-se o grupo Isoptera associado às áreas RF e RSF. Em ambas as áreas ocorreu expressiva densidade desse inseto, provavelmente, devido à qualidade inferior da MO nestas áreas e pela adaptação dos cupins a estas condições. Embora estas áreas tenham apresentado uma alta densidade de araucária, apresentaram, também, uma baixa diversidade de outras espécies vegetais. Este fato fez com que o material vegetal acumulado sobre o solo fosse de baixa qualidade nutricional para a macrofauna.

A M ficou distanciada das demais por apresentar dominância de Sociais (formigas), de predadores (Diplura, Chilopoda e Araneae) e de decompositores (larva de Diptera e Diplopoda), como pode ser observado na Figura 8A. Um maior número de grupos da macrofauna mostrou-se associado com a M.

$\mathrm{Na}$ época chuvosa, o eixo 1 explicou $82 \%$ da variabilidade dos dados, separando a RF das demais áreas (Figura 8B). Este distanciamento foi devido ao aumento expressivo de Formicidae e Isoptera nesta área. A M e a RSF aproximaram-se pela alta ocorrência dos grupos Chilopoda, larvas de Coleoptera, Heteroptera e larvas de Diptera.

A M e a RF caracterizaram-se como áreas de perfis extremos opostos, sendo as maiores densidades encontradas na M (Tabela 10). A esse respeito, Petersen \& Luxton (1982) observaram que os artrópodes são mais abundantes em solos que possuem um maior acúmulo de matéria orgânica. A densidade da fauna do solo decresce com a diminuição da qualidade do estoque de carbono nos solos (Amelung et al., 2002) e com a degradação física e química do solo (Höfer et al., 2001).

A macrofauna edáfica foi sensível às diferenças entre os ecossistemas estudados, neste sentido torna-se um eficaz bioindicador das mudanças funcionais dos sistemas. 
A Eixo $2-16.84 \%$

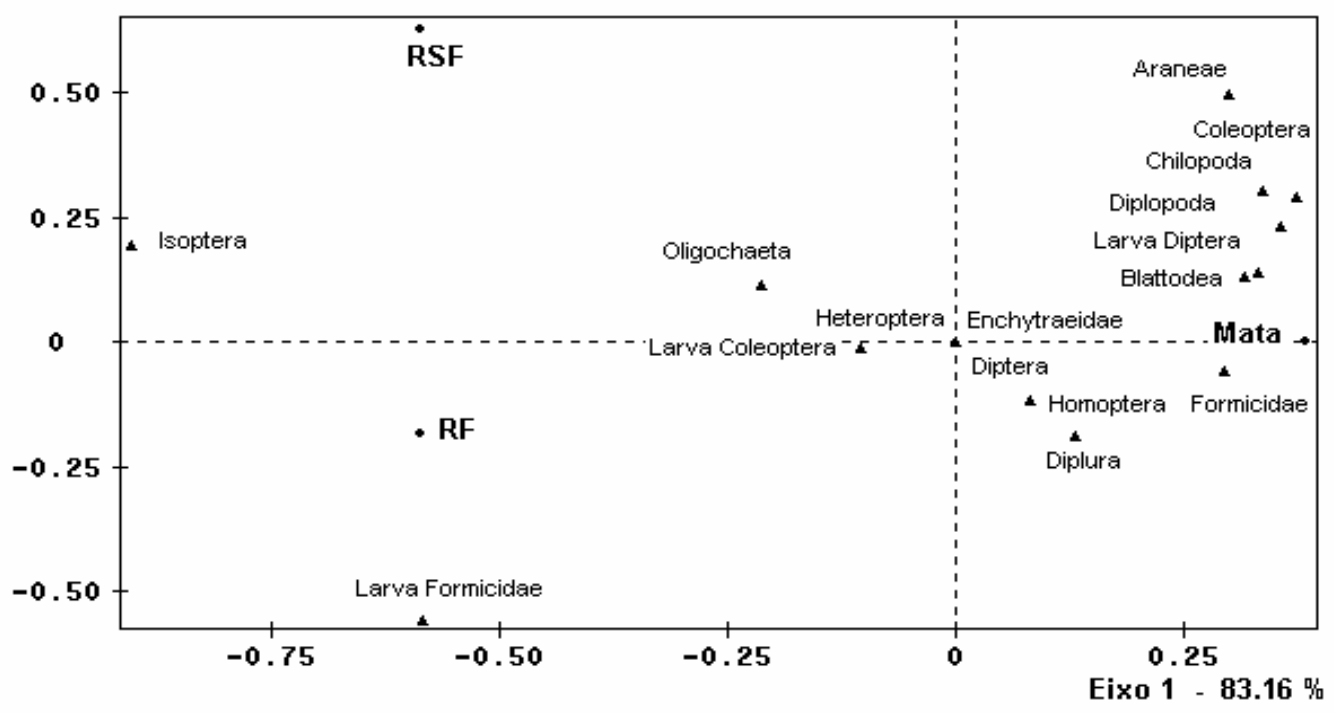

B $\quad$ Eixo $2-17.41 \%$

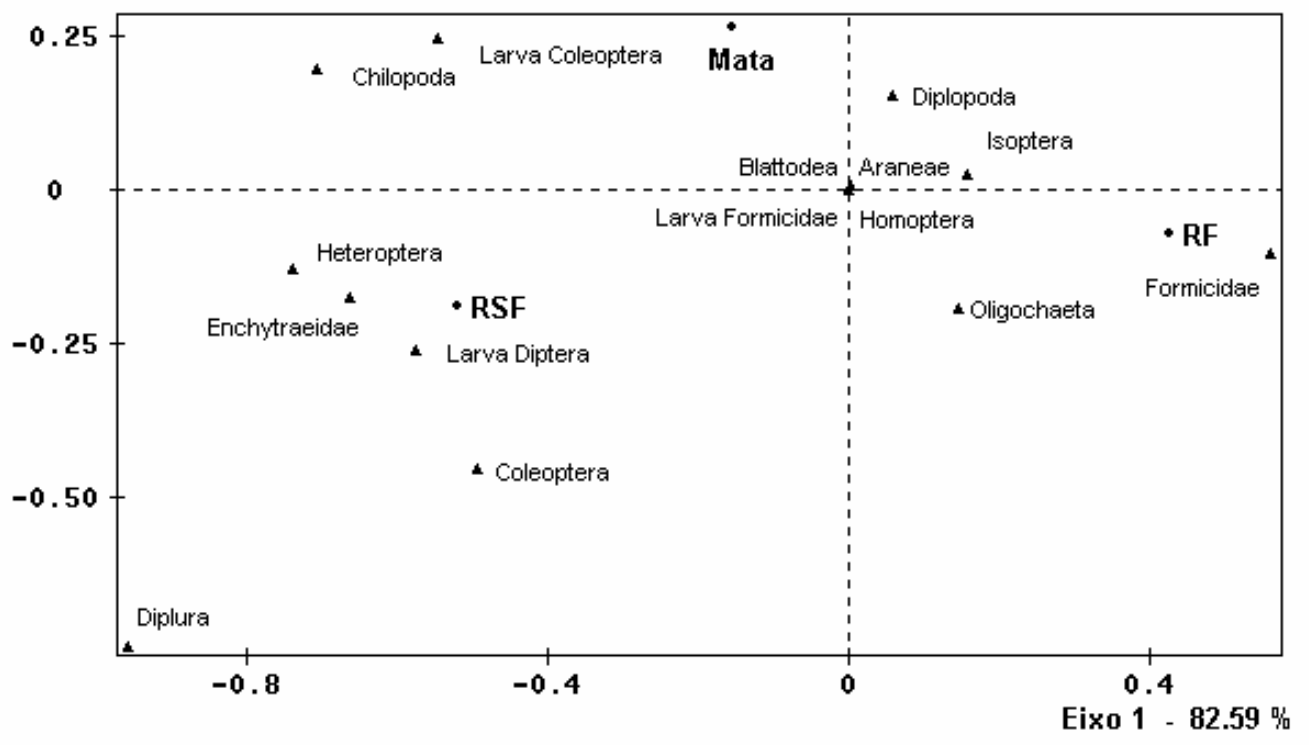

Figura 8 - Diagrama de ordenamento obtido a partir da AFC para as densidades dos grupos da macrofauna edáfica em diferentes ecossistemas de araucária, na época seca (A) e na época chuvosa (B) 


\subsubsection{Distribuição vertical}

A ocorrência da macrofauna edáfica mostrou-se diferenciada entre as camadas de serapilheira e solo, sendo a maioria dos invertebrados encontrados associados ao microhabitat solo, nas três áreas avaliadas.

Não foram detectadas diferenças pela interação área×época. A comunidade da macrofauna da serapilheira na M mostrou-se diferenciada da encontrada na RF (Tabela 13). Não foram detectadas diferenças significativas entre as profundidades do solo das áreas estudadas, sendo a profundidade de $0-10 \mathrm{~cm}$ a que apresentou as maiores densidades, resultado esperado pois é nesta camada que ocorre uma atividade biológica mais intensa.

A alta densidade encontrada na profundidade de 0-10 $\mathrm{cm}$ da área RF deve-se ao aumento acentuado de insetos sociais, apresentando diferença significativa $(\mathrm{P}<0,05$; $\mathrm{F}=6,4)$ com relação às demais profundidades e à serapilheira (Tabela 13).

As diferenças entre as serapilheiras de cada ecossistema foram discutidas separadamente.

Tabela 13. Densidade total (indivíduos por metro quadrado) dos principais grupos da macrofauna edáfica nas camadas de serapilheira e solo em diferentes ecossistemas de araucária. Média das épocas de amostragens

\begin{tabular}{cccc}
\hline & M & RF & RSF \\
\hline serapilheira & $763 \mathrm{Aab}$ & $29 \mathrm{Bb}$ & $94 \mathrm{ABa}$ \\
$\mathbf{0 - 1 0} \mathbf{~ c m}$ & $1350 \mathrm{Aa}$ & $2138 \mathrm{Aa}$ & $773 \mathrm{Aa}$ \\
$\mathbf{1 0 - 2 0} \mathbf{~ c m}$ & $164 \mathrm{Ab}$ & $229 \mathrm{Ab}$ & $376 \mathrm{Aa}$ \\
$\mathbf{2 0 - 3 0 ~ c m}$ & $659 \mathrm{Aab}$ & $99 \mathrm{Ab}$ & $94 \mathrm{Aa}$ \\
\hline
\end{tabular}

Para a análise estatística os valores foram transformados por $(\sqrt{ } \mathrm{x}+1)$.

Letras iguais maiúsculas na mesma linha ou minúsculas na mesma coluna não diferem entre si significativamente ao nível de $5 \%$ de probabilidade de acordo com o teste de Tukey. 


\subsubsection{Diversidade e riqueza}

Neste trabalho, foi calculado o índice de diversidade de Shannon por este mostrar-se apropriado para o uso em Ecologia do Solo, uma vez que é capaz de atribuir valores aos grupos taxonômicos raros da comunidade da fauna do solo. Foram avaliados separadamente o número total de grupos taxonômicos (riqueza) e a uniformidade das comunidades (Uniformidade de Pielou).

Os índices de Uniformidade de Pielou (Equitabilidade) não apresentaram diferenças significativas entre as áreas estudadas e entre épocas (Tabela 14). De modo geral, a dominância de alguns grupos da fauna do solo, como neste caso, formigas e cupins, pode fazer com que os índices de diversidade variem muito, pois esta dominância está sujeita à variação sazonal. Os insetos sociais, neste trabalho, podem estar influenciando a equitabilidade da comunidade como um todo.

Os índices de diversidade de Shannon e as riquezas apresentaram diferença $(\mathrm{P}<0,05)$ entre as áreas e épocas de estudo (Tabela 14). A RSF apresentou diferenças significativas entre as épocas de coleta, com maiores diversidades e valores de riqueza de grupos taxonômicos na época chuvosa, indicando, desta forma, que a ocorrência de chuvas influenciou a ocorrência de diferentes grupos da fauna. A hipótese é que a riqueza de grupos presentes no sistema serapilheira-solo, da área RSF, é decorrente do potencial adaptativo da comunidade da fauna edáfica, o que permite obter vantagens em situações novas ou de estresse. Esta capacidade adaptativa possibilita determinar a capacidade de recuperação desta comunidade frente às alterações ambientais, temporárias ou não.

As diferenças entre as áreas de estudo ocorreram mais expressivamente na época seca (Tabela 14). A maior diversidade foi encontrada na $M$, indicando este ecossistema como o de melhor condição ambiental para a proliferação da macrofauna, no que se refere ao aporte e qualidade da $\mathrm{MO}$ e pelas propriedades físicas e químicas deste solo.

A riqueza encontrada nas áreas estudadas foi, de uma maneira geral baixa, quando comparada à encontrada em outros ecossistemas. Tapia-Coral (2004), em estudo 
da macrofauna, coletada pelo método do TSBF, em diferentes tipos de vegetação de terra firme na Amazônia Peruana, encontrou no solo $(0-30 \mathrm{~cm})$ para áreas de Floresta Primária, um total de 24 grupos taxonômicos, em Plantação Florestal de Cedrelinga catenaeformis, 20, em Plantação Florestal de Simarouba amara, 18 e na Capoeira, 19. A autora observou, ainda, uma maior ocorrência de grupos na serapilheira durante a estação seca, sendo que na Floresta Primária foi coletado o menor valor encontrado no período seco, 18 grupos taxonômicos, e o maior valor encontrado no período chuvoso, 26 grupos.

Tarrá (2003) encontrou 18 grupos taxonômicos da macrofauna no solo (0-30 cm) de sistemas agrossilviculturais da Amazônia Central, na área de influência de espécies perenes. O número mais baixo ocorreu próximo de Bactris gasipaes para palmito e Vismia cayennensis, ambos com 10 grupos taxonômicos.

Costa (2002), amostrando a fauna do solo em plantios experimentais de Eucalyptus grandis, Pseudosamanea guachapele e Acacia mangium, encontrou uma variação média da diversidade pelo índice de Shannon maior do que a encontrada neste trabalho, de 3,51 (bloco Borracheiro/ Acacia mangium) a 1,53 (bloco Borracheiro/ gramíneas). 
Tabela 14. Índice de Diversidade de Shannon, Riqueza ( $\mathrm{n}^{\circ}$ de grupos taxonômicos) e Uniformidade de Pielou da macrofauna coletada no solo até $30 \mathrm{~cm}$ (somatório das profundidades) sob diferentes ecossistemas de araucária

\begin{tabular}{|c|c|c|c|}
\hline Época de coleta & $\mathbf{M}$ & RF & RSF \\
\hline \multicolumn{4}{|c|}{ Shannon } \\
\hline seca & $1,64 \mathrm{~A} a$ & $1,35 \mathrm{~B} \mathrm{a}$ & $1,02 \mathrm{~B} \mathrm{~b}$ \\
\hline chuvosa & $1,45 \mathrm{~A} \mathrm{a}$ & $1,30 \mathrm{~A} \mathrm{a}$ & $1,91 \mathrm{~A} \mathrm{a}$ \\
\hline \multicolumn{4}{|c|}{ Riqueza } \\
\hline seca & $16 \mathrm{~A} \mathrm{a}$ & $8 \mathrm{~B} \mathrm{a}$ & $10 \mathrm{~B} \mathrm{~b}$ \\
\hline chuvosa & $11 \mathrm{~A} \mathrm{a}$ & $10 \mathrm{~A} \mathrm{a}$ & $15 \mathrm{~A} \mathrm{a}$ \\
\hline \multicolumn{4}{|c|}{ Pielou* } \\
\hline seca & 0,59 & 0,65 & 0,44 \\
\hline chuvosa & 0,60 & 0,56 & 0,70 \\
\hline
\end{tabular}

\subsubsection{Larvas de Coleoptera}

Dentre a comunidade da macrofauna edáfica coletada neste trabalho, destacouse a abundância das larvas de Coleoptera, as quais foram identificadas até o nível de Família.

Os coleópteros são insetos endopterigotos e holometabólicos, isto é, em sua metamorfose, as asas se desenvolvem internamente, existe sempre um estágio pupal e os estágios imaturos diferem muito, em geral, dos adultos, tanto em estrutura como habitats e hábitos alimentares (Costa et al., 1988).

Larva é o estágio de crescimento ativo compreendido entre a eclosão do ovo e a fase pupal de todos os Endopterygota e, portanto, de todos os Coleoptera. É um estágio imaturo pós-embrionário que possui caracteres adaptativos próprios, diferentes daqueles dos adultos (Costa et al., 1988).

O conhecimento sobre o comportamento alimentar das espécies de Coleoptera é ainda muito pobre. A maioria das informações foi gerada a partir de observações de 
campo, apoiada na ação do espécimen e no desgaste causado na fonte de alimentação, sem a constatação de sua presença no conteúdo intestinal. As deduções que decorrem destas observações são quase sempre corretas quando se trata de indivíduo de grande porte, mas nem sempre o são quando se observa um indivíduo de poucos milímetros. Como decorrência, as referências para um grande número de taxa é que utilizam provavelmente este ou aquele alimento, não havendo um conhecimento exato do hábito alimentar, já que se baseia simplesmente na presença do indivíduo sobre um dado recurso, ou em um dado ambiente (Marinoni et al., 2003).

Nos ecossistemas estudados foram encontradas 15 famílias de larvas de Coleoptera. Com a finalidade de agrupar as diferentes áreas que possuíam maior grau de similaridade para a densidade encontrada de larvas de Coleoptera, aplicou-se a Análise de Agrupamento, utilizando o coeficiente de correlação r-de Pearson como medida de distância, pelo método de ligação completa. Foram gerados dendrogramas, para cada época de estudo, onde foi possível identificar as áreas com maior ou menor grau de similaridade, de acordo com sua distância.

Com base nos dendrogramas apresentados na Figura 10, observou-se, na época seca, que as áreas RF e RSF ficaram próximas pela baixa diversidade de larvas que apresentaram, quando comparadas à M (Figura 9A). Já na época chuvosa, a RSF aproxima-se da M (Figura 9B), o que pode ser explicado pela presença de um maior número de famílias que aparecem nesta época, e pela ocorrência das famílias Staphylinidae e Nemonychidae que foram encontradas apenas na área M (Tabela 15).

O solo da RSF tem como característica um regime hídrico bastante favorável quanto à permanência de umidade neste perfil, favorecendo a ocorrência das larvas, visto que este grupo é dependente da umidade do solo (Costa et al., 1988). Na época chuvosa esta característica torna-se ainda mais expressiva para a manutenção das larvas nesta área.

$\mathrm{O}$ maior número de famílias encontradas na $\mathrm{M}$ pode indicar que a perda de algumas destas famílias nas áreas manejadas está relacionada com o grau de interferência sofrido por estas áreas e pelas suas condições edafoclimáticas. 
A maioria das larvas coletadas pertencentes à família Nemonychidae, foram identificados como sendo da espécie Rhynchitoplesius eximius. As fêmeas desta espécie ovipositam no cone masculino da Araucaria angustifolia, onde suas larvas se desenvolvem alimentando-se de pólen. Assim que o cone começa a liberar o pólen, as larvas deixam o estróbilo e caem ao chão, enterrando-se em seguida. Isso pode ocorrer com o estróbilo ainda na árvore ou já caído, desde fins de setembro até inícios de novembro (Costa et al., 1988). Este fato indica que a araucária estabelece as condições para a reprodução desta espécie, mas a viabilidade destas larvas está relacionada com as condições do solo.

As larvas da família Staphylinidae, indivíduos identificados como pertencentes à subfamília Osoriinae spp, são detritívoras (Marinoni et al., 2003). Costa et al. (1988) citam que os adultos e larvas deste gênero são encontrados sob casca de troncos caídos, alimentando-se, provavelmente, de matéria em decomposição; algumas espécies que vivem sob casca de árvores mortas parecem alimentar-se de fungos e outras são endógenas, vivendo em raízes de plantas (Crowson, 1981; Frank, 1991 apud Marinoni et al., 2003). As principais famílias coletadas foram: Elateridae, Scarabaeidae, Chrysomelidae, Tenebrionidae e Carabidae (Tabela 15).

A M e a RSF aproximaram-se, na época chuvosa, pelo número de famílias de larvas encontradas (Figura 9). Do mesmo modo, esta aproximação foi observada quando utilizou-se a densidade total da macrofauna (Figura 8), indicando que as larvas de Coleoptera, mesmo sendo estudadas ao nível de Família, foram eficientes em indicar as diferenças entre os ecossistemas de araucária. Este resultado enquadra-se na discussão de Hilty \& Merenlender (2000) apud Oliveira et al. (2001), na qual o uso de apenas uma Ordem ou Família de invertebrados é o ideal, na medida em que um menor número de espécimes é envolvido. 
Tabela 15. Densidade (indivíduos por metro quadrado) das principais famílias de larvas de Coleoptera coletadas na serapilheira e no solo sob diferentes ecossistemas de araucária

\begin{tabular}{|c|c|c|c|c|c|}
\hline \multicolumn{2}{|l|}{$\mathbf{M}$} & \multicolumn{2}{|l|}{ RF } & \multicolumn{2}{|l|}{ RSF } \\
\hline \multicolumn{6}{|c|}{ ÉPOCA SECA } \\
\hline Famílias & Ind $/ \mathbf{m}^{2}$ & Famílias & Ind $/ \mathbf{m}^{2}$ & Famílias & Ind $/ \mathbf{m}^{2}$ \\
\hline Curculionidae & 16 & Scarabaeidae & 5 & Scarabaeidae & 4 \\
\hline Elateridae & 11 & Tenebrionidae & 4 & Chrysomelidae & 3 \\
\hline Scarabaeidae & 11 & Melyridae & 3 & Carabidae & 3 \\
\hline Chrysomelidae & 8 & Carabidae & 3 & Elateridae & 1 \\
\hline Nemonychidae & 4 & Curculionidae & 3 & Total de famílias & 4 \\
\hline Tenebrionidae & 2 & Elateridae & 1 & & \\
\hline Cantharidae & 2 & Cantharidae & 1 & & \\
\hline Lampididae & 1 & Total de famílias & 7 & & \\
\hline Dryopidae & 1 & & & & \\
\hline Staphylinidae & 1 & & & & \\
\hline Total de famílias & 10 & & & & \\
\hline \multicolumn{6}{|c|}{ ÉPOCA CHUVOSA } \\
\hline Famílias & Ind $/ \mathbf{m}^{2}$ & Famílias & Ind $/ \mathbf{m}^{2}$ & Famílias & Ind $/ \mathbf{m}^{2}$ \\
\hline Nemonychidae & 41 & Chrysomelidae & 21 & Chrysomelidae & 38 \\
\hline Chrysomelidae & 24 & Scarabaeidae & 6 & Nemonychidae & 32 \\
\hline Tenebrionidae & 24 & Carabidae & 3 & Carabidae & 7 \\
\hline Elateridae & 10 & Tenebrionidae & 2 & Elateridae & 5 \\
\hline Curculionidae & 8 & Elateridae & 2 & Staphylinidae & 3 \\
\hline Dryopidae & 4 & Total de famílias & 5 & Phengodidae & 3 \\
\hline Staphylinidae & 2 & & & Curculionidae & 2 \\
\hline Scarabaeidae & 2 & & & Scarabaeidae & 1 \\
\hline Ptilodactylidae & 1 & & & Tenebrionidae & 1 \\
\hline Lampyridae & 1 & & & Total de famílias & 9 \\
\hline Total de famílias & 10 & & & & \\
\hline
\end{tabular}


A

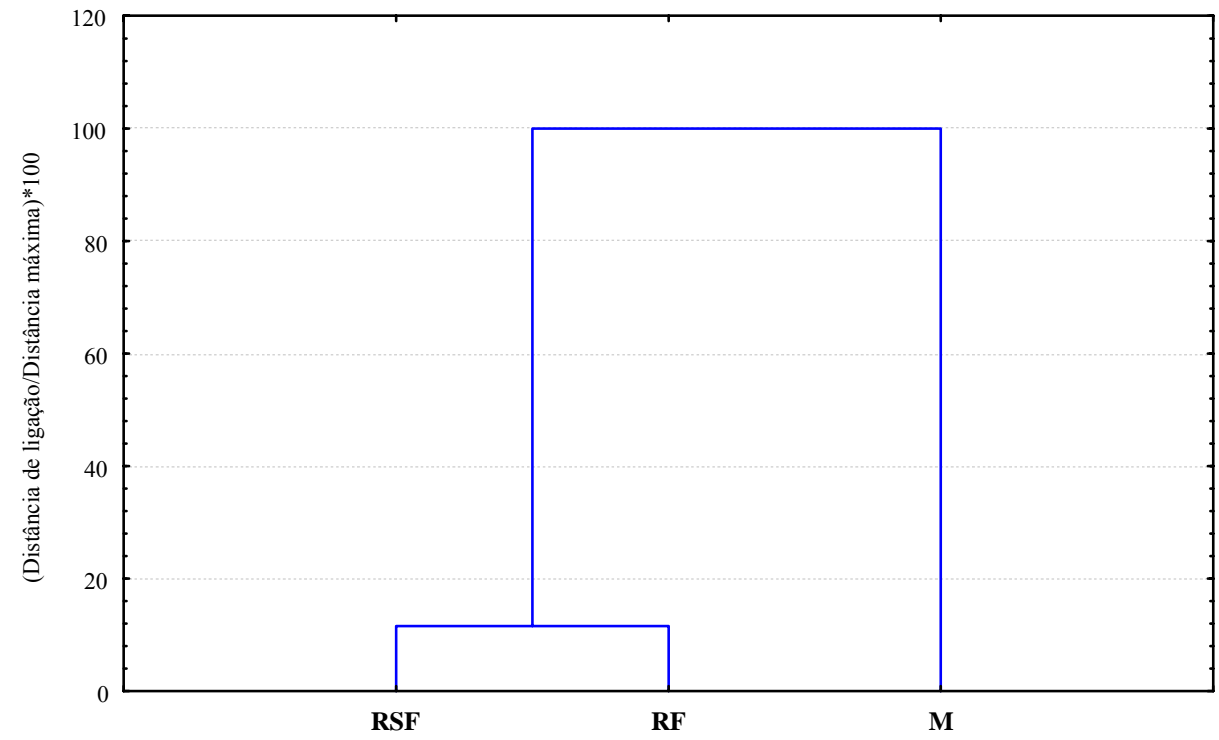

B

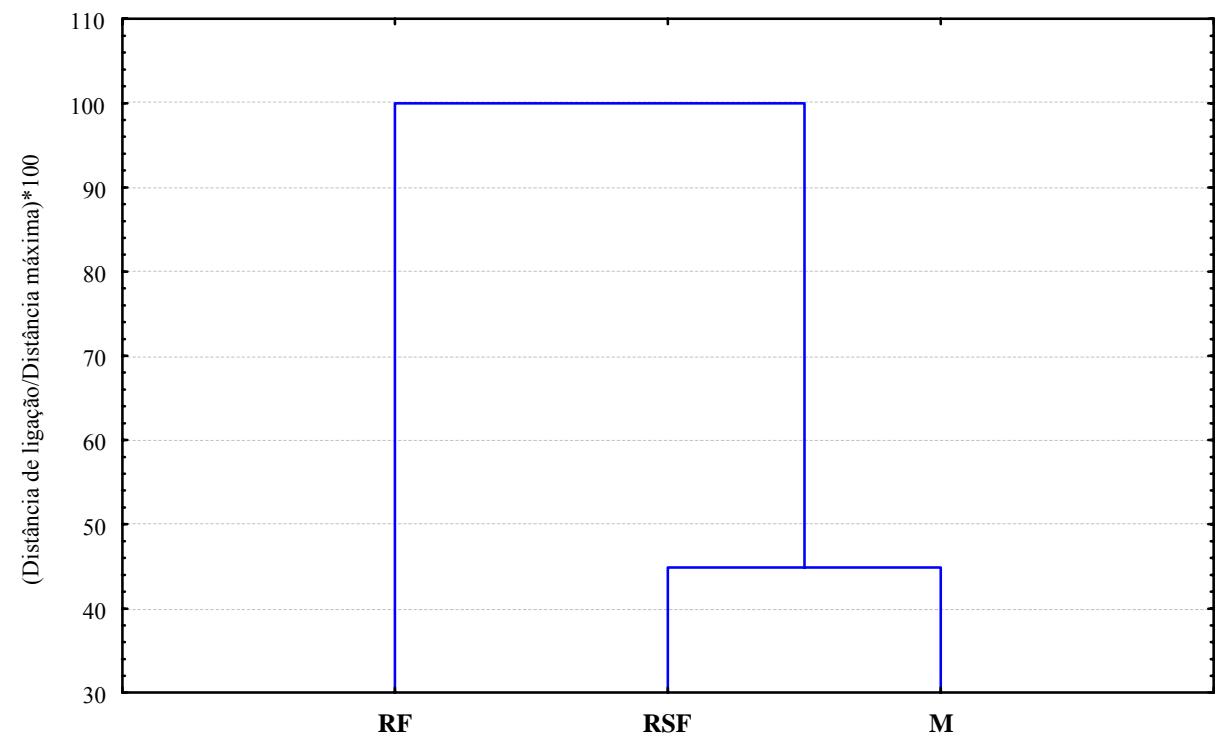

Figura 9 - Dendrograma das Larvas de Coleoptera coletadas nos diferentes ecossistemas de araucária. $\mathrm{A}=$ época seca; $\mathrm{B}=$ época chuvosa 


\subsubsection{Abundância e freqüência dos grupos funcionais}

A abundância relativa foi expressa como a porcentagem do número médio de indivíduos por metro quadrado, do táxon, em relação ao número total de indivíduos para cada grupo funcional.

Os grupos Herbívoros e Decompositores apresentaram baixa freqüência e abundância em todos os ecossistemas. Siira-Pietikainen et al. (2003), em trabalho realizado na Finlândia, encontraram como predominante na floresta intacta o grupo funcional Herbívoros. Observaram, ainda, que a menor umidade do solo nas áreas alteradas pelos cortes desfavoreceu a presença dos decompositores, indicando que a floresta que não foi alterada ofereceu as melhores condições ambientais para a colonização destes grupos.

Os grupos mais abundantes foram os Sociais (Formicidae e Isoptera), sendo que Chilopoda, Araneae, Coleoptera, Larvas de Coleoptera e Diplopoda também foram abundantes e frequentes (Tabela 16 e 17).

Para os artrópodes em geral, a heterogeneidade do ambiente pode estar influenciando a riqueza de espécies (Lawton \& Schröeder, 1977). Estas diferenças estruturais disponibilizam novos sítios de reprodução, alimentação e refúgio para os artrópodes, aumentando as chances de encontro de espécies neste habitat. Sendo a M o ecossistema mais heterogêneo dentre as áreas consideradas neste estudo, apresentando o maior número de espécies vegetais associadas com a araucária e, consequentemente, a maior diversidade da fauna do solo, observou-se que os predadores foram o segundo grupo mais abundante e frequente em ambas as épocas de amostragens (Tabela 16 e 17). Deste modo, os predadores estão relacionados com a estabilidade dos sistemas ${ }^{2}$, indicando a recuperação dos ecossistemas aos quais estão associados.

\footnotetext{
${ }^{2}$ Capacidade do sistema permanecer perto do ponto de equilíbrio, ou de retornar a ele, após um distúrbio. Qualquer impacto nesse equilíbrio dinâmico, com danos ou perdas nas populações nativas animais e vegetais, podem traduzir-se em degradação ambiental e desestabilizando estruturalmente e funcionalmente o ecossistema (Larangeiro, 2003).
} 
Tabela 16. Classificação da abundância dos grupos funcionais coletados na serapilheira e solo até $30 \mathrm{~cm}$ de profundidade, na época seca, sob diferentes ecossistemas de araucária

\begin{tabular}{|c|c|c|c|c|c|c|}
\hline & \multicolumn{2}{|c|}{$\mathbf{M}$} & \multicolumn{2}{|c|}{ RF } & \multicolumn{2}{|c|}{ RSF } \\
\hline & serap & solo & serap & solo & serap & solo \\
\hline & \multicolumn{6}{|c|}{ Sociais } \\
\hline Formicidae & 4 & 4 & 3 & 3 & 4 & 2 \\
\hline \multirow[t]{2}{*}{ Isoptera } & 2 & 2 & 0 & 3 & 2 & 3 \\
\hline & \multicolumn{6}{|c|}{ Herbívoros } \\
\hline Homoptera adulto & 0 & 1 & 0 & 0 & 0 & 1 \\
\hline Heteroptera adulto & 2 & 1 & 0 & 0 & 0 & 0 \\
\hline Heteroptera imaturos & 1 & 0 & 0 & 0 & 0 & 0 \\
\hline Thysanoptera & 1 & 1 & 0 & 0 & 0 & 0 \\
\hline \multirow[t]{2}{*}{ Orthoptera } & 1 & 0 & 0 & 0 & 0 & 0 \\
\hline & \multicolumn{6}{|c|}{ Decompositores } \\
\hline Diptera imaturos & 1 & 1 & 0 & 1 & 0 & 0 \\
\hline Enchytraeidae & 0 & 1 & 0 & 0 & 0 & 0 \\
\hline Oligochaeta & 1 & 1 & 0 & 1 & 0 & 1 \\
\hline Isopoda & 1 & 0 & 0 & 0 & 0 & 0 \\
\hline Diplopoda & 1 & 1 & 0 & 1 & 0 & 1 \\
\hline Psocoptera & 0 & 0 & 2 & 0 & 0 & 0 \\
\hline \multirow[t]{2}{*}{ Symphyla } & 0 & 0 & 0 & 0 & 0 & 0 \\
\hline & \multicolumn{6}{|c|}{ Predadores } \\
\hline Araneae & 2 & 1 & 2 & 0 & 2 & 1 \\
\hline Opilionida & 1 & 1 & 0 & 0 & 0 & 0 \\
\hline Pseudoscorp. & 1 & 0 & 2 & 0 & 2 & 1 \\
\hline Dermaptera & 1 & 1 & 0 & 0 & 0 & 0 \\
\hline Chilopoda & 2 & 2 & 0 & 1 & 2 & 2 \\
\hline \multirow[t]{2}{*}{ Diplura } & 2 & 2 & 0 & 0 & 2 & 1 \\
\hline & \multicolumn{6}{|c|}{ Outros } \\
\hline Coleoptera adulto & 3 & 2 & 3 & 1 & 3 & 2 \\
\hline Coleoptera imaturos & 2 & 2 & 3 & 2 & 0 & 2 \\
\hline Blattodea & 1 & 1 & 0 & 1 & 0 & 0 \\
\hline Outros Hymenop & 1 & 1 & 0 & 0 & 0 & 0 \\
\hline Thysanura & 0 & 1 & 0 & 1 & 0 & 0 \\
\hline Diptera adulto & 1 & 1 & 0 & 0 & 0 & 0 \\
\hline L. Formicidae & 1 & 2 & 0 & 3 & 2 & 0 \\
\hline
\end{tabular}


Tabela 17. Classificação da abundância dos grupos funcionais coletados na serapilheira e solo até $30 \mathrm{~cm}$ de profundidade, na época chuvosa, sob diferentes ecossistemas de araucária

\begin{tabular}{|c|c|c|c|c|c|c|}
\hline & \multicolumn{2}{|c|}{$\mathbf{M}$} & \multicolumn{2}{|c|}{ RF } & \multicolumn{2}{|c|}{ RSF } \\
\hline & serap & solo & serap & solo & serap & solo \\
\hline & \multicolumn{6}{|c|}{ Sociais } \\
\hline Formicidae & 0 & 2 & 0 & 3 & 3 & 2 \\
\hline \multirow[t]{2}{*}{ Isoptera } & 0 & 4 & 0 & 4 & 0 & 3 \\
\hline & \multicolumn{6}{|c|}{ Herbívoros } \\
\hline Homoptera adulto & 0 & 1 & 0 & 0 & 0 & 0 \\
\hline Heteroptera adulto & 0 & 1 & 0 & 1 & 0 & 1 \\
\hline Heteroptera imaturos & 0 & 1 & 0 & 1 & 0 & 0 \\
\hline \multirow[t]{2}{*}{ Orthoptera } & 0 & 0 & 0 & 0 & 0 & 1 \\
\hline & \multicolumn{6}{|c|}{ Decompositores } \\
\hline Diptera imaturos & 2 & 1 & 0 & 1 & 0 & 2 \\
\hline Enchytraeidae & 0 & 0 & 0 & 1 & 0 & 2 \\
\hline Oligochaeta & 0 & 1 & 0 & 1 & 3 & 1 \\
\hline Diplopoda & 3 & 1 & 0 & 0 & 0 & 1 \\
\hline Psocoptera & 2 & 0 & 0 & 0 & 0 & 0 \\
\hline \multirow[t]{2}{*}{ Symphyla } & 2 & 0 & 0 & 0 & 0 & 1 \\
\hline & \multicolumn{6}{|c|}{ Predadores } \\
\hline Araneae & 3 & 1 & 0 & 0 & 3 & 1 \\
\hline Opilionida & 0 & 0 & 0 & 0 & 0 & 1 \\
\hline Dermaptera & 0 & 0 & 0 & 0 & 0 & 1 \\
\hline Chilopoda & 3 & 2 & 0 & 1 & 2 & 2 \\
\hline \multirow[t]{2}{*}{ Diplura } & 2 & 1 & 0 & 1 & 0 & 2 \\
\hline & \multicolumn{6}{|c|}{ Outros } \\
\hline Coleoptera adulto & 0 & 2 & 0 & 2 & 2 & 2 \\
\hline Coleoptera imaturos & 3 & 3 & 0 & 2 & 0 & 3 \\
\hline Blattodea & 0 & 1 & 0 & 0 & 0 & 0 \\
\hline Thysanura & 0 & 0 & 0 & 1 & 2 & 0 \\
\hline Diptera adulto & 0 & 0 & 0 & 0 & 3 & 1 \\
\hline L. Formicidae & 0 & 0 & 0 & 1 & 0 & 1 \\
\hline
\end{tabular}




\subsubsection{Insetos sociais}

Os insetos sociais (Formicidae e Isoptera) apresentaram dominância em todas as áreas e nas duas épocas de estudo (Figura 10). Considerando a abundância e frequência desses grupos, optou-se por discuti-los separadamente.

$\mathrm{Na} \mathrm{RF}$, em ambas as épocas de coleta, foi encontrada uma alta densidade de insetos sociais. Mesmo causando desestruturação temporal da comunidade de insetos sociais, a eliminação do sub-bosque pela ação do fogo reduziu numericamente os inimigos naturais, fornecendo às formigas e cupins condições ideais para propagação e ocupação desta área.

As maiores densidades foram observadas no solo, com exceção da serapilheira da $\mathrm{M}$ na época seca, devido à abundância de formigas nesta camada (Figura 10). A baixa umidade no solo nesta época fez com que as formigas migrassem para a serapilheira da M com composição florística diversificada, permitindo, deste modo, a proliferação destas populações.

Todos os cupins capturados pertencem à subfamília Apicotermitinae. A identificação deste grupo é difícil devido a sua uniformidade morfológica e, principalmente, devido a falta de trabalhos descritivos e taxonômicos.

Como hábito principal do grupo é conhecido que este se alimenta de matéria orgânica em decomposição e escava suas próprias galerias (Torales, 1998).

$\mathrm{Na}$ época chuvosa, a densidade de Isoptera foi superior à de Formicidae, onde um extremo desta dominância ocorreu no solo da M (Figura 10B), onde de um total de 856 indivíduos. $\mathrm{m}^{-2}$ coletados, 474 eram de Isoptera e, no solo da RF, do total de 1333, 800 eram Isoptera. Não foram encontrados insetos sociais nas serapilheira da $M$ e nem na RF. Apenas Formicidae foi encontrada na serapilheira da RSF. 
A

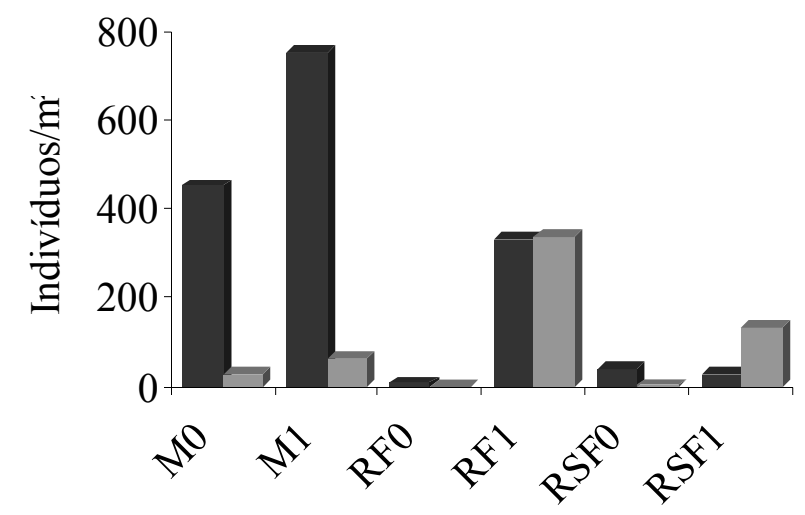

B

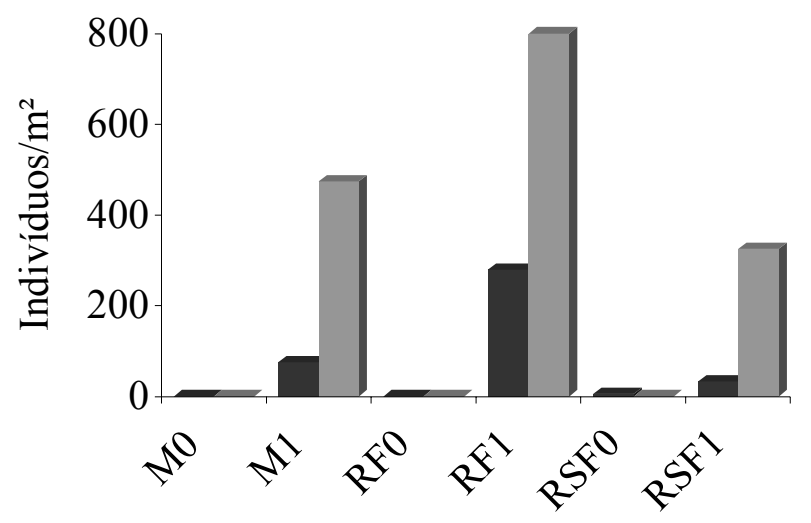

Formicidae Isoptera
- Formicidae

Isoptera

Figura 10 - Densidades (ind $/ \mathrm{m}^{2}$ ) de Formicidae e Isoptera em diferentes ecossistemas de araucária. $0=$ serapillheira, $1=$ solo até $30 \mathrm{~cm}$ de profundidade. $\mathrm{A}=$ época seca; $\mathrm{B}=$ época chuvosa

A maior densidade de cupins encontrada no solo da RF pode indicar que estes utilizaram mais eficientemente os recursos disponíveis e melhor competiram com outros invertebrados do solo. Resultado semelhante ao observado por Tapia-Coral (2004), que encontrou alta densidade de cupins em plantações de Simarouba amara e Cedrelinga catenaeformis. A autora concluiu que a idade das árvores na época da coleta (15 e 16 anos), que ainda não possuiam copas muito fechadas, permitiu o ingresso dos raios solares até o solo, desta forma, favorecendo a presença de cupins nestas plantações. 
Bandeira (1979) afirma que, de uma forma geral, os cupins são mais abundantes em solos não muito protegidos pela vegetação, desde que haja alimento em abundância.

\subsection{Macrofauna da serapilheira}

Dos grupos da macrofauna edáfica coletados na serapilheira (ver em Anexos), apenas Heteroptera, Coleoptera, Chilopoda, Formicidae e Diplura apresentaram diferenças significativas $(\mathrm{P}<0,05)$ para a interação área $\times$ época de coleta (Tabela 18).

$\mathrm{Na}$ área RF, na época chuvosa, não foram encontrados indivíduos da macrofauna nesta camada, apesar da ocorrência das chuvas proporcionando um aumento da umidade do solo. É possível que a água das chuvas tenha lavado os compostos fenólicos do material vegetal depositado sobre o solo e estes são repelentes para a fauna edáfica.

A serapilheira apresentou baixa densidade de indivíduos da macrofauna. Este fato pode ser explicado pela baixa qualidade da serapilheira produzida em matas de araucária. Esta serapilheira caracteriza-se por apresentar altos níveis de lignina e alta relação $\mathrm{C} / \mathrm{N}$, como apresentado na Tabela 19. A esse respeito, Poggiani et al. (1996) descrevem que materiais orgânicos com altos conteúdos de $\mathrm{N}$ e açúcares são mais palatáveis e aceitos pela fauna edáfica do que materiais pobres em nutrientes e ricos em polifenóis.

Outro fator que contribuiu para a menor colonização da serapilheira foi o fato de que o maior aporte de massa seca total (folhas, frutos, galhos e flores) na época chuvosa não acarretou em maior colonização pela macrofauna. Este aporte foi ocasionado, provavelmente, pela queda de resíduos senescentes da parte aérea das plantas após as chuvas neste período. Este material, quando coletado no solo, apresentou menor umidade e maior teor de lignina quando comparado ao da época seca (Tabela 19), portanto, de pior qualidade.

A maior densidade da macrofauna da serapilheira (ind. $/ \mathrm{m}^{2}$ ) foi encontrada na área M. De acordo com Seastedt (1984), os invertebrados do solo cumprem um papel importante na decomposição de materiais com uma baixa relação C:N e altos conteúdos 
de nitrogênio. Os altos estoques de nitrogênio, assim como os baixos teores de lignina e da relação $\mathrm{C} / \mathrm{N}$ encontrados na serapilheira da mata nativa (Tabela 19) podem indicar que estas características estariam favorecendo a colonização da macrofauna.

A maior frequência da macrofauna encontrada na área $M$, na época seca, foi de larvas e adultos de Coleoptera. Nesta mesma época, os grupos encontrados em maior freqüência na $\mathrm{RF}$ foram os predadores Araneae e Pseudoscorpionida e o grupo Coleoptera (adultos e larvas). Na RSF, a maior frequência encontrada foi de Coleoptera e dos predadores Araneae, Chilopoda e Diplura.

$\mathrm{Na}$ época chuvosa, os grupos mais freqüentes na $\mathrm{M}$ foram Diplopoda, Araneae, Chilopoda e larvas de Coleoptera. Na RF, os mais freqüentes foram os adultos e larvas de Coleoptera e, na RSF, foram as larvas de Diptera e Coleoptera, Araneae e Oligochaeta (Tabela 17). Detectou-se uma redução na densidade dos grupos Sociais (Formicidade e Isoptera), associados à serapilheira.

Os predadores ocorreram em alta densidade e freqüência na $\mathrm{M}$ e na RSF, nas duas épocas de coleta, sendo Chilopoda, Araneae e Diplura os mais abundantes. Na RF os predadores ocorreram em menor freqüência em relação às demais áreas (Tabela 16 e 17), o que pode estar relacionado com a perda da cobertura do solo pela ação do fogo.

A remoção da cobertura do solo pode afetar os predadores pois as condições de baixa disponibilidade de nutrientes e baixas entradas de matéria orgânica podem causar um decréscimo na abundância e na biomassa em todas as demais posições tróficas (Bengtsson et al., 1998). 
Tabela 18. Densidade média (ind $\left./ \mathrm{m}^{2}\right)$ da macrofauna coletada na serapilheira dos diferentes ecossistemas de araucária

\begin{tabular}{llccc}
\hline Grupos & Época de coleta & $\mathbf{M}$ & $\mathbf{R F}$ & RSF \\
\hline Heteroptera & seca & $19 \mathrm{Aa}$ & $0 \mathrm{Ba}$ & $0 \mathrm{Ba}$ \\
& chuvosa & $0 \mathrm{Ab}$ & $0 \mathrm{Aa}$ & $0 \mathrm{Aa}$ \\
Coleoptera & seca & $110 \mathrm{Aa}$ & $10 \mathrm{Ba}$ & $19 \mathrm{Ba}$ \\
& chuvosa & $0 \mathrm{Ab}$ & $0 \mathrm{Aa}$ & $2 \mathrm{Aa}$ \\
Chilopoda & seca & $27 \mathrm{Aa}$ & $0 \mathrm{Ba}$ & $5 \mathrm{Ba}$ \\
& chuvosa & $5 \mathrm{Ab}$ & $0 \mathrm{Aa}$ & $2 \mathrm{Aa}$ \\
Formicidae & seca & $454 \mathrm{Aa}$ & $8 \mathrm{Ba}$ & $40 \mathrm{Ba}$ \\
& chuvosa & $0 \mathrm{Ab}$ & $0 \mathrm{Aa}$ & $6 \mathrm{Aa}$ \\
Diplura & seca & $26 \mathrm{Aa}$ & $0 \mathrm{Ba}$ & $2 \mathrm{Ba}$ \\
& chuvosa & $2 \mathrm{Ab}$ & $0 \mathrm{Aa}$ & $0 \mathrm{Aa}$ \\
Outros & seca & $35 \mathrm{Aa}$ & $2 \mathrm{Ba}$ & $2 \mathrm{Ba}$ \\
& chuvosa & $8 \mathrm{Ab}$ & $0 \mathrm{Aa}$ & $0 \mathrm{Aa}$ \\
Total & seca & $736 \mathrm{Aa}$ & $29 \mathrm{Ba}$ & $75 \mathrm{Ba}$ \\
& chuvosa & $27 \mathrm{Ab}$ & $0 \mathrm{Aa}$ & $19 \mathrm{Aa}$ \\
\hline
\end{tabular}

Letras iguais maiúsculas na mesma linha (entre áreas) ou minúsculas na mesma coluna (entre épocas), não diferem entre si significativamente ao nível de 5\% de probabilidade de acordo com o teste de Tukey.

Embora diversos fatores possam estar interferindo na colonização da macrofauna edáfica, tais como, variáveis ambientais (Decaëns et al., 1998), adaptabilidade do predador à cultura, densidade populacional das presas e especificidade do predador (Carcamo \& Spence, 1994; Clark et al., 1997), entre outros, o efeito drástico do fogo sobre esta comunidade é evidente pelos resultados obtidos neste estudo.

A eliminação da serapilheira acarretou a diminuição da fonte de alimento e desestruturou o habitat. Conseqüentemente a recolonização, quando ocorreu, foi lenta e restrita a poucos grupos, visto que a ocorrência do fogo foi em julho de 2001. Resultado semelhante foi observado por Neumann \& Tolhurst (1991), em estudo dos efeitos da queimada sobre os invertebrados da serapilheira e da camada superficial do solo, em florestas de eucaliptos na Austrália. Os autores constataram que o fogo, aplicado durante a estação da primavera, reduziu a atividade de vários grupos da fauna edáfica, tais como colêmbolas, dípteros, lepidópteros e vespas, reduzindo, ainda, as populações de oligoquetos, que só se recuperaram três anos após a queima. 


\subsubsection{Relação entre os atributos químicos e a macrofauna da serapilheira através da análise Biplot}

A partir das correlações de Spearman observou-se que os atributos químicos da serapilheira estão pouco correlacionados com a comunidade da macrofauna, conforme apresentado na Tabela 19. A hipótese é a de que a baixa qualidade da serapilheira, caracterizada pela alta acidez, pelo baixo teor de nutrientes e pelo alto teor de lignina, selecionou os grupos oportunistas que colonizam a MO de difícil degradação.

Na Figura 11 observou-se que as serapilheiras dos diferentes ecossistemas estão em posições distintas no gráfico, indicando a diferença entre estas. A maior densidade da macrofauna associada à $\mathrm{M}$ explica os vetores correspondentes estarem agrupados no quadrante superior junto a este ecossistema.

A umidade do material vegetal é essencial para a sua degradação pelos organismos edáficos. Foram encontradas correlações positivas com o aumento da umidade entre os coleópteros (adultos e larvas) e as formigas (Tabela 20).

O nitrogênio total está negativamente correlacionado com os grupos Coleoptera e Formicidae. Os altos teores de nitrogênio encontrados (Tabela 19) favorece a colonização da serapilheira por comunidades detritívoras mais diversas, aumentando o número de inimigos naturais destes grupos da macrofauna e, consequentemente, diminuindo sua dominância, principalmente na época chuvosa, período em que foi observado maior teor de nitrogênio decorrente da variação na quantidade de material acumulado sobre o solo. 
Tabela 19. Caracterização química da serapilheira dos diferentes ecossistemas de araucária, nas duas épocas de coleta

\begin{tabular}{|c|c|c|c|c|}
\hline & Época de coleta & $\mathbf{M}$ & $\mathbf{R F}$ & RSF \\
\hline \multirow[t]{2}{*}{$\mathrm{pH}\left(\mathrm{CaCl}_{2}\right)$} & seca & $3,6 \mathrm{~B} \mathrm{a}$ & $4,2 \mathrm{~A} \mathrm{a}$ & $3,4 \mathrm{~B} \mathrm{a}$ \\
\hline & chuvosa & $3,2 \mathrm{~B} \mathrm{~b}$ & $3,5 \mathrm{~A} \mathrm{~b}$ & $3,5 \mathrm{~A} \mathrm{a}$ \\
\hline \multirow{2}{*}{$\begin{array}{c}\text { Matéria Orgânica } \\
\left(\text { g.kg-1) }^{-1}\right)\end{array}$} & seca & $71,4 \mathrm{~B} \mathrm{~b}$ & $75,0 \mathrm{~B} \mathrm{a}$ & $93,3 \mathrm{~A} \mathrm{a}$ \\
\hline & chuvosa & $79,6 \mathrm{~A} \mathrm{a}$ & $70,4 \mathrm{~B} \mathrm{a}$ & $78,5 \mathrm{~A} \mathrm{~b}$ \\
\hline \multirow{2}{*}{$\begin{array}{c}\text { Umidade Total } \\
(\%)\end{array}$} & Seca & $38,6 \mathrm{~B} \mathrm{a}$ & $27,5 \mathrm{C} \mathrm{a}$ & $46,6 \mathrm{~A} \mathrm{a}$ \\
\hline & chuvosa & $12,2 \mathrm{~A} \mathrm{~b}$ & $10,5 \mathrm{~A} \mathrm{~b}$ & $11,4 \mathrm{~A} \mathrm{~b}$ \\
\hline \multirow{2}{*}{$\begin{array}{c}\text { Carbono Total } \\
(\%)\end{array}$} & seca & $39,7 \mathrm{~B} \mathrm{~b}$ & $41,7 \mathrm{~B}$ a & $51,8 \mathrm{~A} \mathrm{a}$ \\
\hline & chuvosa & $44,2 \mathrm{~A} \mathrm{a}$ & $39,1 \mathrm{~B} \mathrm{a}$ & $43,6 \mathrm{~A} \mathrm{~b}$ \\
\hline \multirow{2}{*}{$\begin{array}{c}\text { Resíduo Mineral } \\
\text { Total (\%) }\end{array}$} & seca & $28,6 \mathrm{~A} \mathrm{a}$ & $24,9 \mathrm{~A} \mathrm{a}$ & $6,7 \mathrm{~B} \mathrm{~b}$ \\
\hline & chuvosa & $20,4 \mathrm{~B} \mathrm{~b}$ & $29,6 \mathrm{~A} \mathrm{a}$ & $21,5 \mathrm{~B} \mathrm{a}$ \\
\hline \multirow{2}{*}{$\begin{array}{c}\text { Nitrogênio Total } \\
(\%)\end{array}$} & seca & $1,4 \mathrm{~A} \mathrm{~b}$ & $1,0 \mathrm{C} \mathrm{b}$ & $1,2 \mathrm{~B} \mathrm{a}$ \\
\hline & chuvosa & $1,7 \mathrm{~A} \mathrm{a}$ & $1,2 \mathrm{~B} \mathrm{a}$ & $1,3 \mathrm{~B} \mathrm{a}$ \\
\hline \multirow{2}{*}{ Potássio (\%) } & seca & $0,16 \mathrm{~B}$ a & $0,59 \mathrm{~A} \mathrm{a}$ & $0,26 \mathrm{~B} \mathrm{a}$ \\
\hline & chuvosa & $0,14 \mathrm{~A} \mathrm{a}$ & $0,27 \mathrm{~A} \mathrm{~b}$ & $0,21 \mathrm{~A} \mathrm{a}$ \\
\hline \multirow[t]{2}{*}{ Cálcio (\%) } & seca & $0,02 \mathrm{~A} \mathrm{~b}$ & $0,01 \mathrm{~A} \mathrm{a}$ & $0,02 \mathrm{~A} \mathrm{~b}$ \\
\hline & chuvosa & $0,13 \mathrm{~A} \mathrm{a}$ & $0,02 \mathrm{~B} \mathrm{a}$ & $0,15 \mathrm{~A} \mathrm{a}$ \\
\hline \multirow[t]{2}{*}{ Magnésio (\%) } & seca & $0,11 \mathrm{~A} \mathrm{a}$ & $0,13 \mathrm{~A} \mathrm{a}$ & $0,06 \mathrm{~B} \mathrm{~b}$ \\
\hline & chuvosa & $0,10 \mathrm{AB}$ a & $0,08 \mathrm{~B} \mathrm{~b}$ & $0,13 \mathrm{~A} \mathrm{a}$ \\
\hline \multirow[t]{2}{*}{ C/N Total } & seca & $28,2 \mathrm{~B} \mathrm{a}$ & $41,5 \mathrm{~A} \mathrm{a}$ & $43,2 \mathrm{~A} \mathrm{a}$ \\
\hline & chuvosa & $25,6 \mathrm{~B} \mathrm{a}$ & $32,8 \mathrm{~A} \mathrm{~b}$ & $33,4 \mathrm{~A} \mathrm{~b}$ \\
\hline \multirow[t]{2}{*}{ Lignina (\%) } & seca & $35,3 \mathrm{~A} \mathrm{~b}$ & $25,4 \mathrm{~B} \mathrm{~b}$ & $40,4 \mathrm{~A} \mathrm{~b}$ \\
\hline & chuvosa & $89,6 \mathrm{~A} \mathrm{a}$ & $94,2 \mathrm{~A} \mathrm{a}$ & $92,1 \mathrm{~A} \mathrm{a}$ \\
\hline \multirow{2}{*}{$\begin{array}{c}\text { Massa seca total } \\
\left(\mathbf{t} / \mathbf{h a}^{-1}\right)\end{array}$} & seca & $14,6 \mathrm{~A} \mathrm{~b}$ & $5,2 \mathrm{~A} \mathrm{~b}$ & $9,7 \mathrm{~A} \mathrm{a}$ \\
\hline & chuvosa & $37,1 \mathrm{~A} \mathrm{a}$ & $19,3 \mathrm{~B} \mathrm{a}$ & $15,3 \mathrm{~B}$ \\
\hline
\end{tabular}

Letras iguais maiúsculas na mesma linha (entre áreas) ou minúsculas na mesma coluna (entre épocas), não diferem entre si significativamente ao nível de $5 \%$ de probabilidade de acordo com o teste de Tukey. 


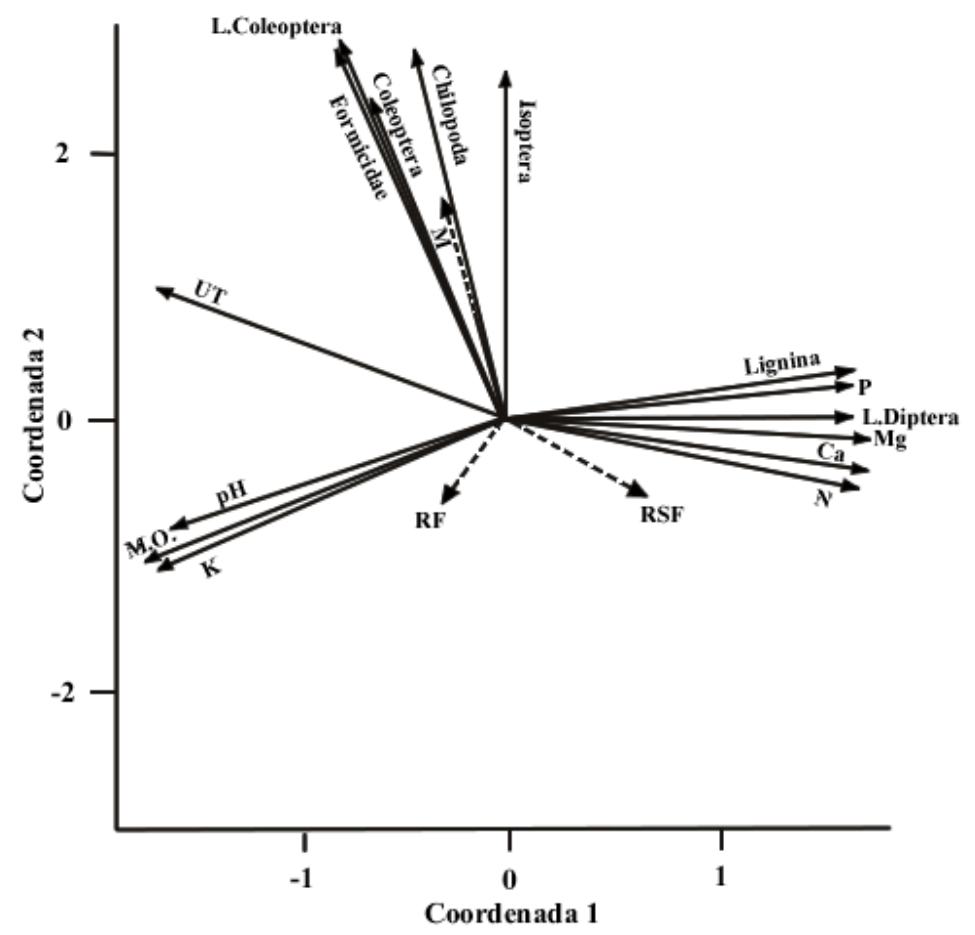

Figura 11 - Biplot para a macrofauna pelos atributos químicos da serapilheira dos diferentes ecossistemas: mata nativa de araucária $(\mathrm{M})$, mata de araucária introduzida (RSF) e mata de araucária impactada pela ação do fogo (RF)

Tabela 20. Coeficientes de correlação de Spearman entre os atributos químicos da serapilheira e principais grupos da macrofauna coletada nos diferentes ecossistemas de araucária

\begin{tabular}{lccccc}
\hline \multicolumn{1}{c}{ Serapilheira } & \multicolumn{4}{c}{ Grupos da macrofauna } \\
& Coleoptera & Chilopoda & L. Coleoptera & Formicidae & Isoptera \\
\hline pH (CaCl) & s.c. & s.c. & s.c. & s.c. & s.c. \\
Umidade total (\%) & 0,66 & s.c. & 0,62 & 0,60 & s.c. \\
Matéria orgânica & s.c. & s.c. & s.c. & s.c. & s.c. \\
Potássio (\%) & s.c. & s.c. & s.c. & s.c. & s.c. \\
Cálcio (\%) & s.c. & s.c. & s.c. & s.c. & s.c. \\
Magnésio (\%) & s.c. & s.c. & s.c. & s.c. & s.c. \\
Carbono total (\%) & s.c. & s.c. & s.c. & s.c. & s.c. \\
Nitrogênio total & $-0,50$ & s.c. & s.c. & $-0,41$ & s.c. \\
Lignina (\%) & s.c. & s.c. & s.c. & s.c. & s.c. \\
\hline
\end{tabular}




\subsection{Alterações da comunidade da macrofauna edáfica pelo índice V de Wardle}

Pela aplicação do Índice V de Wardle (1995), tendo-se como referência a mata natural, observou-se que as áreas de araucária introduzida apresentaram inibição e/ou estimulação dos grupos da comunidade da macrofauna do solo de acordo com as épocas de amostragens (Figura 12).

$\mathrm{Na}$ época seca, a serapilheira e o solo das duas áreas de RSF e RF apresentaram $50 \%$ ou mais dos grupos da macrofauna do solo extremamente inibidos (EI) (Figura 12A). A RSF e RF, na época seca, ficaram distanciadas da mata natural pelo padrão de inibição.

$\mathrm{Na} \mathrm{RF}$ as características físicas e químicas do solo, aliadas à alteração do sistema provocado pelo fogo, implicaram em prejuízo à proliferação e manutenção das populações da macrofauna. Pelos resultados obtidos na época chuvosa, observou-se nesta área um padrão de inibição (IE e IM) em cerca de 30\% (Figura 12B).

Com relação à redução do número de grupos faunísticos em sistemas que sofreram queima, os resultados deste trabalho são concordantes com outros que demonstram o efeito negativo do fogo sobre os organismos do solo (Neumann \& Tolhurst, 1991; Teixeira \& Schubart, 1988). Por outro lado, a biomassa que não foi queimada, principalmente os grandes troncos, mantém áreas com pouca perturbação que funcionam como refúgio temporário para a fauna do solo (Teixeira \& Schubart, 1988). Neary et al. (1999), citam que, dependendo da severidade do fogo, as mudanças sobre os processos no solo podem ser benéficas ou deletérias para o ecossistema como um todo. Queimas moderadas a severas podem resultar em um amplo fluxo de perdas de nutrientes do ecossistema através da volatilização e rápida mineralização dos nutrientes e do aumento dos processos microbiológicos (exemplo: aumento nas taxas de decomposição, nitrificação e desnitrificação), com subseqüentes perdas de nutrientes através da erosão acelerada e lixiviação. 
A

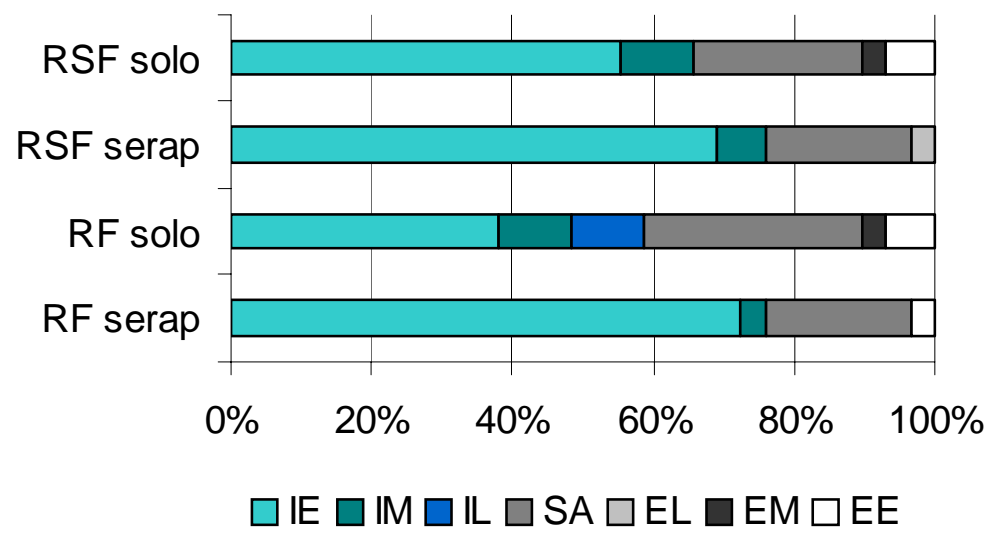

B

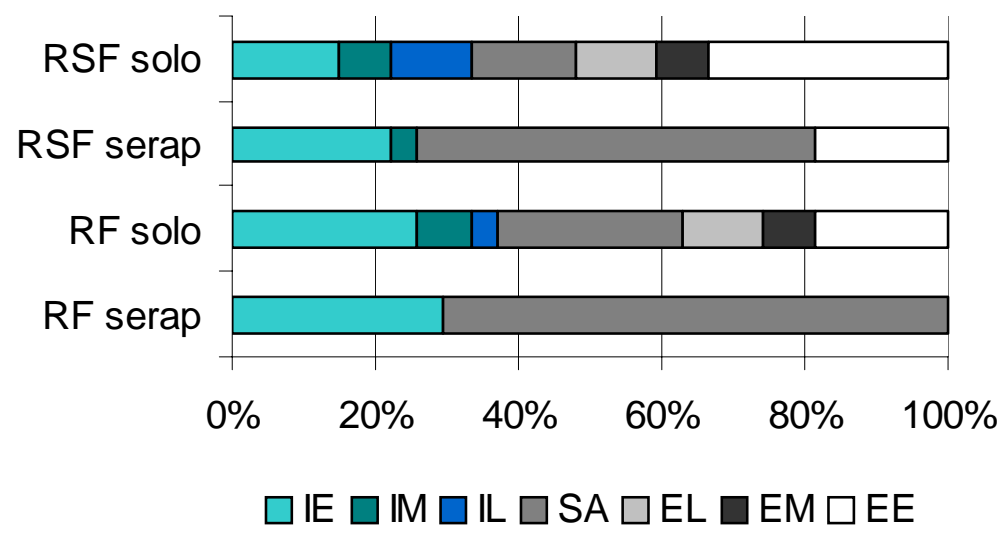

Figura 12 - Resultado da aplicação do Índice V de Wardle (1995), aos grupos da macrofauna coletados na serapilheira e no solo sob diferentes ecossistemas de araucária, na época seca (A) e chuvosa (B). Os resultados estão expressos em porcentagem dos grupos classificados nas categorias de inibição/estimulação. IE = inibição extrema, IM = inibição moderada, IL = inibição leve, $\mathrm{SA}=$ sem alteração, $\mathrm{EL}=$ estimulação leve, $\mathrm{EM}=$ estimulação moderada e EE = estimulação extrema 
No solo da RSF, houve uma recuperação da densidade e da riqueza na época chuvosa, ocorrendo estimulação extrema (EE) dos grupos da macrofauna (Figura 12B).

A aproximação destas áreas na época chuvosa está de acordo com os resultados encontrados nas demais análises utilizadas neste trabalho. A simples presença ou ausência dos grupos da macrofauna edáfica indica mudanças nos ecossistemas estudados. 


\section{CONCLUSÕES}

As características dos solos, aliadas à intervenção na cobertura vegetal e à composição e densidade de espécies vegetais, foram agentes transformadores da comunidade da macrofauna edáfica.

As mudanças na abundância relativa e diversidade dos grupos da fauna edáfica constituem-se num bom indicador de mudanças no sistema. A aplicação do índice V para a macrofauna edáfica demonstrou ser um bom indicador das condições de perturbação do sistema, como a ação do fogo; ou estabilidade, como a floresta replantada sem interferência de fogo.

As larvas de Coleoptera foram eficientes em indicar as diferenças entre os ecossistemas com araucária.

O uso da macrofauna como bioindicadora da qualidade do ambiente

demonstrou ser uma excelente estratégia para o monitoramento dos ecossistemas com araucária, visando à conservação destes habitats e do manejo correto de seus recursos naturais. 


\section{ANEXOS}


Anexo A. Densidade (indivíduos por metro quadrado) coletados no solo (0-10, 10-20 e 20-30 cm de profundidade) e na serapilheira (SE), nos diferentes ecossistemas de araucária, na época seca. Valores entre parênteses representam os erros padrão

\begin{tabular}{|c|c|c|c|c|c|c|c|c|c|c|c|c|}
\hline & \multicolumn{4}{|c|}{$\mathbf{M}$} & \multicolumn{4}{|c|}{ RF } & \multicolumn{4}{|c|}{ RSF } \\
\hline & SE & 0-10 & $10-20$ & $20-30$ & SE & 0-10 & $10-20$ & $20-30$ & SE & 0-10 & $10-20$ & $20-30$ \\
\hline Diptera & 2 & 0 & 0 & 2 & 0 & 0 & 0 & 0 & 0 & 0 & 0 & 0 \\
\hline Heteroptera & 19 & 5 & 0 & 0 & 0 & 0 & 0 & 0 & 0 & 0 & 0 & 0 \\
\hline Homoptera & 0 & 16 & 5 & 0 & 0 & 0 & 0 & 0 & 0 & 0 & 0 & 2 \\
\hline Coleoptera & 110 & 94 & 6 & 2 & 10 & 14 & 0 & 0 & 19 & 6 & 3 & 5 \\
\hline Orthoptera & 2 & 0 & 0 & 0 & 0 & 0 & 0 & 0 & 0 & 0 & 0 & 0 \\
\hline Blattodea & 3 & 3 & 2 & 0 & 0 & 0 & 0 & 2 & 0 & 0 & 0 & 0 \\
\hline Psocoptera & 0 & 0 & 0 & 0 & 2 & 0 & 0 & 0 & 0 & 0 & 0 & 0 \\
\hline Isopoda & 3 & 0 & 0 & 0 & 0 & 0 & 0 & 0 & 0 & 0 & 0 & 0 \\
\hline Diplopoda & 2 & 18 & 3 & 0 & 0 & 3 & 0 & 0 & 0 & 2 & 2 & 0 \\
\hline Chilopoda & 27 & 80 & 3 & 2 & 0 & 11 & 2 & 2 & 5 & 11 & 2 & 2 \\
\hline Araneae & 14 & 5 & 0 & 0 & 2 & 0 & 0 & 0 & 3 & 2 & 0 & 0 \\
\hline Oligochaeta & 2 & 5 & 3 & 2 & 0 & 3 & 0 & 5 & 0 & 0 & 0 & 3 \\
\hline Cas. Oligoch. & 3 & 0 & 0 & 0 & 0 & 0 & 0 & 0 & 0 & 0 & 0 & 0 \\
\hline L. Diptera & 6 & 14 & 3 & 2 & 0 & 5 & 0 & 0 & 0 & 0 & 0 & 0 \\
\hline L. Coleopt & 19 & 45 & 24 & 11 & 6 & 35 & 2 & 19 & 0 & 8 & 3 & 6 \\
\hline L. Formicid & 3 & 14 & 0 & 59 & 0 & 154 & 0 & 10 & 2 & 0 & 0 & 0 \\
\hline Hymenopt & 2 & 2 & 0 & 0 & 0 & 0 & 0 & 0 & 0 & 0 & 0 & 0 \\
\hline Formicidae & 454 & 253 & 53 & 450 & 8 & 294 & 2 & 37 & 40 & 21 & 2 & 5 \\
\hline Thysanura & 0 & 2 & 0 & 0 & 0 & 2 & 0 & 0 & 0 & 0 & 0 & 0 \\
\hline Isoptera & 27 & 27 & 2 & 35 & 0 & 309 & 27 & 2 & 2 & 70 & 24 & 40 \\
\hline ovos Hyme & 0 & 0 & 0 & 0 & 0 & 192 & 0 & 0 & 0 & 234 & 0 & 0 \\
\hline Diplura & 26 & 59 & 0 & 0 & 0 & 0 & 0 & 0 & 2 & 2 & 0 & 0 \\
\hline Dermaptera & 3 & 2 & 0 & 0 & 0 & 0 & 0 & 0 & 0 & 0 & 0 & 0 \\
\hline Pseudoscorp. & 2 & 0 & 0 & 0 & 2 & 0 & 0 & 0 & 3 & 0 & 2 & 0 \\
\hline Opilionida & 2 & 0 & 0 & 0 & 0 & 0 & 0 & 0 & 0 & 0 & 0 & 0 \\
\hline pupa Coleop. & 0 & 5 & 0 & 0 & 0 & 3 & 0 & 0 & 0 & 0 & 0 & 0 \\
\hline ninfa Hetero. & 2 & 0 & 0 & 0 & 0 & 0 & 0 & 0 & 0 & 0 & 0 & 0 \\
\hline Enchytraeidae & 0 & 0 & 2 & 0 & 0 & 0 & 0 & 0 & 0 & 0 & 0 & 0 \\
\hline Thysanopt & 2 & 0 & 0 & 0 & 0 & 0 & 0 & 0 & 0 & 0 & 0 & 0 \\
\hline Total & $\begin{array}{c}734 \\
(153) \\
\end{array}$ & $\begin{array}{c}648 \\
(137)\end{array}$ & $\begin{array}{l}106 \\
(33)\end{array}$ & $\begin{array}{c}563 \\
(474) \\
\end{array}$ & $\begin{array}{c}29 \\
(11) \\
\end{array}$ & $\begin{array}{c}1026 \\
(746)\end{array}$ & $\begin{array}{c}32 \\
(27) \\
\end{array}$ & $\begin{array}{c}75 \\
(39) \\
\end{array}$ & $\begin{array}{c}75 \\
(35) \\
\end{array}$ & $\begin{array}{c}355 \\
(294)\end{array}$ & $\begin{array}{c}37 \\
(17) \\
\end{array}$ & $\begin{array}{c}62 \\
(30) \\
\end{array}$ \\
\hline
\end{tabular}


Anexo B. Densidade (indivíduos por metro quadrado) coletados no solo (0-10, 10-20 e 20-30 cm de profundidade) e na serapilheira (SE), nos diferentes ecossistemas de araucária, na época chuvosa. Valores entre parênteses representam os erros padrão

\begin{tabular}{|c|c|c|c|c|c|c|c|c|c|c|c|c|}
\hline & \multicolumn{4}{|c|}{$\mathbf{M}$} & \multicolumn{4}{|c|}{ RF } & \multicolumn{4}{|c|}{ RSF } \\
\hline & SE & 0-10 & $10-20$ & $20-30$ & SE & 0-10 & $10-0$ & $20-30$ & SE & $0-10$ & $10-20$ & $20-30$ \\
\hline Diptera & 0 & 0 & 0 & 0 & 0 & 0 & 0 & 0 & 3 & 3 & 3 & 3 \\
\hline Heteroptera & 0 & 3 & 2 & 0 & 0 & 0 & 0 & 2 & 0 & 8 & 0 & 0 \\
\hline Homoptera & 0 & 0 & 0 & 2 & 0 & 0 & 0 & 0 & 0 & 0 & 0 & 0 \\
\hline Coleoptera & 0 & 18 & 2 & 0 & 0 & 32 & 2 & 0 & 2 & 43 & 19 & 2 \\
\hline Orthoptera & 0 & 0 & 0 & 0 & 0 & 0 & 0 & 0 & 0 & 2 & 0 & 0 \\
\hline Blattodea & 0 & 3 & 0 & 0 & 0 & 0 & 0 & 0 & 0 & 0 & 0 & 0 \\
\hline Psocoptera & 2 & 0 & 0 & 0 & 0 & 0 & 0 & 0 & 0 & 0 & 0 & 0 \\
\hline Diplopoda & 5 & 8 & 0 & 2 & 0 & 0 & 0 & 0 & 0 & 6 & 0 & 0 \\
\hline Symphyla & 2 & 0 & 0 & 0 & 0 & 0 & 0 & 0 & 0 & 2 & 0 & 2 \\
\hline Chilopoda & 5 & 37 & 2 & 0 & 0 & 6 & 0 & 0 & 2 & 24 & 11 & 3 \\
\hline Araneae & 3 & 5 & 3 & 0 & 0 & 0 & 0 & 0 & 3 & 2 & 0 & 0 \\
\hline Oligochaeta & 0 & 0 & 2 & 3 & 0 & 10 & 3 & 0 & 3 & 3 & 3 & 3 \\
\hline Cas. Oligoch. & 0 & 0 & 0 & 6 & 0 & 0 & 0 & 0 & 0 & 0 & 0 & 0 \\
\hline L. Diptera & 2 & 16 & 0 & 0 & 0 & 6 & 5 & 3 & 0 & 27 & 5 & 3 \\
\hline L. Coleoptera & 10 & 112 & 43 & 30 & 0 & 29 & 13 & 14 & 0 & 114 & 26 & 11 \\
\hline L. Formicidae & 0 & 0 & 0 & 0 & 0 & 10 & 5 & 0 & 0 & 3 & 5 & 2 \\
\hline Formicidae & 0 & 24 & 3 & 48 & 0 & 141 & 134 & 3 & 5 & 27 & 3 & 2 \\
\hline Thysanura & 0 & 0 & 0 & 0 & 0 & 2 & 0 & 0 & 2 & 0 & 0 & 0 \\
\hline Isoptera & 0 & 467 & 2 & 5 & 0 & 768 & 32 & 0 & 0 & 74 & 251 & 0 \\
\hline ovos Hyme & 0 & 0 & 0 & 0 & 0 & 91 & 0 & 0 & 0 & 19 & 0 & 0 \\
\hline Diplura & 2 & 3 & 0 & 0 & 0 & 6 & 0 & 0 & 0 & 35 & 8 & 0 \\
\hline Dermaptera & 0 & 0 & 0 & 0 & 0 & 0 & 0 & 0 & 0 & 2 & 0 & 0 \\
\hline Opilionida & 0 & 0 & 0 & 0 & 0 & 0 & 0 & 0 & 0 & 2 & 0 & 0 \\
\hline pupa Coleop & 0 & 3 & 0 & 0 & 0 & 0 & 0 & 0 & 0 & 5 & 2 & 0 \\
\hline ninfa Heterop & 0 & 2 & 0 & 0 & 0 & 2 & 0 & 0 & 0 & 0 & 0 & 0 \\
\hline Enchytraeidae & 0 & 0 & 0 & 0 & 0 & 3 & 2 & 2 & 0 & 18 & 3 & 2 \\
\hline Ensifera imat. & 0 & 0 & 0 & 0 & 0 & 0 & 2 & 0 & 0 & 0 & 0 & 0 \\
\hline Total & 29 & 702 & 58 & 96 & 0 & 1112 & 197 & 24 & 19 & 418 & 339 & 32 \\
\hline
\end{tabular}




\section{REFERÊNCIAS BIBLIOGRÁFICAS}

AL ASSIUTY, A.M.; BAYOUMI, B.M.; KHALIL, M.A.; VAN STRAALEN, N.M. The influence of vegetational type on seasonal abundance and species composition of soil fauna at different localities in Egypt. Pedobiologia, v. 37, p. 210-222, 1993.

ÀlVAREZ-SÁNCHEZ, J; NARANJO-GARCIA, E.; GUEVARA, S. Perspectivas de estudios de acumulación de la hojarasca en el subdosel y animales asociados: el caso de los moluscos. In: ÀlVAREZ-SÁNCHEZ, J; NARANJO-GARCIA, E. (Ed.). Ecología del suelo em la selva tropical húmeda de México. Xalapa: UNAM, Instituto de Biología y Facultad de Ciencias, 2003. cap 2, p. 79-87.

AMELUNG, W.; MARTIUS, C.; BANDEIRA, A.G.; GARCIA, M.V.B.; ZECH, W. Lignin characteristics and density fractions of termite nests in an Amazonian rain forest - indicators of termite feeding guilds? Soil Biology and Biochemistry, v. 34, p. 367-372, 2002.

ANDERSON, J.D.; INGRAM, J.S.I. Tropical soil biology and fertility: a handbook of methods. 2.ed. Wallingford: CAB International, 1993. 171p. 
ANDERSON, J.; FLANAGAN, P.; CASWELl, E.; COLEMAN, D.; CUEVAS, E.; FRECKMAN, D.; JONES, J.; LAVELLE, P.; VITOUSEK, P. Biological processes regulating organic matter dynamics in tropical soils. In: COLEMAN, D.; MALCOM, J.; VEHARA, G. (Ed.). Dynamics of soil organic matter in tropical ecosystems. Honolulu: University of Hawaii; Department of Agronomy and Soil Science, 1989. cap. 3, p. 111-117.

ANDERSON, J.M.; INESON, P.; HUISH, S. A. Nitrogen and cation mobilization by soil fauna feeding on leaf litter and soil organic matter fram deciduos woodlands. Soil Biology and Biochemistry, v. 15, p. 463-467, 1983.

AZEVEDO, O. Os pinheiros do brasil. Informação Florestal, n. 6, p. 15-18, 1994.

BADEJO, M.A.; VAN STRAALEN, N.M. Seasonal abundance of springtails in two contrasting environments. Biotropica, v. 25, p. 222-228, 1993.

BANDEIRA, A.G. Ecologia de cupins (Insecta: Isoptera) da Amazônia Central: efeitos do desmatamento sobre as populações. Acta Amazônica, v. 9, p. 481-499, 1979.

BANDEIRA, A.G.; SOUZA, P.C.S. Influência do pinheiro (Pinus caribea) sobre a fauna do solo na Amazônia. Boletim do Museu Paraense Emílio Goeldi, v. 114, p. 1-13, 1982.

BANDEIRA, A.G.; HARADA, A.Y. Densidade e distribuição vertical de macroinvertebrados em solos argilosos e arenosos na Amazônia Central. Acta Amazônica, v. 28, p. 191-204, 1998.

BARNES, D. R. Zoologia dos invertebrados. 4. ed. Pennsylvania: Roca, 1984. 1179p. 
BEGON, M.; HARPER, J.L.; TOWNSEND, C.R. Ecology: individuals, populations and communities. 3 ed. Oxford: Blackwell Science, 1996. 1068p.

BENGTSSON, J.; LUNDKVIST, H.; SAETRE, P.; SOHLENIUS, B.; SOLBRECK, B. Effects on organic matter removal on the soil food web: Forestry practices meet ecological theory. Applied Soil Ecology, v. 9, p. 137-143, 1998.

BERZAGHI, A.J.P. Dinâmica da serapilheira na mata de Araucaria e Podocarpus do Parque Estadual de Campos do Jordão, SP. São Paulo, 1994. 118p. Dissertação (Mestrado) - Instituto de Biociências, Universidade de São Paulo.

BLAIR, J.M.; PARMELEE, R.W.; WYMAN, R.L. A comparision of the forest floor invertebrate communities of four forest types in the northeastern U.S. Pedobiologia, v. 38, p. 146-160, 1994.

BORROR, D.J.; DELONG, D.M. Introdução ao estudo dos insetos. São Paulo: Edgard Blucher, 1969. 653p.

BOUMA, J. Comment on micro-, meso-, and macroporosity of soil. Soil Science Society American Journal, v. 45, p. 1244-1245, 1981.

BRASIL. Ministério da Agricultura. Instituto Brasileiro do Meio Ambiente e dos Recursos Naturais Renováveis. Portaria no 06, de 23 de janeiro de 1992. In: IBAMA. Lista oficial de espécies da flora brasileira ameaçadas de extinção. p. 870-872.

BRITEZ, R.M.; REISSMAN, C.B.; SILVA, S.M.; SANTOS FILHO, A. Deposição estacional de serapilheira e macronutrientes em uma floresta de araucária. Revista do Instituto Florestal, v. 4, p.766-772, 1992. 
BRUSSAARD, L. Soil fauna, guilds, functional groups and ecosystems processes. Applied Soil Ecology, v. 9, p. 123-135, 1998.

BYZOV, B.A.; KURAKOV, A.V.; TRETYAKOVA, E.B.; THANH, V.N.; LUU, N.D. T.; RABINOVICH, Y.M. Principles of digestion of microorganisms in the gut of soil millipedes: specificity and possible mechanisms. Applied Soil Ecology, v. 9, p. 145-151, 1998.

CAMARGO, O. A. de; MONIZ, A.C.; JORGE, J.A.; VALADARES, J.M.A.S. Métodos de análise química, mineralógica e física de solos do Instituto Agronômico de Campinas. Campinas: Instituto Agronômico, 94p. 1986. (IAC, Boletim Técnico, 106).

CÁRCAMO, E.A.; SPENCE, J.R. Crop type effects on the activity and distribution of ground beetle (Coleoptera: Carabidae). Environmental Entomology, v. 23, p. 684-692, 1994.

CLARK, M.S.; GAGE, S.E.; SPENCE, J.R.E. Habitats and management associated with common ground beetles (Coleoptera: Carabiade) in a Michigan agricultural landscape. Environmental Entomology, v. 26, p.519-527, 1997.

COLEMAN, D.C.; CROSSLEY, D.A. Fundamentals of soil ecology. London: Academic Press, 1996. 205p.

COLINVAUX, P.A. Ecology. New York : John Wiley, 1986. 725p.

CONNELL, J.H. Diversity in tropical rain forests and coral reefs. Science, v. 199, p. $1302-1310,1978$. 
CORREIA, M.E.F. Organização de comunidades da fauna do solo: o papel da densidade e da diversidade como indicadores de mudanças ambientais (compact disc). In: CONGRESSO BRASILEIRO DE CIÊNCIAS DO SOLO, 26., Rio de Janeiro, 1997. Palestras, Rio de Janeiro: Sociedade Brasileira de Ciência do Solo. 20p.

CORREIA, M.E.F.; ANDRADE, A.G. Formação da serapilheira e ciclagem de nutrientes. SANTOS, G.A.; CAMARGO, F.A.O. (Ed.). Fundamentos da matéria orgânica do solo: ecossistemas tropicais e subtropicais. Porto Alegre: Gênesis, 1999. p. 197-225.

CORREIA, M.E.F.; REIS, L.L.; CAMPELLO, E.F.C.; FRANCO, A.A. Populações da macrofauna do solo em agricultura itinerante na região da Mata Atlântica, RJ. In: O uso da macrofauna edáfica na agricultura do século XXI. Londrina: Embrapa Soja, p. 200-224, 2003. (Série Documentos, 224)

COSTA, C.; VANIN, S.A.; CASARI-CHEN, S.A. Larvas de Coleoptera do Brasil. São Paulo: Museu de Zoologia da Universidade da São Paulo, 1988. 282p.

COSTA, P. Fauna do solo em plantios experimentais de Eucalyptus grandis Maiden, Pseudosamanea guachapele Dugand e Acacia mangium Willd. Seropédica, 2002. 93p. Dissertação (Mestrado) - Instituto de Agronomia, Universidade Federal Rural do Rio de Janeiro.

COTTAM, G.; CURTIS, J.T. The use of distance measures in phytossociological sampling. Ecology, v. 37, p. 451-460, 1956.

CROWSON, R.A. The biology of the Coleoptera. London: Academic Press, 1981. $802 \mathrm{p}$. 
CURRY, J.P.; GOOD, J.A. Soil fauna degradation and restoration. Advances in Soil Science, v. 17, p. 171-215, 1992.

DANGERFIELD, J.M.; TELFORD, S.R. Species diversity of julid millipeds: between habitat comparisons within seasonal tropics. Pedobiologia, v. 36, p. 321-329, 1992.

DEANGELIS, D.L.; BARTELL, S.M.; BRENKERT, A.L. Effects of nutrient recycling and food-chain length on resilience. The American Naturalist, v. 134, p. 778-805, 1989.

DECAËNS, T.; DUTOIT, T.; ALARD, D.; LAVELLE, P. Factors influencing soil macrofaunal communities in post-pastoral successions of western France. Applied Soil Ecology, v. 9, p. 361-367, 1998.

DELITTI, W.B.C. Aspectos comparativos da ciclagem de nutrientes minerais na mata ciliar, no campo cerrado e na floresta implantada de Pinus elliottii var. elliottii. São Paulo, 1984. 248 p. Tese (Doutorado) - Instituto de Botânica, Universidade de São Paulo.

DELLA LUCIA, T.M.C.; ARAÚJO. M.S. Fundação e estabelecimento de formigueiros. In: DELLA LUCIA, T.M.C. (Ed.). As formigas cortadeiras. Viçosa: Folha de Viçosa, 1993a. cap. 7, p. 60-83.

DELLA LUCIA, T.M.C.; FOWLER, H.G. As formigas cortadeiras. In: DELLA LUCIA, T.M.C. (Ed.). As formigas cortadeiras. Viçosa: Folha de Viçosa, 1993b. cap. 1, p. 1-3.

DIGBY, P.G.N.; KEMPTON, R.A. Multivariate analysis of ecological communities. 4. ed. London: Chapman \& Hall, 1987. 206p. 
DINDAL, D.L. Soil biology guide. New York: John Wiley, 1990. 1349p.

DORAN, J.W.; PARKIN, T.B. Defining and assessing soil quality. In: DORAN, J.W; COLEMAN, D.C.; BEZDICEK, D.F.; STEWART, B.A. (Ed.). Defining soil quality for a sustainable environment. Madison: Soil Science Society of American, 1994. p. 3-21.

EHRNSBERGER, R. Bodenzoologie und Agrarökosysteme. Informationsdienst Naturschutz Landschaftspflege, v. 6, p. 11-41, 1993.

EKSCHIMITT, K.; WOLTERS, V.; WEBER, M. Spiders, Carabids and Staphylinids: the ecological potential of predatory macroarthropods. In: BENCKISER, G. (Ed.). Fauna in soil ecosystems: recycling processes, nutrient fluxes and agricultural production. New York: Marcel Dekker, 1997. cap. 9, p. 307-362.

FERNANDES, A.V.; BACKES, A. Produtividade primária em floresta com Araucaria angustifolia no Rio Grande do Sul. Iheringia - Série Botânica, v. 51, p. 63-78, 1998.

FOWLER, H.G. Formigas indicam nível de recuperação de áreas degradadas pela mineração: Provas de melhoria ambiental. Ciência Hoje, v. 24, p. 69-71, 1998.

FRAGOSO, C.; ROJAS, P. Soil biodiversity and land management in the tropics. The case of ant and earthworms. In: WORLD CONGRESS OF SOIL SCIENCE, 15., Acapulco, 1994. Anais. Acapulco: International Society of Soil Science, 1994. p. 232-237.

GABRIEL, K.R. The biplot graphic display of matices with application to principal component analysis. Biometrika, v. 58, p. 453-467, 1971. 
GASSEN, D.N. Os benefícios de corós em lavouras sob plantio direto. Comunicado Técnico Online, n. 47, 27p. 2000.

GOLFARI, L. Coníferas aptas para repoblaciones florestales en el Estado de São Paulo. Silvicultura em São Paulo, n. 6, p. 7-62, 1970.

GONZÁLEZ, G.; ZOU, X.; BORGES, S. Earthworm abundance and species composition in abandoned tropical croplands: comparison of tree plantations and secondary forests. Pedobiologia, v. 40, p. 385-391, 1996.

NOSS, R.F.; WESTRA, L. Ecological integrity. Washington, DC: Island Press, 1998. $126 \mathrm{p}$.

GUZMÁN, G.B; ÀLVAREZ-SÁNCHEZ, J. La comunidad de desintegradores em uma selva húmeda tropical. In: ÀLVAREZ-SÁNCHEZ, J; NARANJO-GARCIA, E. (Ed.). Ecología del suelo en la selva tropical húmeda de México. Xalapa: UNAM, Instituto de Biología y Facultad de Ciencias, 2003. cap. 4, p. 162-184.

HANAGARTH, W.; MARTIUS, C.; BECK, L.; GARCIA, M. Soil fauna and litter decomposition in primary and secondary forest and a mixed culture system in Amazonia. In: BECK, L.; GASPAROTTO, L. (Ed.). Soil fauna and litter decomposition in primary and secondary forests and a mixed culture system in amazonia. Karlsruhe: SHIF Project ENV 052, 1999. 291p. (Final Report 19961999).

HÖFER, H.; HANAGARTH, W.; GARCIA, M.; MARTIUS, C.; FRANKLIN, E.; ROMBKE, J.; BECK, L. Structure and function of soil fauna communities in Amazonian anthropogenic and natural ecosystems. European Journal Soil Biology, v. 37, p. 1-7, 2001. 
JOLY, A.B. Botânica: chaves de identificação das famílias de plantas vasculares que ocorrem no Brasil. São Paulo: Editora Nacional, 1977. 159p.

KARLEN, D.L.; MAUSBACH, M.J.; DORAN, J.W.; CLINE, R.G.; HARRIS, R.F.; SCHUMAN, G.E. Soil quality: a concept, definition, and framework for evaluation. Soil Science Society of America Journal, v. 61, p. 4-10, 1997.

KIEHL, E.J. Fertilizantes orgânicos. Piracicaba: Agronômica Ceres, 1985. 492p.

KRAPFENBAUER, A.; GASCH, J. Derwaldbodenhumus als zustandsweiser. Forstaeitung. Österreichische, v. 2, p. 28-32, 1989.

LAL, R. Modifications of soil fertility characteristics by management of soil physical properties. In: LAL, R.; GREENLAND D.J. (Ed.). Soil physical properties and crop production in the tropics. New York: John Willey, 1979. cap. 2, p. 397-406.

LANDINA, M.M.; KLEVENSK, I.L. Effect of soil compactation and composition of soil air. Soviety Soil Science, v. 16, p. 46-54, 1984.

LARA, F.M. Princípios de entomologia. São Paulo: Ícone, 1992. 331p.

LARANJEIRO, A.J. Estabilidade da entomofauna num mosaico de plantação de eucalipto e áreas naturais de conservação. Piracicaba, 2003. 142p. Tese (Doutorado) - Escola Superior de Agricultura “Luiz de Queiroz”, Universidade de São Paulo.

LAVELLE, P. Faunal activities and soil processes: adaptive strategies that determine ecosystem function. In: WORLD CONGRESS OF SOIL SCIENCE, 15., Acapulco, 1994. Anais. Acapulco: International Society of Soil Science, 1994. p. 189-220. 
LAVELLE, P. Diversity of soil fauna and ecosystem function. Biology International, v. 33, p. 3-16, 1996.

LAVELLE, P.; BLANCHART, E.; MARTIN, S.; SPAIN, A.; TOUTAIN, F.; BAROIS, I.; SCHAEFER, R.A. Hierarchical model for decomposition in terrestrial ecosystems: application to soils of the humid tropics. Biotropica, v. 25, p. 130-150, 1993.

LAVELLE, P.; BIGNELL, D.; LEPAGE, M.; WOLTERS, V.; ROGER, P.; INESON, P.; HEAL, O.W.; DHILLION, S. Soil function in a changing world: the role of invertebrate ecosystem engineers. European Journal Soil Biology, v. 33, p. 159-193, 1997.

LAWTON, J.H.; SCHRÖDER, D. Effects of plant type, size of geographical range and taxonomic isolation on number of insect species associated eith British plants. Nature, v. 265, p. 137-140, 1977.

LEBART, L.; FÉNELON, J.P. Traitment des donnés statistiques. (Systeme Portable pour l'Ánalyse dês Donnés). http:/www.linux.lettere.unige.it/htm/stat2/1.htm (20 jul. 2004).

LEE, K.E. Earthworms: Their ecology and relationships with soils and land use. Sydney: Academic Press, p. 4-59, 1985.

LEE, K.E.; WOOD, T.G. Termite and soil. New York: Academic Press, 1971. 251p.

LEKHA, A.; GUPTA, S.R. Decomposition of Popolus and Leucaena leaf litter in an agroforestry system. International Evironmental Science, v. 15, p. 97-108, 1989. 
LIBARDI, P.L.; REICHARDT, K.; NIELSEN, D.R.; JOSÉ, C.; BAZZA, M. An approximate method of estimating soil water diffusivity for different soil bulk densities. Water Resources Research, v. 18, p. 177-181, 1982.

LINDEN, R.D.; HENDRIX, P.F.; COLEMAN, D.C.; VAN VILET, P.C.J. Faunal indicators of soil quality. In: DORAN, J.W.; COLEMAN, D.C.; BEZDICEK, D.F.; STEWART, B.A. (Ed.). Defining soil quality for a sustainable environment. Madison: Soil Science Society of American, 1994. p. 91-106.

LOPES ASSAD, M.L. Fauna do solo. In: VARGAS, M.A.T.; HUNGRIA, M. (Ed.). Biologia dos solos dos cerrados. Planaltina: EMBRAPA-CPAC, cap. 7, p. 363-444, 1997.

MARINONI, R.C.; GANHO, N.G.; MONNÉ, M.L.; MERMUDES, J.R.M. Hábitos alimentares em Coleoptera (Insecta): compilação, organização de dados e novas informações sobre alimentação nas famílias de coleópteros. Ribeirão Preto: Holos, 2003. 63p.

MARTINS, F.R.; SANTOS, F.A.M. Técnicas usuais de estimativa da biodiversidade. Rio Claro: Revista Holos, p. 236-267, 2000. Edição especial.

MATTOS, J.R. O pinheiro brasileiro. Curitiba: Grêmio Politécnico, 1972. 648p.

MOORE, J.C.; WALTER, D.E.; HUNT, H.W. Arthropod regulation of micro-and mesobiota in bellow-grond detrital food webs. Annual Reviews of Entomology, v. 33, p. 419-439, 1988. 
NEARY, D.G.; KLOPATEK, C.C.; DEBANO, L.F.; FFOLLIOTT, P.F. Fire effects on belowground sustainability: a review and synthesis. Forest Ecology Management, v. 122, p. 51-71, 1999.

NEUMANN, F.G.; TOLHURST, K. Effects of fuel reduction burning on epigeal arthropods and earthworms in dry sclerophyll eucalypt forest of west-central victoria. Australian Journal of Ecology, v. 16, p. 315-330. 1991.

ODUM, E.P. Ecologia. Rio de Janeiro: Guanabara, 1988. 434p.

OLIVEIRA, B. As regiões de ocorrencia normal da Araucária: Ligeira contribuição para o estudo ecológico do Pinho Brasileiro. Anuário Brasileiro de Economia Florestal, v. 1, p. 185-199, 1948.

OLIVEIRA, C.R.F.; MATOS, C.H.C.; GONÇALVES, J.R. Porque os insetos podem ser considerados bons indicadores ecológicos? Folha Florestal, n. 99, p. 12-13, 2001.

OLIVEIRA, E.P. Estudo dos invertebrados terrestres e distribuição vertical em diferentes ecossistemas da Amazônia Central (compact disc). In: CONGRESSO LATINO AMERICANO DE CIÊNCIAS DO SOLO, 13., Águas de Lindóia, 1996. Anais. Águas de Lindóia: SBCS, 1996. p. 117-118.

PALACIOS-VARGAS, J.G. Introduccion a los insectos sin alas (Protura, Diplura, Collembola, Thysanura). Manuales y guias para el estudio de microartropodos. Xalapa: UNAM, Instituto de Biología y Facultad de Ciencias, 1991. cap. 2, p. 1-21. 
PANKHURST, C.E.; LYNCH, J.M. The role of the soil biota in sustainable agriculture. In: PANKHURST, C.E.; DOUDE, B.M.; GUPT, V.V.S.R.; GRACE, P.R. (Ed). Soil biota: management in sustainable farming systems. Victoria: CSIRO, 1994. p. 3-9.

PAOLETTI, M.G. Using bioindicators based on biodiversity to assess landscape sustainability. Agriculture, Ecosystems and Environment, v. 74, p. 1-18, 1999.

PERES FILHO, O.; SALVATORI, J.R.; SANCHEZ, G.; NAKANO, O.; TÉRAN, F.O. Componentes do material utilizado na construção do termiteiro do cupim-demontículo, (Isoptera: Termitidae). Pesquisa Agropecuária Brasileira, v. 25, p. 167-171, 1990.

PETERSEN, H.; LUXTON, M. A survey of the main animal taxa of detritus food web. Oikos, v. 39, p. 293-294, 1982.

POGGIANI, F.; SCHUMACHER, M.V. Ciclagem de nutrientes em Florestas Nativas. In: GONÇALVES, J.L.M.; BENEDETTI, V. (Ed.). Nutrição e fertilização florestal. Piracicaba: IPEF/ESALQ-USP, 2000. cap. 10, p. 587-308.

POGGIANI, F.; OlIVEIRA, R.E. de; CUNHA, G.C. da. Práticas de ecologia florestal. Documentos Florestais, n. 16, p. 1-44, 1996.

POWER, R.F.; TIARKS, A.E.; BOYLE, J.R. Assesing soil quality: Practicable standards for sustainable forest productivity in the United States. In: BIGHAM, J. M.; KRAL, D.M.; VINEY, M.K.; ADAMS, M.B.; RAMAKRISHNA, K.; DAVIDSON, E.A. (Ed.). The contribution of soil science to the development and implementation of criteria and indicators of sustainable forest management. Madison: Soil Science Society of American, 1998. p. 53-80 (Special Publication, 53). 
PRIMAVESI, A. Manejo ecológico do solo: a agricultura em regiões tropicais. São Paulo: Nobel, 1990. 549p.

PRITCHETT, W.L. Properties and management of forest soils. New York: John Wiley, 1979. 500p.

RAIJ, B.; QUAGGIO, J.A.; CANTARELLA, H.; ANDRADE, J.C. Análise química para avaliação da fertilidade de solos tropicais. Campinas: Instituto Agronômico. 2001. 284p.

REITZ, R.; KLEIN, R.M.; REIS, A. Projeto madeira do Rio Grande do Sul. Itajaí: Herbário Barbosa Rodrigues, 1988. 527p.

ROMARIZ, D.A. Aspectos da vegetação do Brasil. Rio de Janeiro: IBGE, 1973. 60p.

SANTOS, E.M.R. Densidade, diversidade e biomassa da fauna do solo em serapilheira manipulada numa floresta secundária da Amazônia Central. Manaus, 2000. 68p. Dissertação (Mestrado) - Instituto Nacional de Pesquisa do Amazonas, Universidade do Amazonas.

SAS INSTITUTE.SAS/STAT: users guide, release 6.03. SAS Institute Inc., Cary, 1988.

SCHUMACHER, M.V.; BRUN, E.J.; HERNANDES, J.I.; KÖNIG, F.G. Produção de serapilheira em uma floresta de Araucaria angustifolia (Bertol.) Kuntze no municipio de Pinhal Grande, RS. Revista Árvore, v. 28, p. 29-37, 2004.

SEASTEDT, T.R. The role of microarthropods in decomposition and mineralization processes. Annual Review of Entomology, v. 29, p. 25-46, 1984. 
SEIBERT, P. Plano de manejo do parque estadual de Campos do Jordão. São Paulo: Instituto Florestal, 1975. 153p. (Boletim Técnico, 19).

SHAW, C.; LUNDKVIST, H.; MOLDENKE, A.; BOYLE, J. The relationships of soil fauna to long-term forest productivity in template and boreal ecosystems: processes and research strategies. In: DICK, W.; MEES, C. (Ed.). Long-term field trials to assess environmental impacts of harvesting. Rotorua: Forest Research Institute, p. 39-77, 1991.

SIIRA-PIETIKAINEN, A.; HAIMI, J.; SIITONEN, J. Short-term responses of soil macroarthropod community to clear felling and alternative forest regeneration methods. Forest Ecology and Management, v. 172, p. 339-353, 2003.

SILVA, D.J.; QUEIROZ, A.C. de. Análise de alimentos: métodos químicos e biológicos. 3 ed. Viçosa:Universidade Federal de Viçosa, 2002. 235p.

SPAIN, A.V.; LAVELLE, P.; MARIOTTI, A. Stimulation of plant growth by tropical earthworms. Soil Biology and Biochemistry, v. 24, p. 1629-1633, 1992.

STORK, N.E.; EGGLETON, P. Invertebrates as determinants and indicators of soil quality. American Journal of Alternative Agriculture, v. 7, p. 2-6, 1992.

STOTT, D.E.; KENNEDY, A.C.; CAMBARDELA, C.A. Impact of soil organisms and organic matter on soil struture. In: LAL, R. (Ed.). Soil quality and soil erosion, Boca Raton: CRC Press, 1999. cap. 4, p. 57-74.

SWIFT, M.J.; HEAL, O.W.; ANDERSON, J.M. Decomposition in terrestrial ecosystems. Berkeley: University of California Press, 1979. 14p. 
TAPIA-CORAL, S.C. Macro-invertebrados do solo e estoques de carbono e nutrientes em diferentes tipos de vegetação de terra firme na Amazônia Peruana. Manaus, 2004. 135p. Tese (Doutorado) - Instituto Nacional de Pesquisa do Amazonas, Universidade Federal do Amazonas.

TARRÁ, I.L.C. Relações entre os grupos funcionais da macrofauna e o volume dos macroporos do solo em sistemas agrossilviculturais da Amazônia Central. Manaus, 2003. 80p. Dissertação (Mestrado) - Instituto Nacional de Pesquisa do Amazonas, Universidade Federal do Amazonas.

TEIXEIRA, L.B.; SCHUBART, H.O.R. Mesofauna do solo em áreas de floresta e pastagem na Amazônia Central. Belém: EMBRAPA-CPATU, p. 1-16, 1988. (Boletim, 95).

TEUBEN, A.; VERHOEF, H.A. Direct contribution by soil arthropods to nutrient availability through body and faecal nutrient content. Biology and Fertility of Soil, v. 14, p. 71-75, 1992.

TIAN, G.; BRUSSARD, L.; KANG, B.T. Biological effects of plant residues with contrasting chemical compositions under humid tropical conditions: effects on soil fauna. Soil Biological Biochemistry, v. 25, p. 731-737, 1993.

TORALES, G.J. Isopetera. In: MORRONE, J.J.; COSCARÓN, S. (Ed.). Biodiversidad de artrópodos argentinos: una perspectiva biotaxonómica. La Plata: Ediciones Sur, 1998. cap. 6, p. 48-66. 
VALENTIN, J.L. Agrupamento e ordenação. In: PERES-NETO, P.R.; VALENTIN, J.L.; FERNANDEZ, F.A.S. (Ed.). Oecologia Brasiliensis -Tópicos em tratamento de dados biológicos. Rio de Janeiro: UFRJ-Instituto de Biologia, v. 2, p. 27-55, 1995.

WARDLE, D.A. Impacts of disturbance on detritus food webs inagroecosystems of contrasting tillage nd weed management practices. Advances in Ecological Research, v. 26, p. 105-182, 1995.

WHITTAKER, R.H. Communities and ecosystems. 2 ed. New York: Macmillan, 1975. $387 \mathrm{p}$.

WOOD, T.G. Termites and the soil environment. Biology and fertility of soils, v. 6, p. 228-236, 1988. 